\title{
UNCLASSIFIED
}

\section{A RE-OPTIMIZATION \\ OF SEVERAL PROCESS PARAMETERS \\ FOR THE GAS COOLED REACTOR CONCEPT}

\author{
PREPARED BY \\ R. C. WALKER \\ G. E. WADE \\ E. R. RUDOCK \\ W. A. MASSENA \\ E. R. ASTLEY
}

PROCESS DESIGN OPERATION

FACILITIES ENGINEERING OPERATION

JUNE 30, 1958

IRRADIATION PROCESSING DEPARTMENT HANFORD ATOMIC PRODUCTS OPERATION

\section{GENERAL ELECTRIC}




\section{DISCLAIMER}

This report was prepared as an account of work sponsored by an agency of the United States Government. Neither the United States Government nor any agency Thereof, nor any of their employees, makes any warranty, express or implied, or assumes any legal liability or responsibility for the accuracy, completeness, or usefulness of any information, apparatus, product, or process disclosed, or represents that its use would not infringe privately owned rights. Reference herein to any specific commercial product, process, or service by trade name, trademark, manufacturer, or otherwise does not necessarily constitute or imply its endorsement, recommendation, or favoring by the United States Government or any agency thereof. The views and opinions of authors expressed herein do not necessarily state or reflect those of the United States Government or any agency thereof. 


\section{DISCLAIMER}

Portions of this document may be illegible in electronic image products. Images are produced from the best available original document. 
SEVERAL PROCESS PARAMETERS FOR

THE GAS COOLED REACTOR CONCEPT

Prepared By

R. C. Walker

G. E. Wade

E. R. Rudock

W. A. Massena

E. R. Astley

PROCESS DESIGN OPERATION

FACIIITIES ENGINEERING OPERATION

June 30.1958

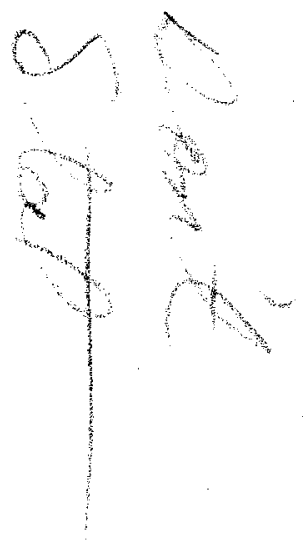




\section{DISTRIBUTION}

1-20. HOO-AEC, Attention: A. T. Gifford

21-30. R. A. Gharpie', ORNE

31-35. Philip Bush, Kaiser Engineers

36-38. TISE - Oak Ridge

39. F. W. Albaugh

LO. E. R. Astley

41. J. R. Carrell

42. A. B. Carson

43. R. I. Dickeman

44. W: Jo Dowis

45. E. I. Etheriage

46: E. A. Eschbach

47. 0 . H. Greager

48. W. K. MacCready

49. H. W. Heacock

50. G. I. Locke

51. H. P. Shaw

52. W. A. Massena

53. L. H. McEwen

54. J. S. McMah on

55. H. M. Parker - P. F. Gast

56. P. H. Reinker $-\mathrm{H}$. F. Zuhr

57. E. R. Rudock

58. R. J. Schier

59. G. E. Wade

60. R. C. Walker:

61. D. F. Watson

62. 300 Area Files

63. Record Center

64-75. Extra

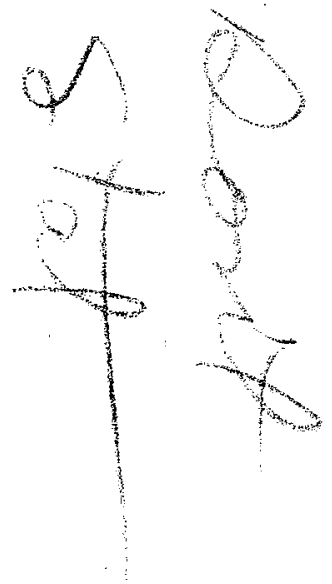

UNCIASSIFIED 
I. INTRODUCTION

II. SUMMARY AND CONCLUSIONS

Page

III. BASIS FOR RE-OPTIMIZATION

IV. DISCUSSION

A. REACTOR CONCEPT

B. HEAT RECOVERY CYCIE

12

C. REACTOR PHYSTCS AND FUEL ELEMENTS

31

D. HEAT TRANSFER AND FIUID FLOW CONSIDERATIONS

31

E. ECONOMIC EVALUATION

49

V. APPENDIX

45 


\section{A RE-OPTIMIZATION OF SEVERAL PROCESS PARAMETERS} FOR THE GAS COOLED REACTOR CONCEPT

I. INTRODUCTION

Subsequent to the completion of Phase I and II of the HAPO Gas-Cooled Reactor Study(1), work was directed toward a third phase, which was to be an engineering study of a single reactor concept selected from the parameters developed during the initial phases of this study program. The concept was to be more fully optimized and sufficient design studies were to be performed to provide a firm basis for estimates of capital and net electrical power costs as well as to clearly define areas of process technology requiring further definition and/or development.

However, instructions were received from the Division of Reactor Development to concentrate all HAPO efforts in support of the gas-cooled reactor program on a development program in the areas of $\mathrm{CO}_{2}$-graphite reactions and measurements of gas-cooled prototype reactor lattice parameters in the Physical Constants Test Reactor (PCTR).

Accordingly, HAPO effort has now been re-directed along these lines and the report which follows contains a summarization of all work which has been performed on the GCR concept between the time of completing the Phase I and II work and receipt of the latest directive.

(1) HW-54727 and HW-54727 ADD, A Parametric Study of the Gas-Cooled Reactor Concept, Staff of the Process Design Operation, March 1, 1958, Unclassified 
II. SUMMARY AND CONCLUUSIONS

It should be re-emphasized here that the unit power costs obtained in this supplementary study are still in the "order of magnitude" category since capital cost estimates and fuel element fabrication costs are based on preliminary estimates which would require further investigation for a given reactor concept. However, it is felt that cost differences among the various cases are sufficiently accurate to permit valid comparisons and, of course, the primary benefit obtained is an indication of the trends in power cost which might be expected from variations in process parameters.

On this basis, the additional or supplementary conclusions regarding the gas-cooled reactor concept which have been derived from this study are:

1. The graphite-to-uranium ratio is relatively insensitive to variations in the other process conditions considered and for most of the more optimum cases falls in the range of 70 to 80 to one (atom-to-atom ratio).

2. In confirmation of the results of the Phase I work, this study has show that power costs are relatively unaffected by nominal differences in reactor $\triangle \mathrm{T}$ with optimum power costs for the cases studied falling within the range of $500-525 \mathrm{~F}$.

3. The length-to-diameter ratio of the reactor core appears to be a strong function of the coolant flow area ratio* with optimum values in the range of 0.6 to 1.0 , the lower values being associated with the smaller flow area ratios.

4. Specific tube power is another process variable which is strongly affected by the flow area selected and for the range of combinations investigated, falls within the range of 75 to $140 \mathrm{kw} / \mathrm{ft}$ with lower values again being related to the lower flow area ratios.

5. Initial enrichment requirements are strongly affected by an increase in the flow area ratio although less fuel is contained in the lattice for a given $\mathrm{N}_{\mathrm{g}} / \mathrm{N}_{\mathrm{u}}$ ratio. This paradox occurs due to the fact that optimum power density increases with increasing flow channel areas. The higher fuel specific power necessitates subdividing the total fuel volume into an increased number of smaller rods which have correspondingly greater amounts of stainless steel cladding and thus higher fuel enrichment requirements.

6. Net power costs for many of the cases studied fell within a rather narrow range; in fact, the optimum values for the three flow area ratios fall within a $0.24 \mathrm{mill} / \mathrm{kwh}$ bracket. However, this can be expected from a study of this nature and while different bases for capital and fuel cost estimates could alter the optimum ranges somewhat, the values resulting from this study are probably not too far in error since the $0.24 \mathrm{mill} / \mathrm{kwh}$ range cited above is equivalent to approximately $\$ 500,000 / y r$ in operating or fuel costs or $\$ 3,350,000$ in capital investment for a 300 MW plant and the method of cost analysis assumed.

* Flow area-to-lattice area ratio. 
In sumary, the tabulation shows the optimum range of values obtained for each of the parameters investigated:

\section{TABIE I}

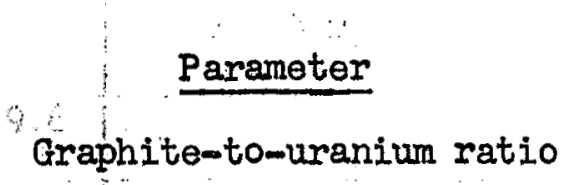

Length-to-Diameter Ratio

Specific Tube Power * (kw-ft)

Reactor $\Delta \mathrm{T}(\mathrm{F})$
Flow Area Ratio

\begin{tabular}{ccc}
\hline I5\% & $\frac{25 \%}{40 \%}$ \\
$70-80$ & $70-80$ & $70-80$
\end{tabular}

$0.6-0.7 \quad 0.8-0.9 \quad 0.9-1.0$

$75-85 \quad 110-120 \quad 130-140$

$500-520 \quad 500-510 \quad 510-525$

Initial Enrichment (Wt. \% U-235) 1.51-1.73 $2.38-2.61 \quad 4.35-4.80$

Net Power Cost (mills/kwh) $9.36-9.41 \quad 9.34-9.42 \quad 9.46-9.58$ 9.5

*Average power in maximum performance tube.

The values of net power cost have been plotted in Figure 1 which indiaates, in addition to a plctorial trend of these values, that the optimum value for the flow area ratio is approximately 20 percent.

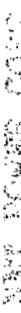

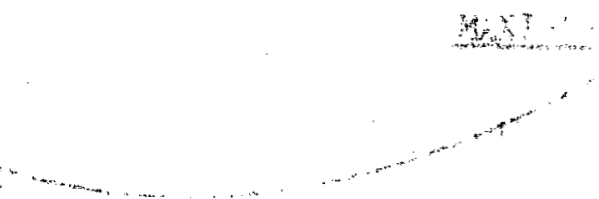

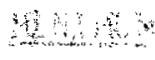

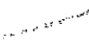

93

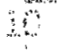
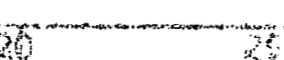

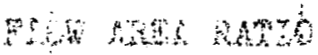




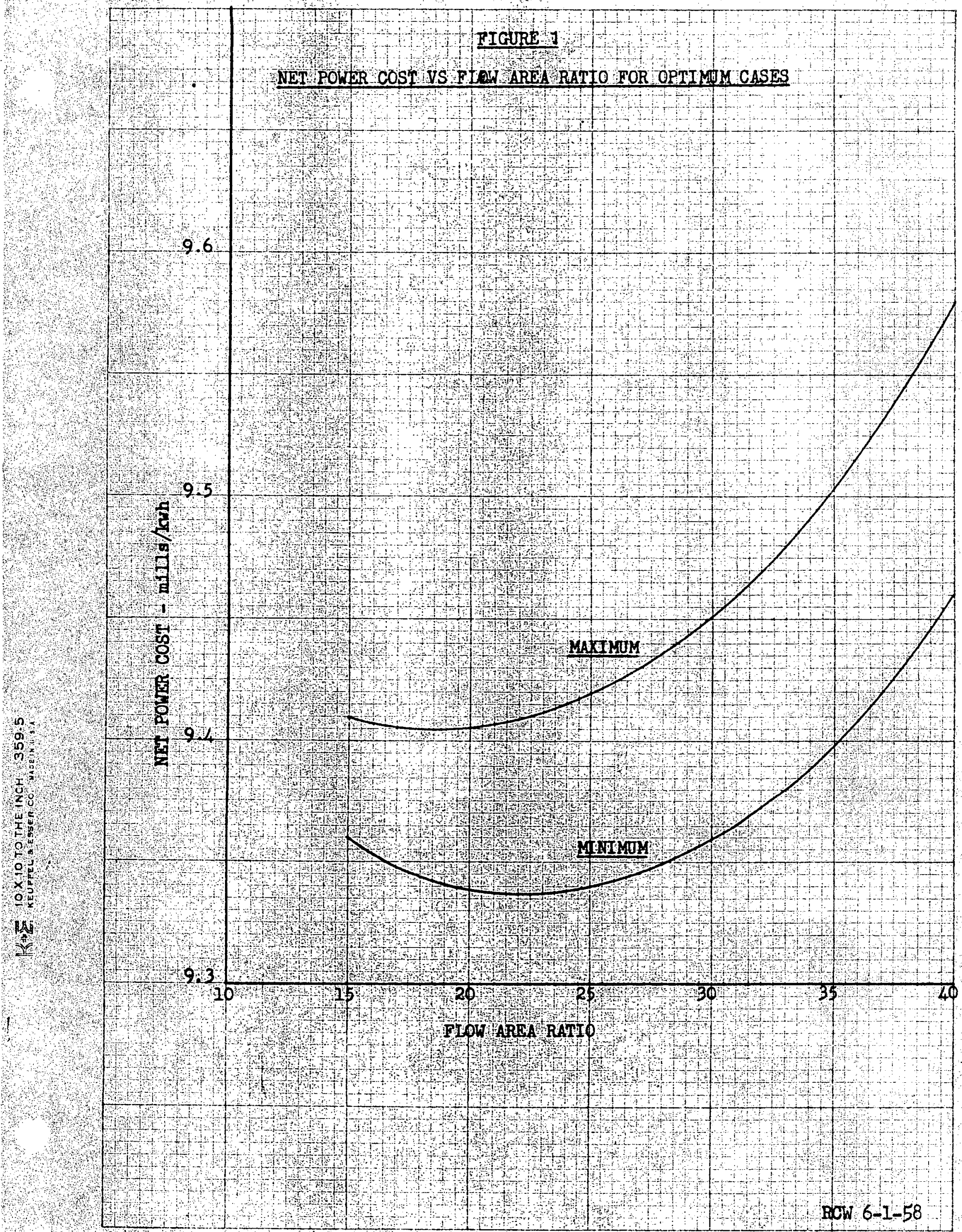




\section{BASIS FOR RE-OPTIMIZATION STUDIES}

As a result of the work performed during the initial phases of the HAPO GGR Study, many of the process variables were reduced to an absolute value or condition either due to direct optimization or due to an arbitrary selection based on a combination of economics and practicability. Some parameters, however, were not fully optimized in the original study due to time limitations and, for this reason, it was concluded that some additional analysis should be made prior to the selection of the most attractive combination of process parameters for a GCR concept.

A. Established Criteria

Parameter values which were recommended on the basis of the Phase I and II work and which were used for the re-optimization study described here are as follows:

1. Heat Recovery - Closed cycle gas turbine

2. Gas Coolant - Helium

3. Lattice - 8 inches $\mathrm{x} 8$ inches

4. Reactor Thermal Power Rating - $1000 \mathrm{MW}$

5. Goal Exposure - $5000 \mathrm{MWD} / \mathrm{T}$

6. Fuel Element - Stainless steel clad $\mathrm{UO}_{2}$ rods arranged in clusters

7. Bulk Coolant Temperature - Reactor Outlet (or Turbine Inlet) - $1300 \mathrm{~F}$

8. Stainless Cladding Temperature Limit - $1600 \mathrm{~F}$

9. Orificing Efficiency - 80\%

10. Flattening Efficiency - $75 \%$

11. Plant Operating Factor - 80\%

12. Reactor Vessel Plate Thickness - 4.5 inches

\section{B. Parameters Selected for Re-Optimization}

Process variables which could not be completely resolved during the initial studies and which were considered as the basis for this additional study are as follows: 


\section{Parameter}

1. Graphite-to-Uranium Ratio

(atom-to-atom)

2. Iength of Active Zone-to-Core Diameter Ratio

3. Specific Tube Power (kw/ft)

4. Process Channel Area (Percent of Lattice Area)

5. Reactor $\Delta \mathrm{T}(\mathrm{F})$
Values Selected for Analysis

$50 ; 70 ; 80 ; 100$

$\sqrt{\pi}: 1 ; 1.25: 1 ; 0.75: 1 ; 0.5: 1$

$20 ; 40 ; 60 ; 80$

$15 ; 25 ; 40$

$450 ; 500 ; 550 ; 600$

This selection resulted in 768 combinations or cases which were programmed for solution on IBM Data Processing Equipment where possible. Details of the various phases of this study are given in the sections which follow. 
IV. DISCUSSION

A. REACTOR CONCEPT

Due to the curtailment of the originally scheduled Phase III program, many of the areas which were recommended for further study in the Phase I report could not be investigated as thoroughly as would be required for any specific reactor concept. However, some additional conclusions have been reached which were not included in the Phase I'report and which should be considered in determining the exact configuration for any particular concept.

1. Pressure Vessel

A comparison of maximum operating pressures for both cylindrical and spherical vessels with maximum wall thicknesses of 4.5 inches was made for each reactor case determined by the values of specific tube powers and $I / D$ ratios considered. It was found that operating pressures could be higher for the spherical vessel by a factor of 1.1 to 1.8 over that of a cylindrical vessel large enough to: house the same reactor. However, the weight of the spherical vessel was greater by a factor of 1.5 . This indicates that the material costs for the spherical vessel will be higher than the cylindrical vessel by at least this ratio but, since the power plant efficiency is so sensitive to system pressure (a $1 \frac{1}{2} \%$ decrease in the plant $\triangle P / P$ ratio will increase plant efficiency by one percent and will justify the capital expenditure of an additional three million dollars), it was concluded that the additional vessel costs were justified and that a spherical pressure vessel is recommended for all reactor cases.

No final determination was made on the number of vessel openings that would be required for a given reactor concept; however, for vessels of very heavy wall thicknesses, the design of multiple openings and reinforcements are influenced by the methods available. for fabricating the vessel as a whole. Accordingly, the number and size of the openings for a reactor pressure vessel must be determined by a studied balance of the many factors which will affect the opening designs. These factors are:
a. Methods of charging and discharging fuel elements
b. Opening seals
c. Ratio of fuel channels to ressel openings
d. Vessel code reinforcement limits
e. Feasibility and methods of fabrication and stress relieving
f. Effect of number of openings on vessel costs 
2. Fuel Channel Orientation

The orientation of the fuel channels effects the vessel, control equipment, charging machinery and fuel element design. It was found that there are different advantages for both vertical and horizontal channels and that the final choice of the optimum arrangement cannot be made without more extensive study of the relative problems which must be considered. However, it was possible to make some tentative conclusions during this preliminary study:

a. Vertical Channels

(1) Vessel design will be less complicated and operating pressure can be higher.

(2) Graphite lay-up problems will be about the same as the horizontal channel but the volume of graphite required will be less.

(3). Equipment arrangement will be more restrictive due to the vertical fliel channel openings and vertical control rod openings being side by side and parallel through the top of the vessel.

(4) Fuel charging equipment and charging procedures will be more difficult.

(5) Support of fuel elements will be more difficult and will contribute higher loading stresses to the materials used in the fuel element design.

b. Horizontal Channels

(1) Top entry vertical control rods will be independent of fuel channels which will result in greater freedom of the design。

(2) Two fuel charging faces can be utilized where vessel openings on one face are independent of the other face, thereby reducing the number of vessel openings and required reinforcement on a given face:

(3) Improved plant operating efficiency can possibly be attained by having two charging and discharging faces avail$\mathrm{able}$ which may be worked independently of one another thereby reducing fuel replacement outage time.

(4) The horizontal fuel channel permits the consideration of a split graphite core to reduce system pressure drop losses. By dividing the core so that the fuel channel is made up of two separate and equal half lengths and feeding the inlet coolant gas into each end of the fuel channel with the gas from each half channel discharging from the center core separation, pressure losses in the reactor core are reduced by a factor of eight. 
Operating pressures are lower because of a slightly larger vessel compared to the vessel for a vertical channelled reactor.

(6) Reactor building and fuel handling equipment costs would be higher.

\section{Fuel Charging and Discharging}

Experience at Hanford has show that malfunction and breakdown of machinery designed for the charging and discharging of fuel elements has a significant effect on plant time operating efficiency and that the importance of prototype development and critical design of this equipment cannot abe overemphasized: Details of the chargedischarge-procedure and the charging machinery could not be developed in this type of study; however, fuel charging for a gas-cooled reactor of the sizes covered in this study could be accomplished by several different procedures all of which must be preceded by a period of shutdown cooling. A few of the alternative methods are:

a. Helium replaced from the system by air as a low flow coolant. Work areas air-pressurized prior to breaking the seals to the reatctor vessel openings. Operators would then work with the machines at the reactor openings or,

b. All charging and discharging accomplished from a remote control station. Manipulators to renove the vessel opening seals with operation of the fuel handling machines controlled from this station. Work areas allowed-to become pressurized from the low pressure coolant but so contained as to prevent leakage of the coolant to other parts of the reactor building or,

c. Fuel handling machines with the feature of double sealing wherein the operators would work beside the machines. The machines would, in effect, be portable pressure, vessels which would contain seal removal manipulators, fuel handing controls and new or used fuel elements: The machines would be first attached and sealed to the reactor fressel prior to breaking open vessel seals.

It is apparent that none of the three systems outlined above will be straightforward, simple/design projects. Each method has special advantages and a thorough study of the charging procedures, building and equipment costs and reliability of operation must be undertaken prior to selection of a final procedure. "However, the latter method appears to be the most feasible method of the three and should be given primary consideration.

\section{B. HEAT RECOVERY CYCLE}

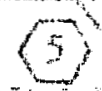

During these re-optimization studies, the cycle shown in Figure 2 was used which is the same cycle that had $d^{2}$ een used for the Phase I and II studies. Variations of the basic cycle were investigated briefly but their added complication and/or eost madethem unsuitable for further study. However, several refinements that could not be incorporated in the Phase I and II studies are included in this study.

$$
\text { is }
$$




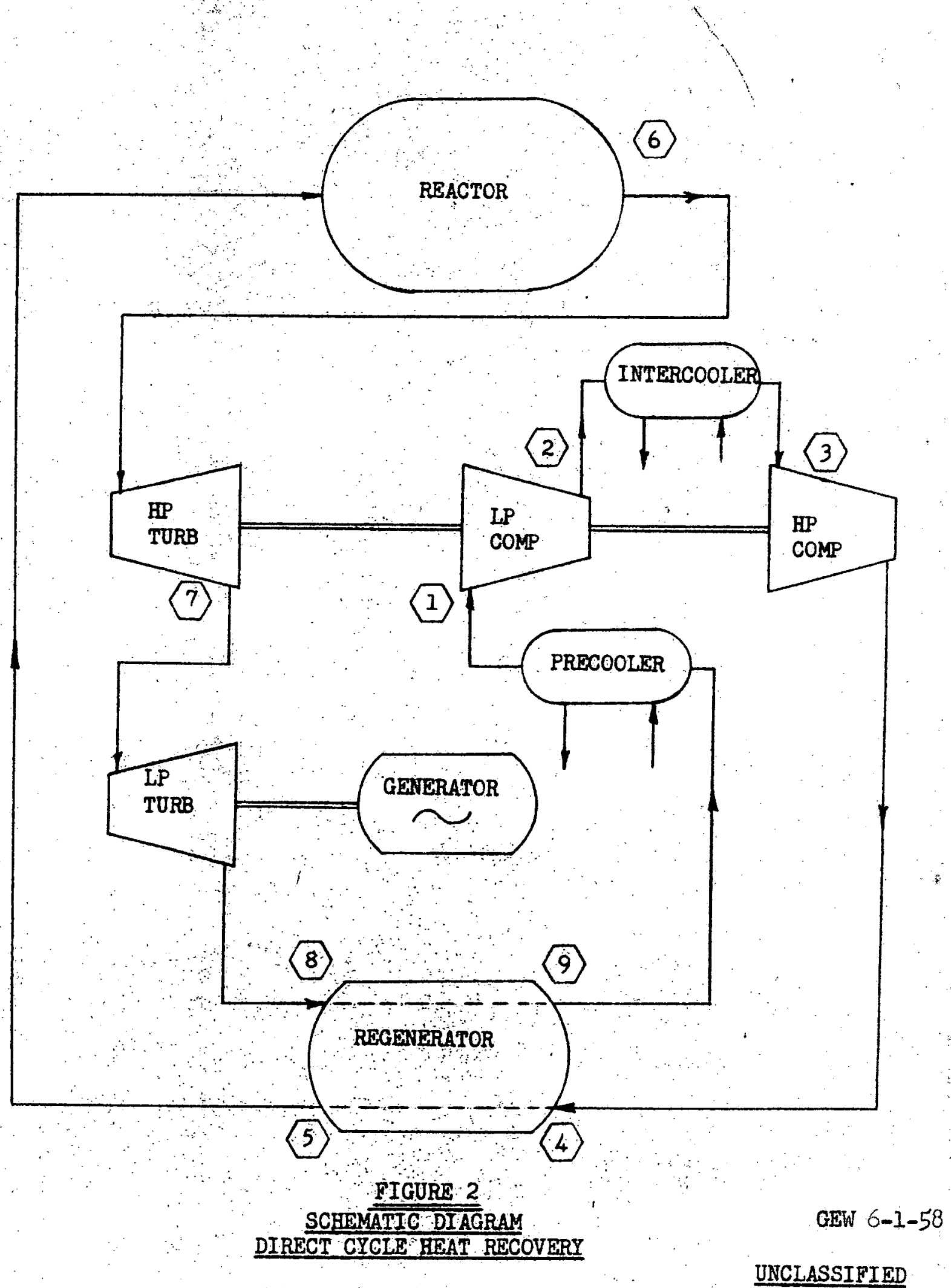

93902 
An initial step in this re-optimization was to optimize the regenerator efficiency. These calculations indicated that above $90 \%$ regenerator efficiency, regenerator size (capital costs) and pressure drop (pumping costs) increased faster than the value of the heat recovered. Below 90 percent regenerator efficiency, the value of the heat dumped exceeded the capital and pumping costs. Therefore, a regenerator efficiency of 90 percent was used for all further calculations of the heat recovery cycle. A bare tube cross-flow type heat exchanger was used because it had lower capital costs and pressure losses than the plate-fin counterflow exchanger used for previous studies.

Minimum total costs for the pre-cooler and inter-cooler were calculated by balancing cooler capital costs and gas pumping costs. The optimum efficiency for the pre-cooler or inter-cooler was obtained when the product of water flow rate and specific heat was four times the same product for the gas. Actually, a ratio of 10 to I would give lower costs, but the availability of the required rolume of water was doubtful.

It was also assumed that a minimum eycle temperature of $80 \mathrm{~F}$ would be possible with water available at a maximum temperature of $65 \mathrm{~F}$. For design purposes, a cross-flow exchanger with finned tubes was used for the inter-cooler and pre-cooler. This configuration was picked after performance calculations were made for: (I) $\mathrm{C}_{\text {ross }}-\mathrm{fl}$ low finned tubes;

(2) Counter-parallel-flow plain tubes; (3) Cross-flow dimpled tubes; and

(4) Cross-flow continuous finned tubes.

The specific values of constants and parameters used in the heat cycle calculations are given in Table II. The se values all differ from those used in the Phase $I$ and II study because of: (I) Further optimization (reactor outlet temperature and regenerator efficiency); (2) Further calculation refinements (bleed added); and (3) More conservative values were indicated (compressor turbine efficiencies, etc.).

The equations for solving the cycle thermal efficiency are listed below. (See Page 30 for nomenclature.) The breakdown is desirable because it permits calculation of conditions at intermediate points in the cycle as well as the over-all cycle thermal efficiency.

Referring to Figure 2, the temperature rise across the compressors can be calculated based on an assumed minimum cycle temperature $\left(\mathrm{T}_{1}\right)$ and $a$ cycle pressure ratio:

$$
\Delta \mathrm{T}_{I-2}=\left[\left(\frac{\mathrm{P}_{4}}{\mathrm{P}_{1}}\right)^{\psi / \mathrm{N}}-1\right] \frac{\mathrm{T}_{I}}{\eta_{\mathrm{c}}}
$$

The compressor outlet temperature is given by:

$$
\mathrm{T}_{2}=\mathrm{T}_{4}=\mathrm{T}_{1}+\Delta \mathrm{T}_{1-2}
$$

This assumes intercooling to a constant minimum temperature between stages of compression. In the selected cycle, it was assumed that there would be two stages of compression. 


\section{TABLE II}

Heat Recovery System Design Constants and Parameters

Reactor Outlet Temperature

Compressor Inlet Temperature

Cooling Water Temperature

Compressor Adiabatic Efficiency

Turbine Adiabatic Efficiency

Compressure \& Turbine Mechanical Efficiency

Generator Efficiency

Regenerat or Efficiency

Gas used for Cooling Bearing or Bypassed for Clean-up (Bleed)

Number of stages of compression

Maximum Cycle Pressure

Cycle Pressure Ratio

Reactor Heat Generation

Parasitic Pressure Loss
$1300 \mathrm{~F}$

$80 \mathrm{~F}$

$65 \mathrm{~F}$

85 percent

85 percent

97 percent

$97 \frac{1}{2}$ percent

90 percent

1 percent

2

200 thru 600 psia

$1 \frac{1}{2}$ thru 5

$1000 \mathrm{MW}$

3 thru 17 percent

Coolant Flow and Reactor Temperature Rise-

Reactor Temperature Rise (F)

450

500

550

600
Coolant Flow (lb/hr)

$$
6.08 \times 10^{6}
$$

$5.47 \times 10^{6}$

$4.79 \times 10^{6}$

$4.56 \times 10^{6}$ 
The inlet temperature to the high pressure turbine is assume to be the maximum cycle temperature $\left(\mathrm{T}_{6}\right)$. The outlet temperature from this turbine can be calculated because the compressor work has been determined. The equation is:

$$
\mathrm{T}_{7}=\mathrm{T}_{6}-\frac{\mathrm{N}\left(\Delta \mathrm{T}_{1-2}\right)}{(\mathrm{I}-\mathrm{B}) \eta_{\mathrm{m}}}
$$

These temperatures require a pressure ratio for this turbine as determined by:

$$
\frac{P_{6}}{P_{7}}=\left[\frac{T_{6}}{T_{6}-\left(\frac{T_{6}-T_{7}}{\eta_{t}}\right)}\right]^{1 / \psi}
$$

The pressure ratio across the low pressure, generator drive, turbine is given by:

$$
\frac{P_{7}}{P_{8}}=\frac{P_{4} / P_{1}}{P_{6} / P_{7}}\left(1-\eta_{p}\right)
$$

This assumes that the effect of the pressure losses around the loop are approximately equal to some lumped pressure loss inserted in the loop.

$$
\frac{\Delta \mathrm{P}_{2-3}}{\mathrm{P}_{2}}+\frac{\Delta \mathrm{P}_{4-5}}{\mathrm{P}_{4}}+\frac{\Delta \mathrm{P}_{5-6}}{\mathrm{P}_{6}}+\cdots=\eta_{\mathrm{p}}
$$

The temperature at the outlet of the low pressure turbine is given by:

$$
\mathrm{T}_{8}=\left[\frac{\mathrm{T}_{7}}{\left(\frac{\mathrm{P}_{7}}{\mathrm{P}_{8}}\right) \psi}-\mathrm{T}_{7}\right] \eta_{\mathrm{t}}+\mathrm{T}_{7}
$$

Assuming equal weight flows on both sides of the regenerator, the outlet temperature is given by:

$$
\mathrm{T}_{9}=\mathrm{T}_{8}-\eta_{\mathrm{R}}\left(\mathrm{T}_{8}-\mathrm{T}_{4}\right)
$$

The reactor inlet temperature is given by:

$$
T_{5}=\eta_{R}\left(T_{8}-T_{4}\right)+T_{4}
$$

The cycle thermal efficiency can be calculated from:

$$
\eta_{\text {th }}=\frac{T_{7}-T_{8}}{T_{6}-T_{5}}
$$

when $c_{p}$ is constant as for helium 
To determine the plant gross electrical output, the electrical and mechanical efficiencies and total reactor power are combined with Equation (10) giving:

$$
W K=\frac{T_{7} T_{8}}{T_{6}-T_{5}} \quad\left(\eta_{e}\right)\left(\eta_{m}\right)(\mathrm{MW})
$$

The required helium flow rate per lilowatt of electrical power is given by:

$$
W_{e}=\frac{3413}{c_{p}\left(T_{7}-T_{8}\right) \eta_{e} \eta_{m}}
$$

The efficiency of the precooler or intercooler can be calculated from:

$$
\eta_{a}=\left\{\begin{array}{ll}
W_{2} & c \\
W_{\text {water }}
\end{array}\right)\left(\frac{T_{2}-T_{3}}{T_{2}-T_{10}}\right)
$$

By programing these equations for solution on an IBM-650 computer, it was possible to study a range of these parameters as well as to investigate in more detail each of the 768 reactor cases being studied. Pertinent data has been plotted in Figures 3 through 11 (Pages 19 to 27 inclusive) in which the base case uses the values listed in Table I except for the one value being varied. The parameters were varied over ranges that were considered reasonable variations from the assumed conditions with an assumed pressure drop of nine percent.

Figure 3 shows the effect on cycle thermal efficiency by varying the regenerator effectiveness $\left(\eta_{R}\right)$. Superimposed on this figure are the constant reactor $\Delta \mathrm{T}$ lines. It should be noted that varying regenerator efficiency has no effect on the gas flow rate. As was mentioned earlier, 90 percent regenerator efficiency seems to be near optimum from an economic standpoint.

Figure 4 shows the effect of varying cycle parasitic pressure Ioss on thermal efficiency. Again, the constant reactor $\triangle T$ lines are superimposed. In the method used to evaluate the reactors, these constant reactor $\triangle \mathrm{T}$ 's or constant weight flow lines represent the points taken to determine power generation. This was simpler because it permitted calculation of fuel requirements, piping, pressure loss and heat transfer on the basis of four reactor flows. Figure 4 is the basic group of curves used in optimizing the power recovery system. Actually a similar curve converted to net electrical output as a function of $\eta_{\mathrm{p}}$ for each of the four reactor $\triangle \mathrm{T}$ 's was used. All heat plant parameters were specified except the pressure loss $\left(\eta_{\mathrm{p}}\right)$ which varied with specific fuel power, revotor size and shape, coolant flow, etc. Thus when $\eta_{p}$ was determined, the net electrical output could be read from the graph mentioned above. 
Figure 5 shows the effect of raising the minimum cycle temperature above $80 \mathrm{~F}$. This variation could be expected during the summer months if cooling water temperatures raised above $65 \mathrm{~F}$. On the other hand, improved efficiency might be attained in the winter with a lower minimum cycle temperature.

Figure 6 shows the effect of varying the maximum cycle temperature $\left(T_{6}\right)$. As fuel elements, turbines and piping are perfected, this temperature can be expected to increase. It is this parameter that holds the greatest promise for future improvement of cycle efficiency.

Figures 7 and 8 illustrate what would happen to the cycle efficiency and flow rate if turbines and compressors can be made more efficient. Small gains in efficiency on the order of those investigated may be possible, but no large changes are expected in the near future.

Figure 9 shows the effect of bleed flow on the cycle efficiency. It has been assumed that 100 percent of the gas goes through the precoolers, compressors and intercooler. Some of the gas at the discharge of the second compressor will bypass the reactor and turbines. This gas (called bleed gas) may be used for cooling or may be sent through a purification loop.

Figure 10 illustrates what happens as the number of compressors in series, with intercooling, is increased. This figure shows an increase in cycle efficiency as the number of compression stages is increased. What the figure does not show is the added complication and cost of an additional compressor and intercooler or the added pressure drop associated with this equipment. For our studies two stages of compression were determined to be optimum.

Figure 11 compares the base case with "good" and "bad" cases. It is interesting to note that the cycle efficiency increase or decrease obtained by calculation can also be obtained by addition or subtraction of the individual parameter changes. This figure illustrates that a 40 percent or higher cycle efficiency can conceivably be attained. This efficiency is possible assuming 90 percent regenerator effectiveness (on economic limits) and that turbines and compressors of the required efficiency can be built. The studies indicate that pressure losses as low as three percent are possible: of course, higher maximum temperatures than those studied are also a very promising possibility for raising the efficiency even higher. For a maximum reactor outlet temperature of $1700 \mathrm{~F}$, a limit possible with molybdenum blades, ceramic fuel and counterflow piping; the cycle thermal efficiency for Case $\mathrm{C}$ with a regenerator efficiency of 90 percent would be approximately 50 percent.

Equipment costs for this study were taken from the same limited data which was used for the previous study. It was assumed that four power loops, each with an approximate rating of $80 \mathrm{MW}$, would be utilized. The cost of this power recovery equipment (turbines, compressors and heat exchangers) would vary as the maximum cycle pressure varied. For the 768 cases studied, all power equipment costs were in the range of 32 to 35 million dollars. This figure does not include piping, instrumentation, building or water pumping costs which were figured separately. 


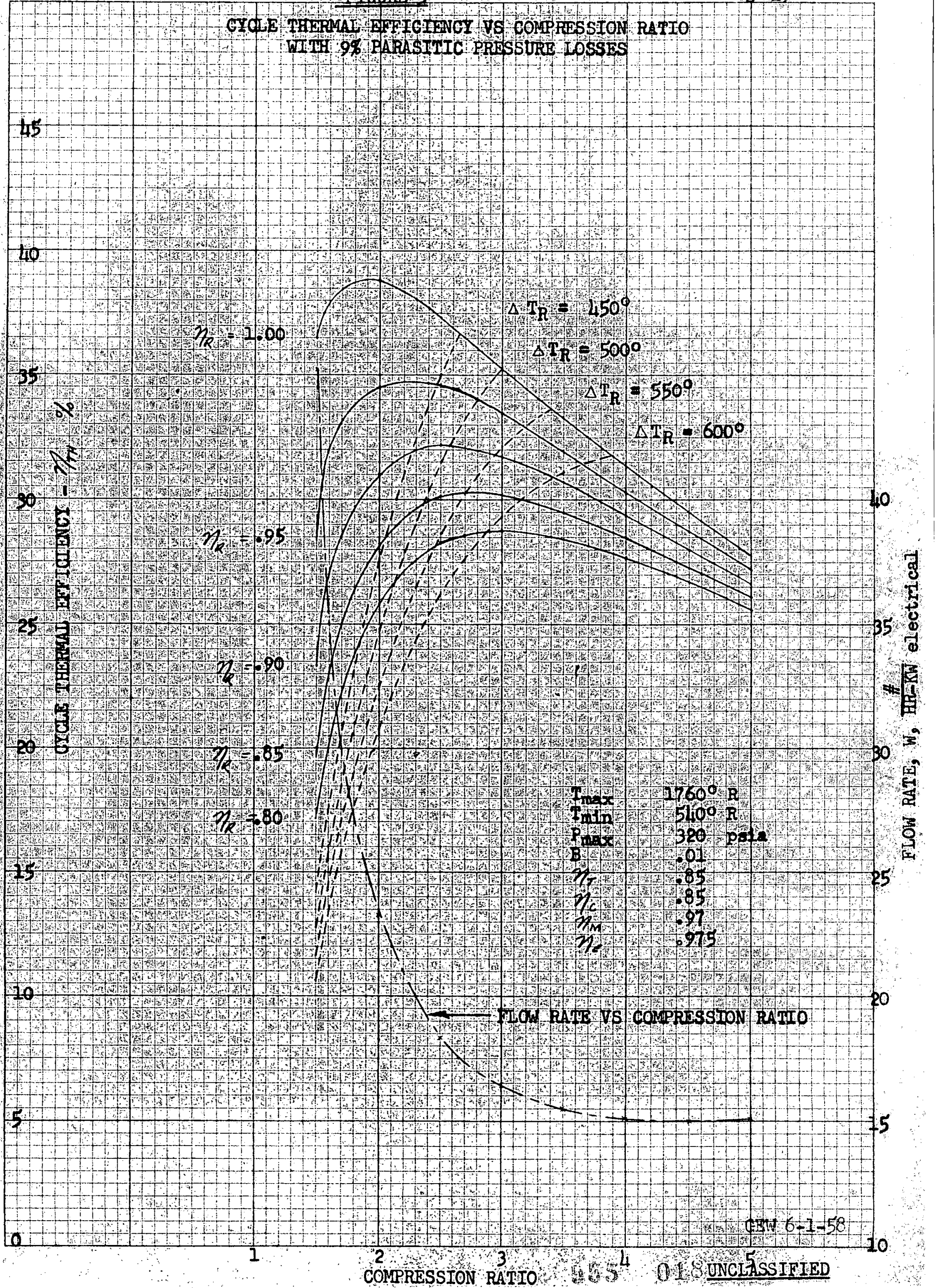




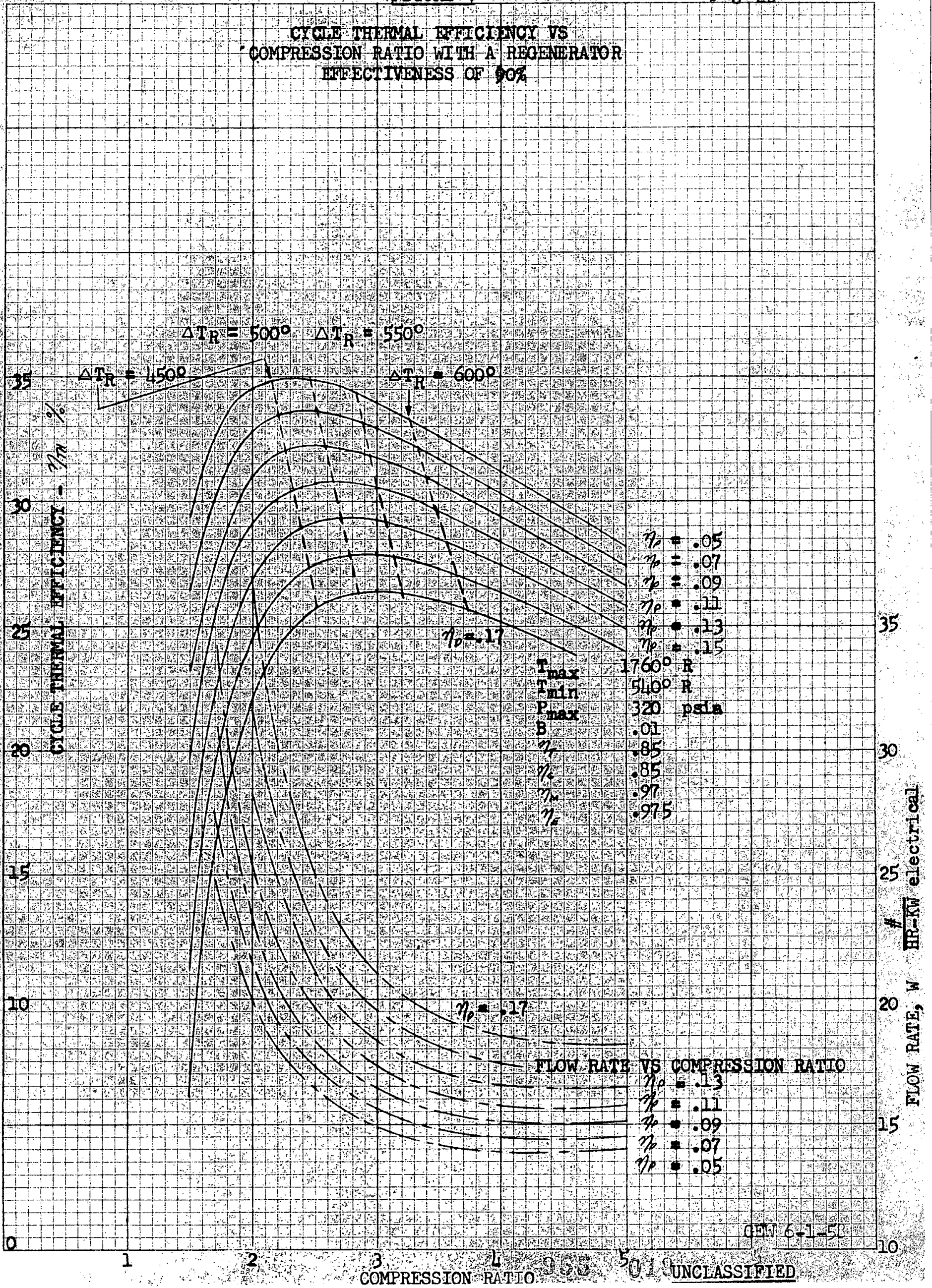




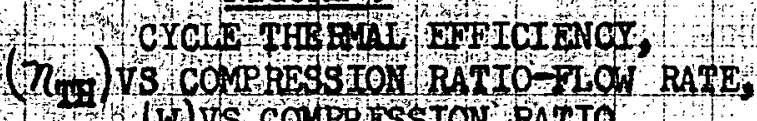 (W) VS GOMPESSIOA RATIO}

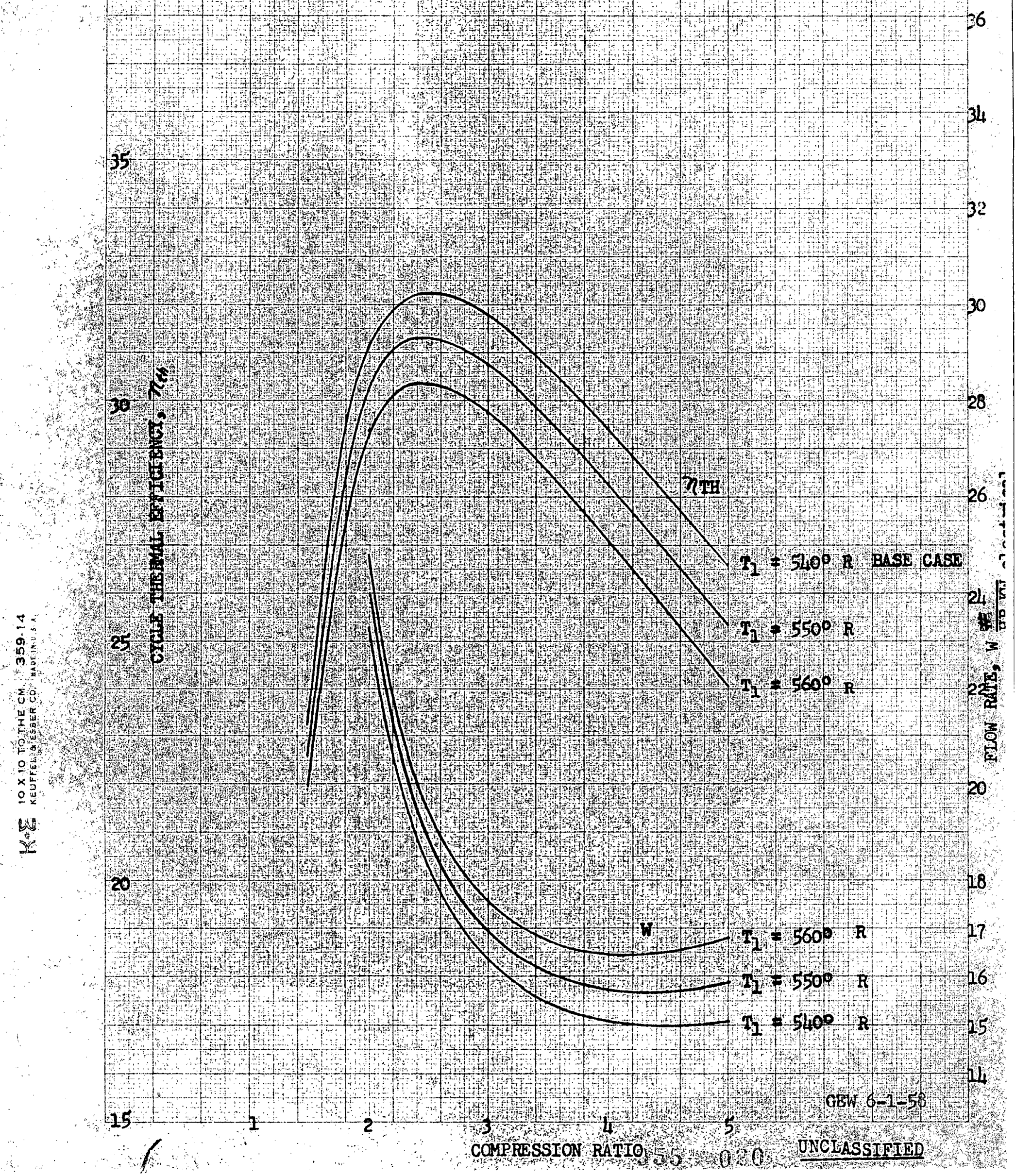



AS A F UNCTION OF HAXMUN CT CLE THOPERATURE






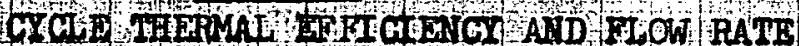

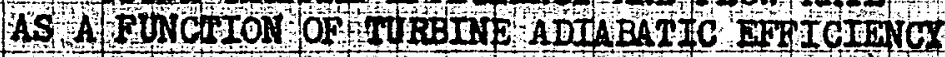

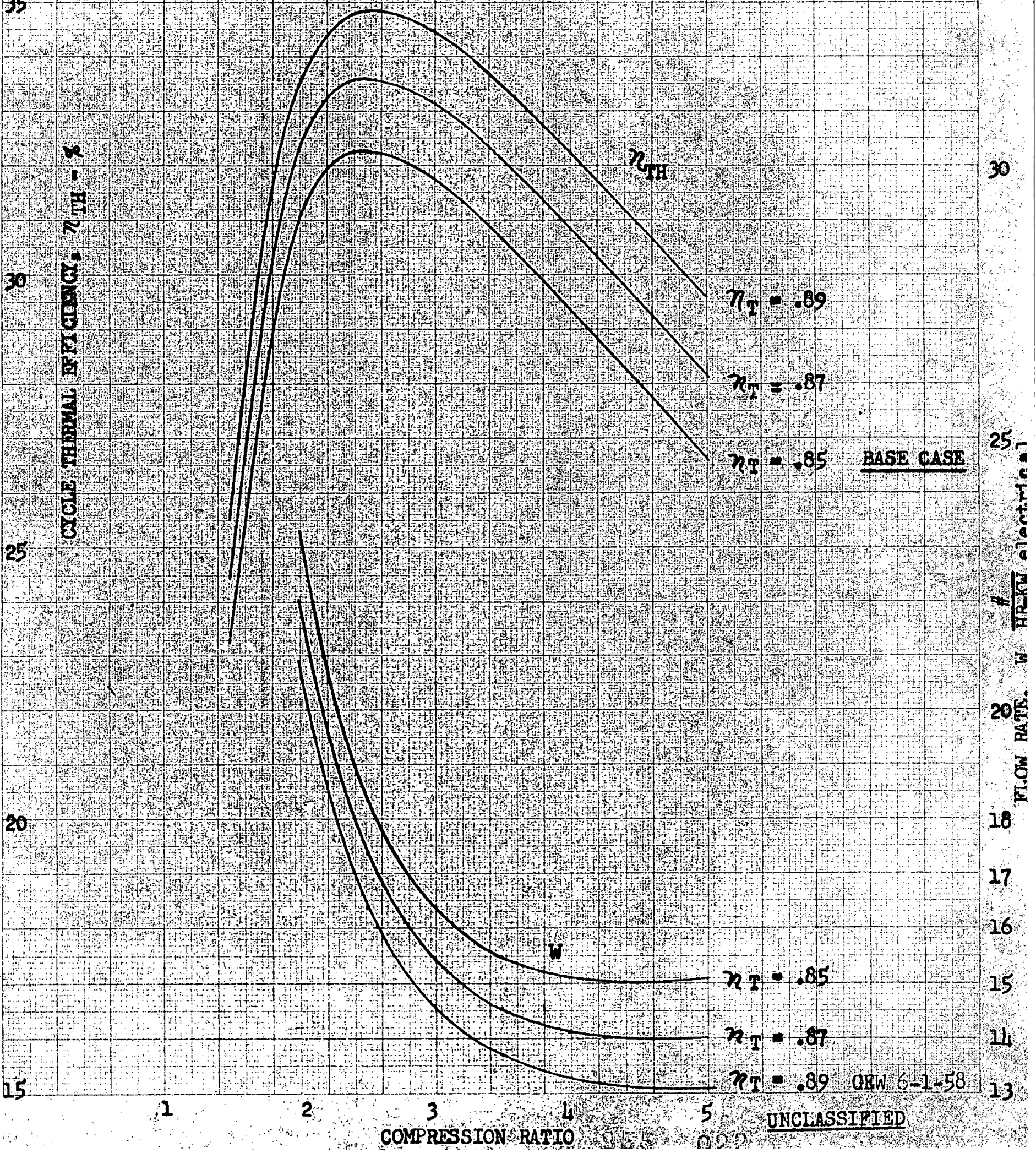




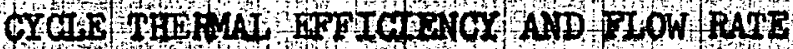

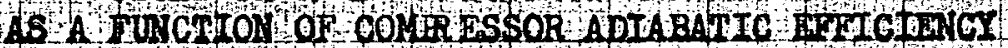

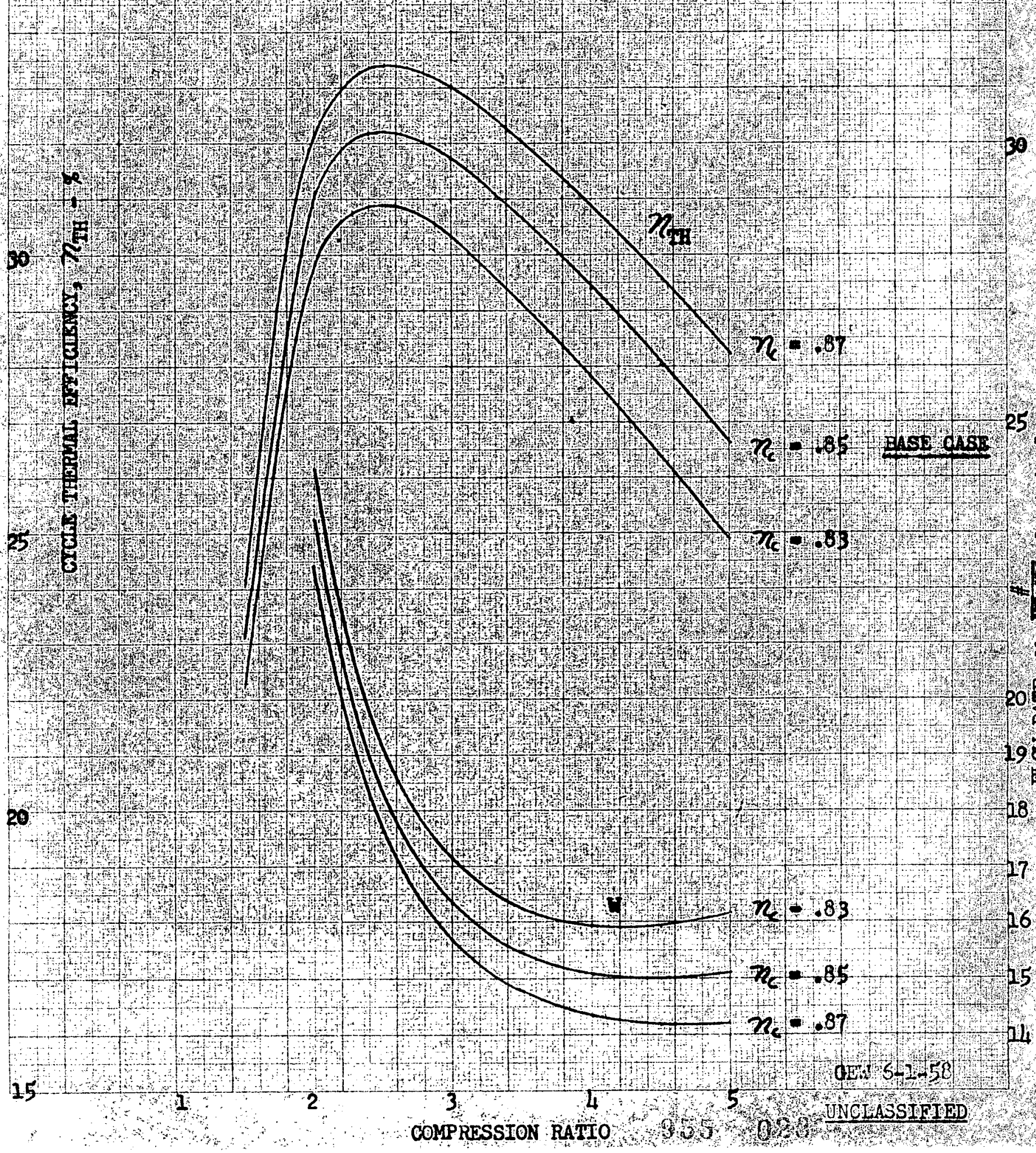




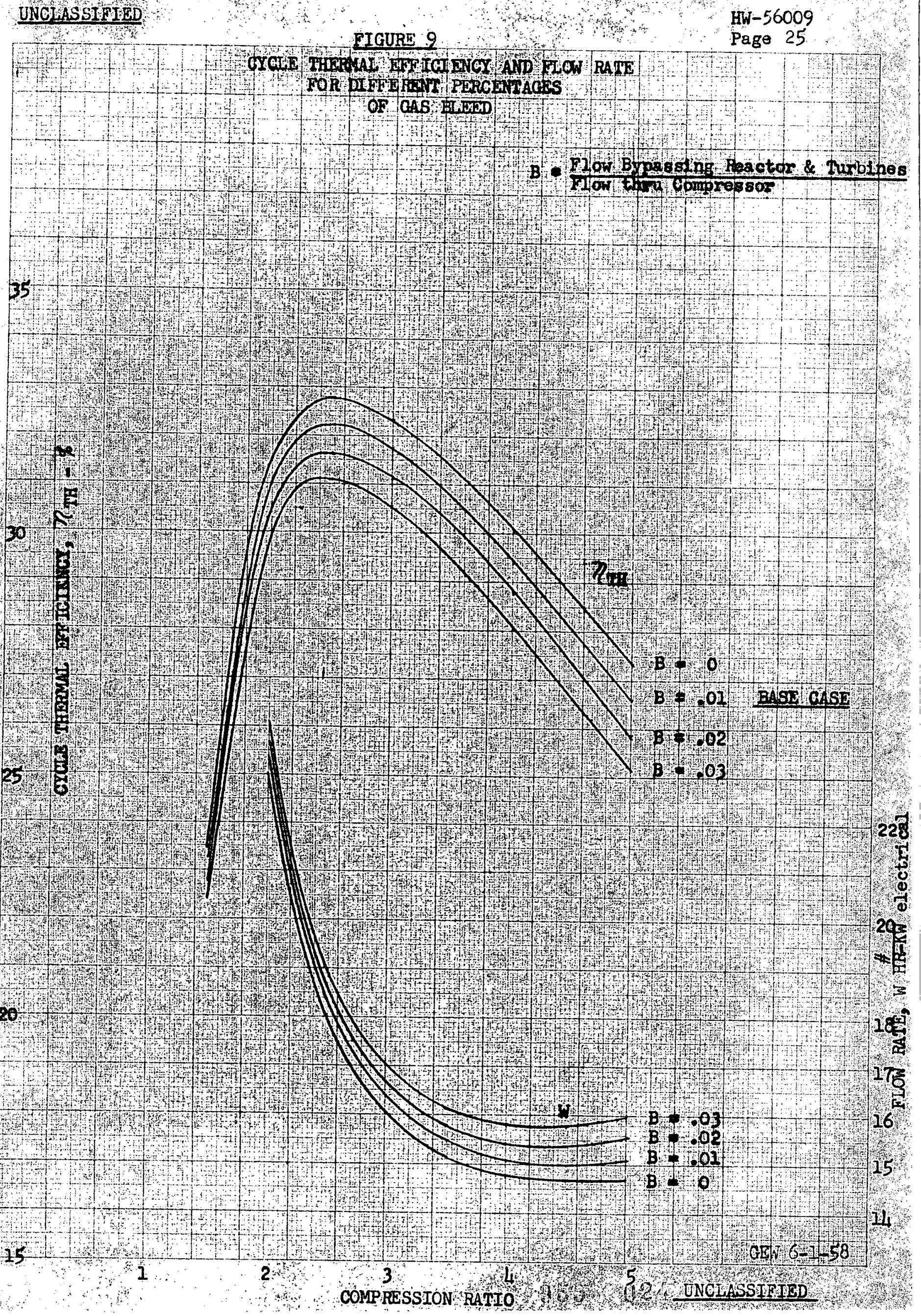




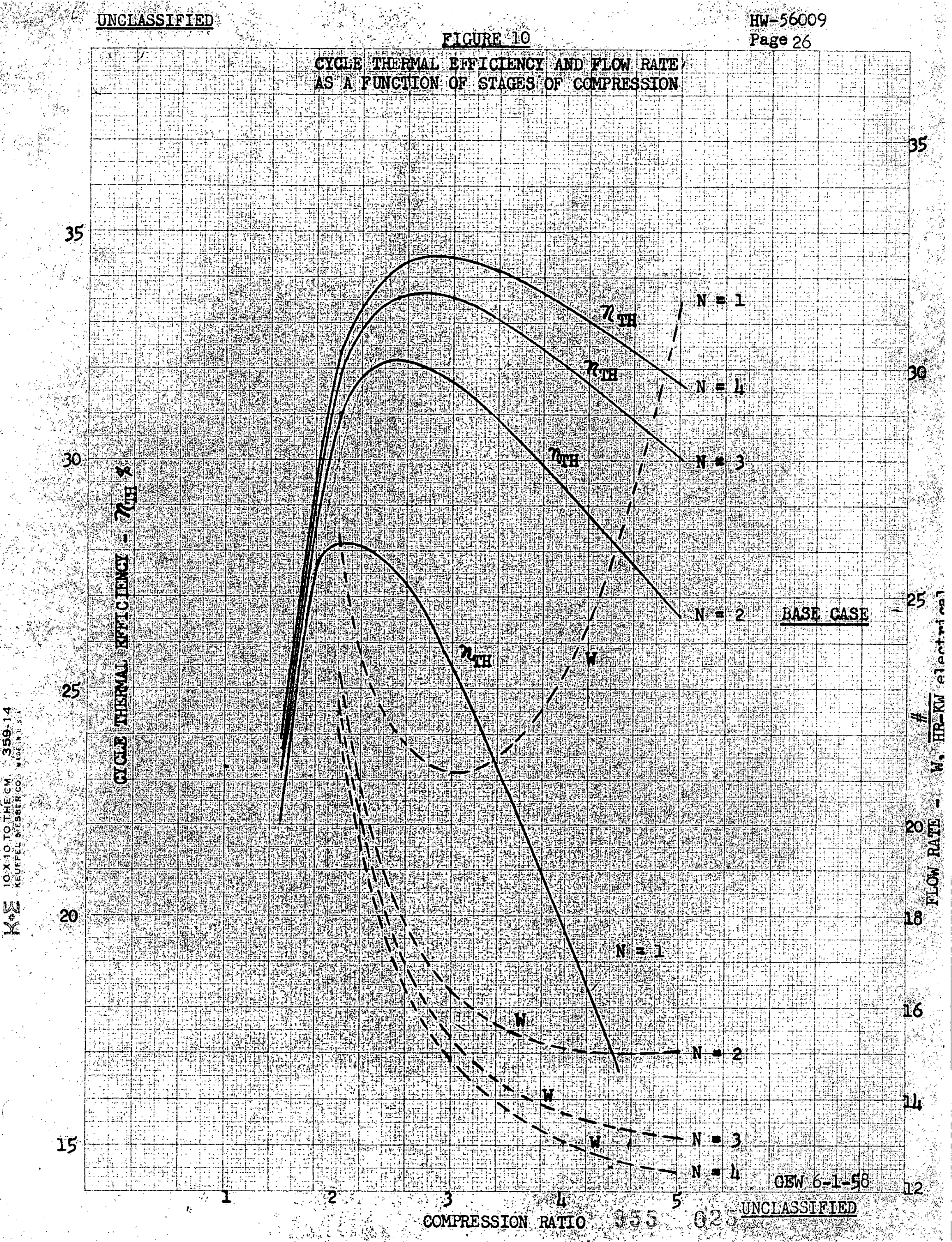




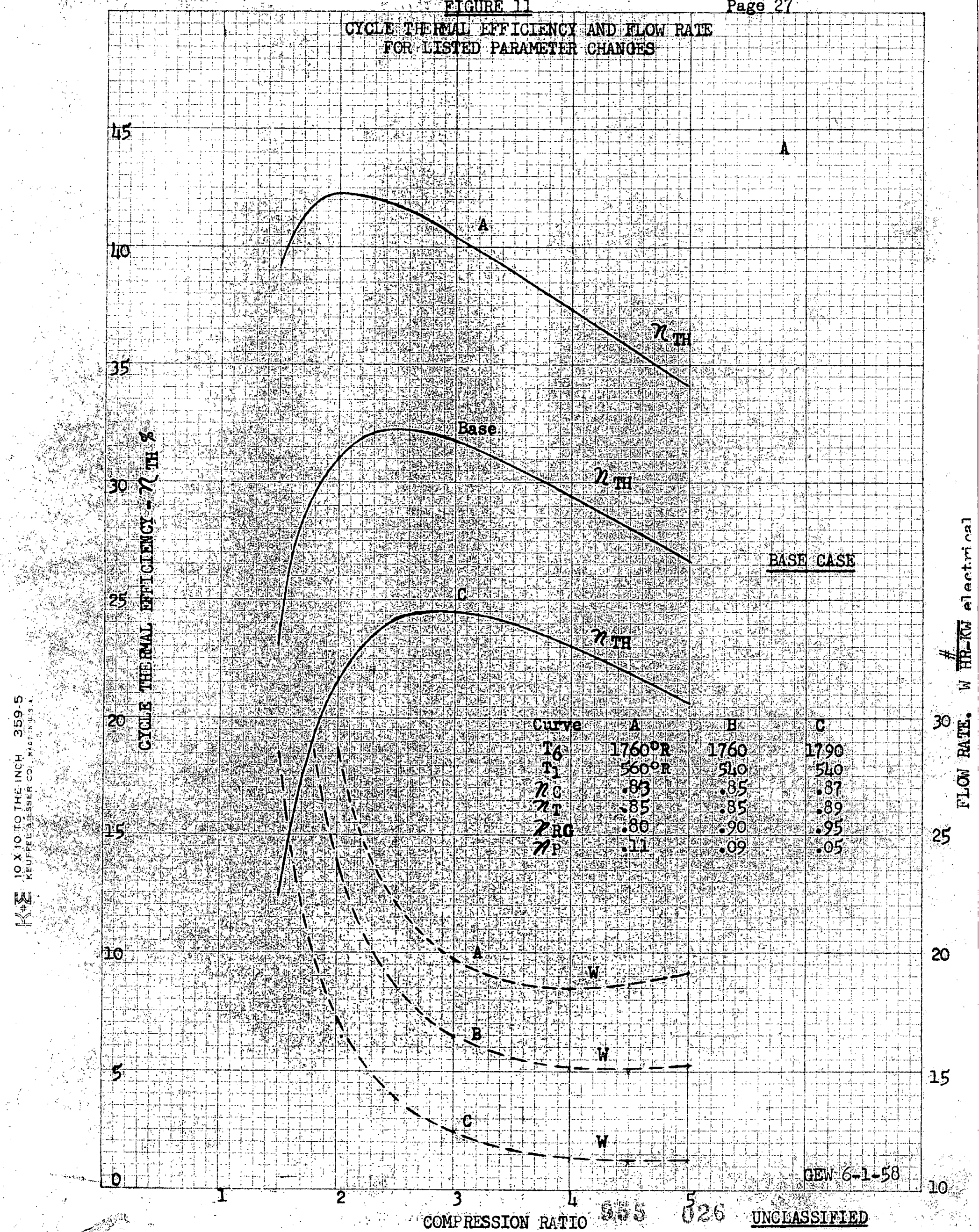

Pago 27 
The net electrical power was calculated assuming 6 to 7 MW were utilized for water pumping and building services. The smaller figure was used for the two high reactor $\Delta T^{\prime} S$ and the larger figure for the lower reactor $\triangle \mathrm{T}$ 's (high water pumping requirement).

Using the results of the Phase I and II studies, it was determined that the expenditure of three million dollars in labor and material (does not include 40 percent overhead) was justified if a one percent increase in cycle thermal efficiency could be achieved. The converse of this statement is also true. This value for improvements is limited to a narrow span of two percent change before re-evaluation is necessary.

Ways of increasing the thermal efficiency by one percent are listed in Table III. The changes listed in Table III are additive so several smaIl changes could result in a surprising increase in electrical power output. These changes are additive over a rather large span of values.

To effect a $60 \mathrm{psig}$ increase in maximum cycle pressure, with no change in cycle efficiency, a sum of $\$ 1.1 \times 10^{\circ}$ in equipment and labor costs can be expended and still reduce power costs. In practice, this change and the resulting decrease in parasitic losses would be worth an additional amount. Again, the value of the pressure increase should be re-evaluated if the pressure varies over a very wide range.

For a final design, allowable expenditures similar to those noted above should be used to justify any plant additions or parameter changes. In addition, all components should be examined. These costs will be significant as the total capital cost for the most optimum cases in this study is on the order of 84 to 86 million dollars.

In summary, it should be noted that, for the more optimum cases studied, the maximum cycle pressure will be high $\left(530^{\circ} \mathrm{psig}\right)$ and the net electrical. power will be approximately $320 \mathrm{MW}$. Total parasitic pressure losses will be approximately 7 percent with 3 percent in the reactor core and 4 percent in the vessel entry, piping and heat exchangers. 


\section{TABLE III}

Changes in Design Constants Required to Effect a One Percent Increase in Cycle Thermal Efficiency (1)

Cycle Maximum Temperature

$+30 \mathrm{~F}$

Cycle Minimum Temperature

$-10 F$

Compressor Adiabatic Efficiency

f 1.6 percent

Turbine Adiabatic Efficiency

$\downarrow 1.5$ percent

Parasitic Pressure Losses

- 1.6 percent

Regenerator Efficiency

t 2.5 percent

Bleed

- 2 percent

(1) These are approximate average values for a system pressure ratio range of 2 to 3.5. The changes are additive or subtractive, i.e., a seven percent increase in $\eta_{\text {th }}$ would be possible if all of the above constants were varied in the proper direction. 


\section{NOME NCLATURE}

Symbol

\section{T}

$\mathbf{P}$

$\psi$

$\gamma$

N

$\eta_{\mathrm{c}}$

B

$\eta_{\mathrm{m}}$

$\eta_{t}$

$\eta_{\mathrm{p}}$

$\eta_{\mathrm{R}}$

$\eta_{\text {th }}$

WK

$\eta_{\mathrm{e}}$

MW

W

We

$c_{p}$

a.

\section{Subscripts}

$1,2,3,350$.,
Quantity

Temperature at a point

Pressure at a point

$\gamma-1 / \gamma$

Ratio of $c_{p}$ to $c_{v}$

Number of stages of compression

Adiabatic compressor efficiency

Gas bleed for cleanup, cooling, etc.

Mechanical efficiency for machinery set

Adiabatic turbine efficiency

Cycle parasitic pressure loss, $\Sigma \Delta \mathrm{P} / \mathrm{P}$

Regenerator efficiency

Cycle thermal efficiency

Gross electrical output

Electrical efficiency for generator

Reactor power level

Weight rate of flow

Flow rate pert unit aftelectrical output

Speedfic heat it constiant pressune

Precooler or intercooler efficiency
Units

$\mathrm{R}$

psia

None

None

None

Percent

Percent

Percent

Percent

None

Percent

Percent

Megawatts

Percent

Megawatts

$\mathrm{lb} / \mathrm{hr}$

$\mathrm{Ib} / \mathrm{An} / \mathrm{n} \div \mathrm{kWW}$

Btw/iloin $\mathrm{F}$

Percent

Refer to points on flow diagram 
C. REACTOR PHYSICS AND FUEL ELEMENT CONSIDERATIONS

The detailed method for the calculation of the reactor physics data developed for this study is identical with that delineated in Section III of HW-54727 ADD. However, due to the consideration of additional values for some of the parameters, the conclusions in regard to optimum enrichment values has changed somewhat. Briefly stated, it now appears that the initial enrichment corresponding to the optimum range of net power costs would be closer to two weight percent U-235. This increase over the previous study results is primarily due to the fact that, while higher specific tube powers can be tolerated in reactors with shorter active zone lengths, this gain is partially nullified by a corresponding increase in the required volume of stainless steel cladding. Figure 12, on the following page, has been included to show the anticipated trend in enrichment requirements as a function of the flow area ratio for the more optimum values of the other parameters considered.

As in the initial studies, it was again found that fuel costs for the better cases studied would be of the order of 2.5 to $3.0 \mathrm{mills} / \mathrm{kwh}$. This, of course, is based on the use of multi-element clusters of $\mathrm{UO}_{2}$ clad in stainless steel and it must be recognized that considerable investigation of fabrication techniques and irradiation characteristics must be completed prior to definitely establishing this as the most attractive type element for the gas-cooled reactor concept.

Nuclear safety characteristics were evaluated by means of "blackness weighting" of the temperature coefficient of reactivity. In all cases, results showed that the optimum reactor concepts have negative moderator temperature coefficients at exposures in excess of $3000 \mathrm{MWD} / \mathrm{T}$. Therefore, it can be concluded that both transient and shutdown control requirements would be minimized in addition to simplifying reactor operation. This is in contrast to natural uranium fueled reactors which have strong positive temperature coefficients which places substantially larger demands on the safety system strength.

\section{HEAT TRANSFER AND FLUID FLOW CONSIDERATIONS}

Using the parameter values.which were selected for this study, the following data was developed for each of the resulting cominations:

1. Fuel rod dimensions and number required

2. Total cladding cross-sectional area

3. Number of process channels

4. Active zone length

5. Reactor vessel diameter

6. Reactor inlet pressure

7. Both reactor core and vessel $\Delta \mathrm{P}$ 


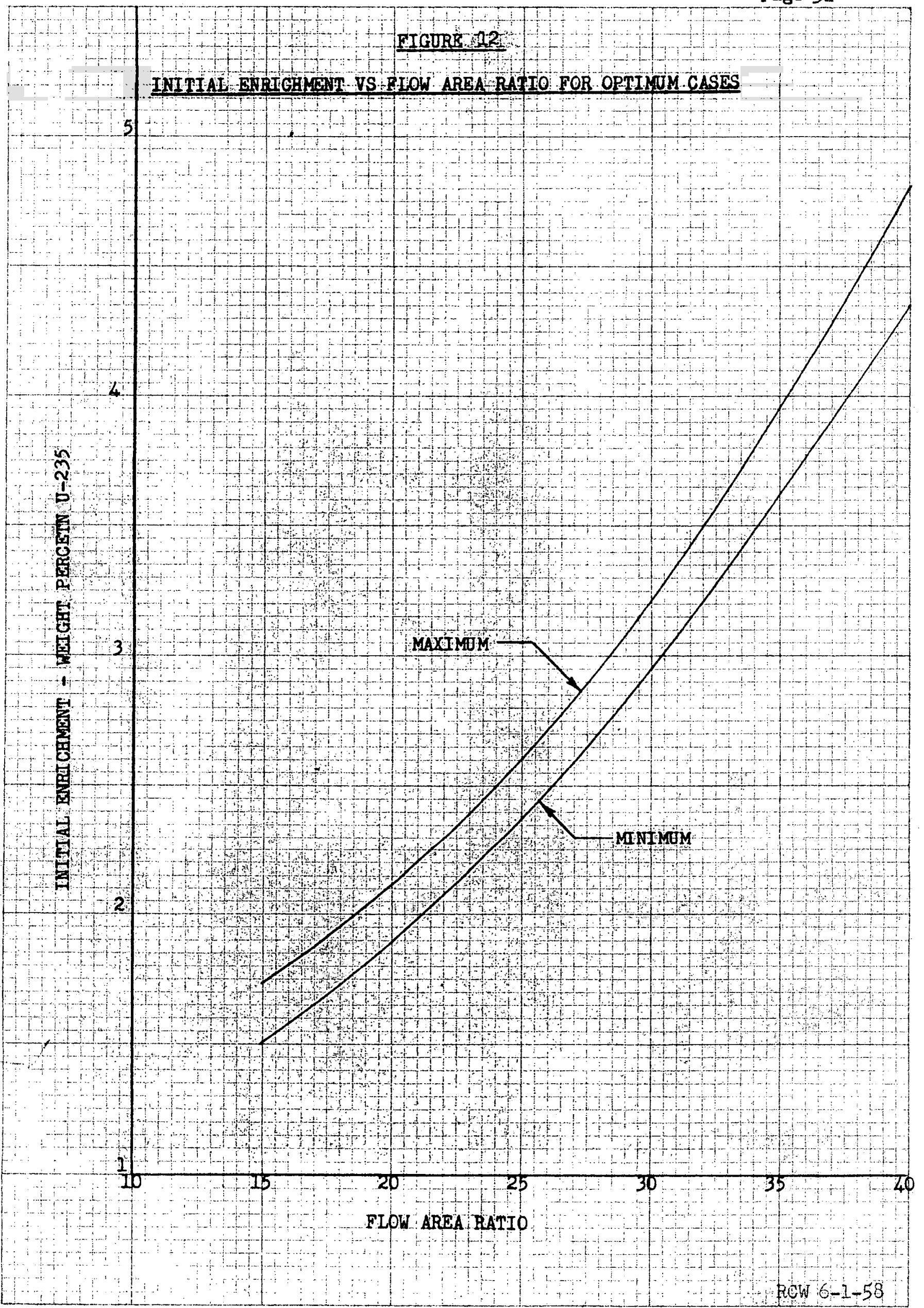


As in the Phase I and II studies, data processing equipment was utilized where possible due to the large quantity of detailed calculations required. This data was ultimately utilized in arriving at estimated power costs for the many cases considered and it is of interest to note some of the trends which influence these costs. For example, variations in specific power have a strong effect on power costs. If specific tube power is increased while holding all other variables $f$ ixed, the decrease in reactor core size will be inversely proportional to the increase in specific tube power. This results in a reduction of reactor capital costs and reduced fuel inventory charges. However, the increased specific power requires more fuel element surface area to remove the generated heat without exceeding fuel element temperature limits. This requires a larger number of fuel rods and consequently, increased flel element fabrication costs. The larger surface area results in larger volumes of stainless steel cladding which in turn requires higher fuel enrichment. The fuel element for these conditions also has more rods and therefore, increased flow resistance which implies greater pumping costs. The nature of these opposing costs indicates that the graph of power cost vs. specific power will have a minimum.

Figures 13 to 15 inclusive are included on the following pages to show the approximate trend in the optimum values of specific tube power, core lengthto-diameter ratio and reactor $\Delta \mathrm{T}$, each as a function of the flow area ratio. As mentioned previously, optimum values of reactor $\Delta \mathrm{T}$ are relatively unaffected by the percentage of flow area while it can be seen that specific tube power and length-to-diameter ratio are strongly affected by variations in this parameter.

The results of the parameter study have been qualified by two fuel element Iimitations: (I) Cases in which the individual fuel rods are less than $1 / 8$ inch in diameter and (2) Cases in which the spacing of the rods results in local Reynolds numbers of less than 10,000. (It will be remembered that the fuel elements consist of stainless clad $\mathrm{UO}_{2}$ rods arranged in a square or rectangular cluster in the square channel.

The first restriction arises from the extreme uncertainty of fabrication cost information at such small diameters. The second stems from the fact that at Reynolds Numbers below 10,000, there is the possibility of laminar flow, in which case the fluid film resistance is substantially increased. This increased resistance would result in local "hot spots". Cases which are qualified as stated are shown Figures 17 to 64 inclusive in the Appendix by the following symbols:

$\square$ Iocal Reynolds Number less than 10,000

$\bigwedge$ Fuel rod diameter less than $1 / 8$ inch

1. Reactor Heat Transfer Calculations

The reactor core and fuel element configuration is determined by the following parameters: 


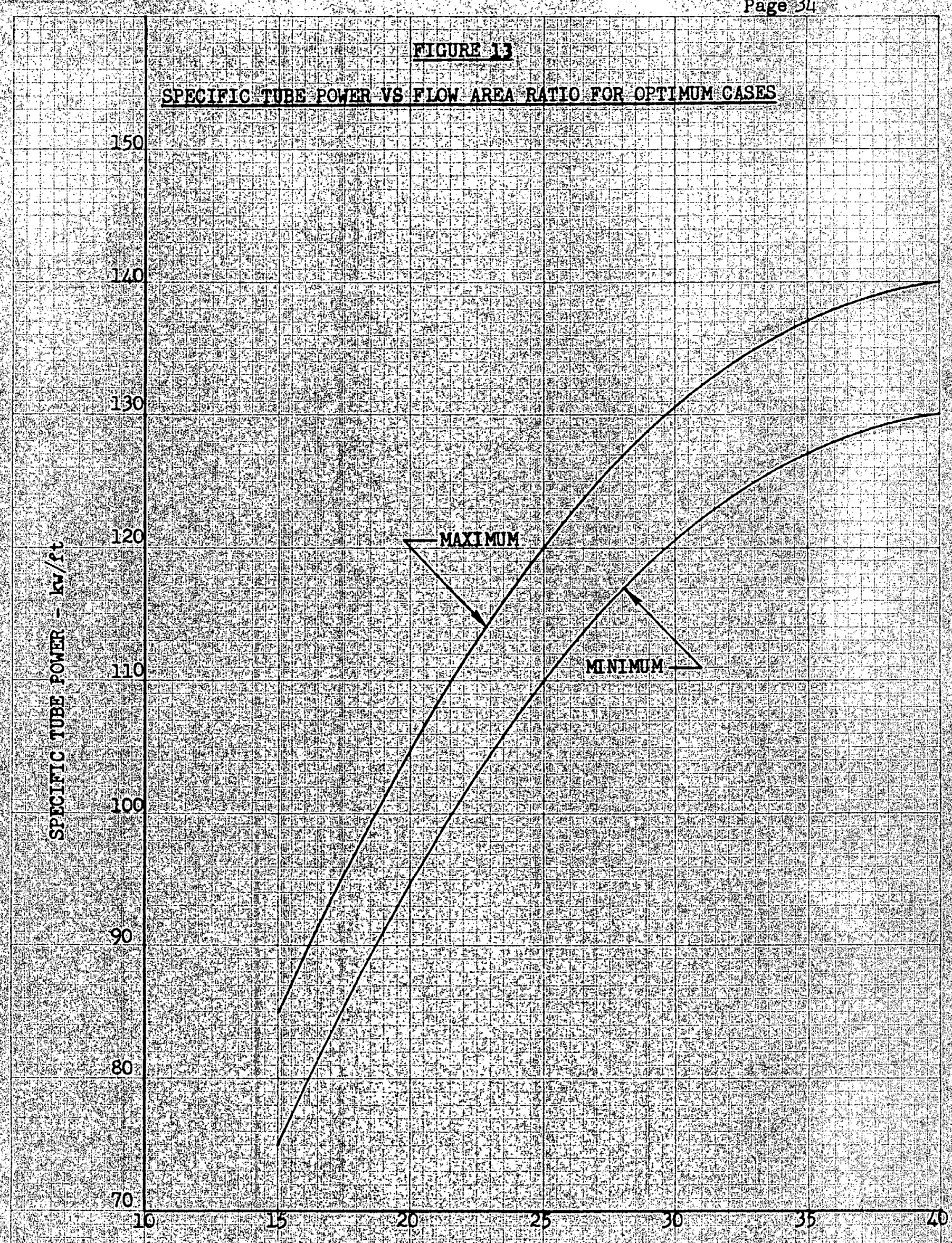

HLOW AREA HATAO 


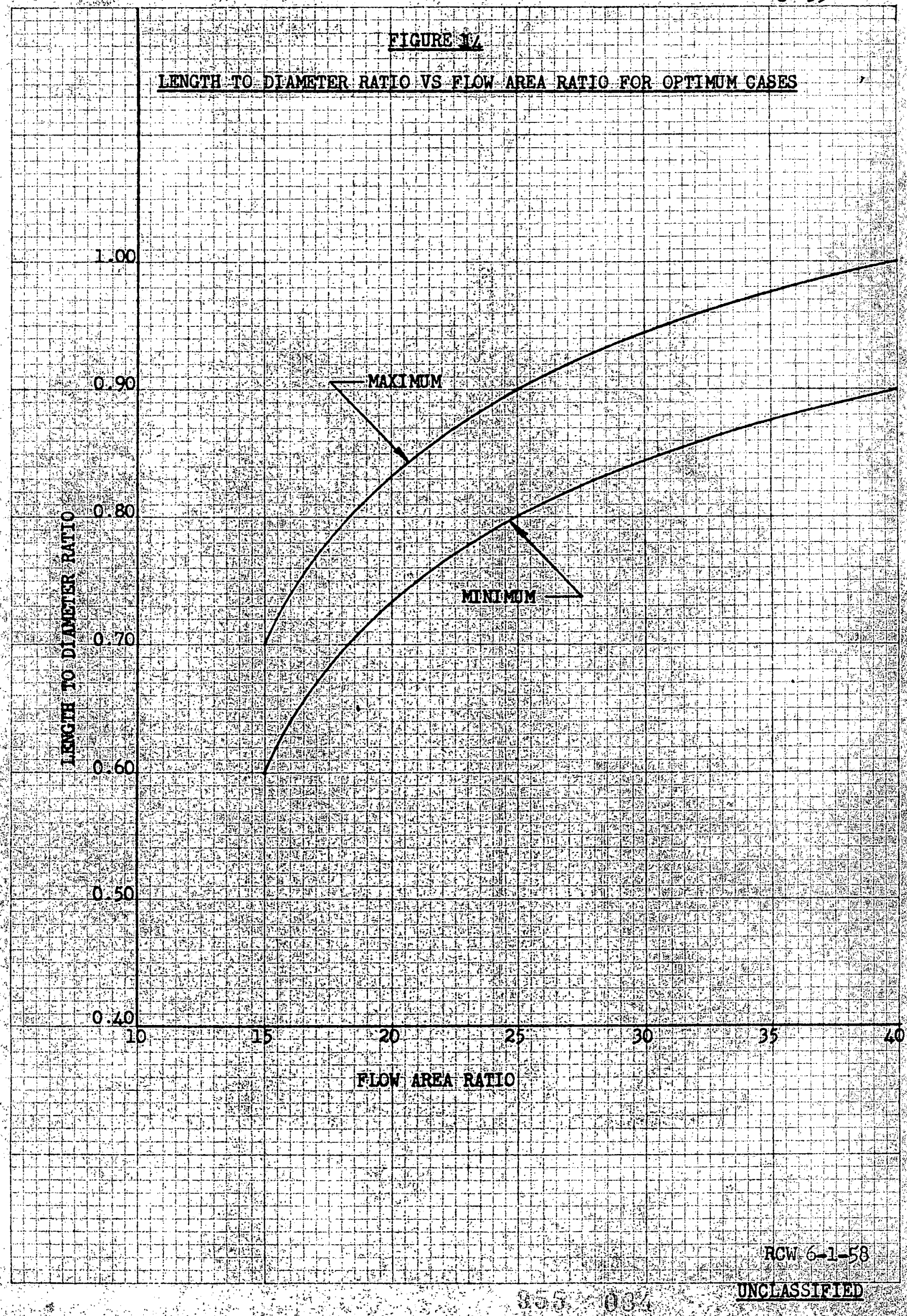







a. Power level,

b. Reactor outlet temperature and $\Delta \mathrm{T}$,

c. Specific tube power,

d. Core length-to-diameter ratio,

e. Iattice spacing,

f. Percent flow area, and

g. Moderator-to-uranium ratio.

The methods used in this study for heat transfer calculations is identical to that described in HW-54727 ADD, section IV; however, an additional fuel element requirement is that the rods cannot be spaced too closely, to prevent local "hot spots". "The required fuel rod spacing is determined from the condition that the local Reymolds Number (between the rods) must exceed 10,000, the lower boundary of turbulent flow.

Reynolds Number is defined as

$$
\begin{aligned}
& \text { Re }=\frac{G D_{e}}{\mu} \\
& \text { where } G=10 c \text { al mass flow rate }- \text { lb/hr-ft }{ }^{2} \\
& \mu=\text { viscosity }-1 \mathrm{~b} / \mathrm{hr}-\mathrm{ft} \\
& D_{e}=100 \text { al equivalent diameter }-\mathrm{ft} .
\end{aligned}
$$

$D_{e}$ is given by

$$
D_{e}=\frac{4 \times \text { flow area }}{\text { wetted perimeter }}
$$

The region where the Reynolds Number is being. investigated is shown below:

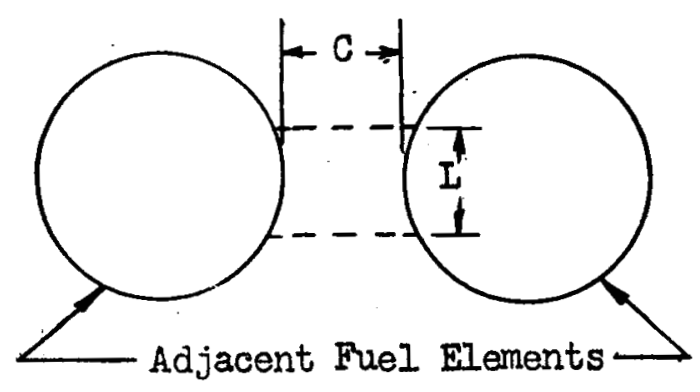


If the curvature of the rods is neglected, the area in this region is IC and

$$
D_{e}=\frac{4 I C}{2 L}=2 C
$$

Therefore,

$$
\mathrm{R}_{\theta}=\frac{2 \mathrm{G} C}{\mu}
$$

and

or

$$
\frac{2 a c}{\mu}>10,000
$$<smiles>CC(C)[R5](=O)O[Na]</smiles>

Also, $G$ was taken to be equal to $0.75 \mathrm{G}_{\text {avg. }}$ (2) as an average value; therefore,<smiles></smiles>

2. Reactor FIuid Flow Calculations

The method of calculating the reactor core pressure drops and flow rates are also the same as outlined in HW-54727 ADD; however, an additional computation was made in this study to determine the reactor vessel pressure drop characteristics. Figure 16 is a schematic drawing of the reactor vessel flow path. Coolant gas enters the annulus surrounding the core from a number of individual pipes. The gas passes through the core supports which are a square array of short cylinders.

Calculations of the flow resistance of the annulus was straightforward because the geometry of the flow passage was specified." The various turning, expansion, and contraction losses were computed using the $K$ values listed in Figure 16.

Computing the pressure drop through the core supports was more difficult because the flow pattern was radially inward and because three flow zones were utilized to obtain an 80 percent orificing efficiency.

The $\triangle P$ through the cylindrical supports was calculated from:

(2) HW-53279, "Effect of Spacing on Heat Transfer Characteristics of Cluster Fuel Elements", D. L. Condotta, October 17, 1957. 


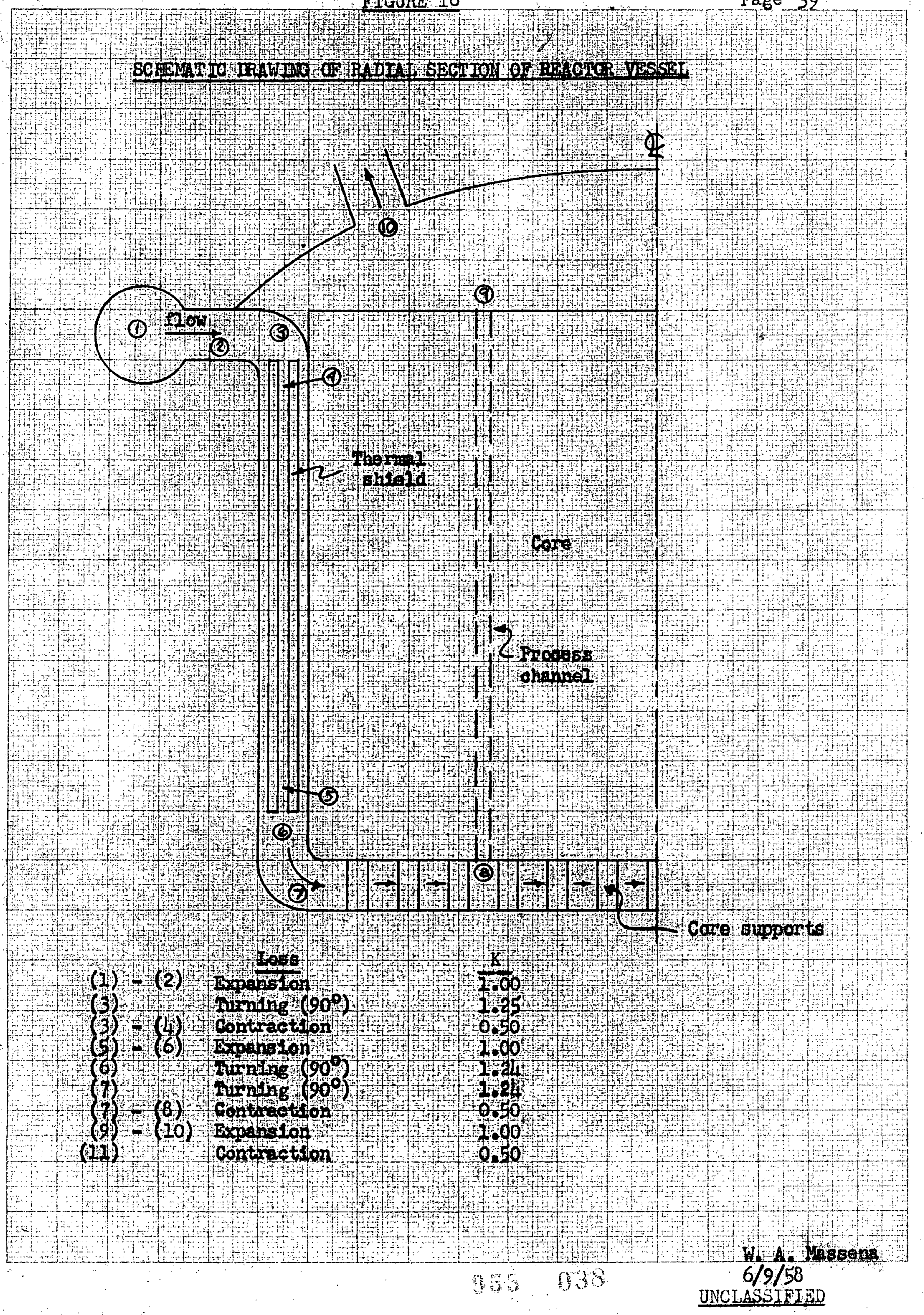




$$
P=f I \frac{G_{\max } V}{2 g}
$$

where

$$
f=\frac{\left(0.044+0.08 x_{1}\right)\left(D_{0} G_{\max }\right)^{-0.15}}{\mu\left(x_{t}-1\right)^{n}}
$$

and $D_{0}=$ cylinder diameter $-f t$.

$G_{\max }=\max$ flow rate based on minimum flow area $-\mathrm{Ib} / \mathrm{hr}^{-f t^{2}}$

$\mathrm{x}_{1}=$ pitch-to-diameter ratio in Iongitudinal direction

$x_{t}=$ pitch-to-diameter ratio in transverse direction

$n=0.43+\frac{(1.13)}{x_{1}}$

$v=$ specific volume $-1 \mathrm{~b} / \mathrm{ft}^{3}$

$I=$ length of flow path $-f^{t}$

E. ECONOMIC EVALUATION

As an aid in evaluating the parameters considered in this additional study, the program which was developed for solution by IBM Data Processing equipment was designed to compute and print out such values as:

1. Annual burnout cost

2. Annual fuel fabrication cost

3. Annual charge on inventory of enriched uranium

4. Annual charge on inventory of fabricated fuel elements

5. Annual plutonium credit

6. Net annual fuel cost

7. Total annual cost including fuel cost, operating and maintenance cost and annual charge on capital investment.

8. Net capital investment per kilowatt of saleable power.

9. Net power cost. 
In addition to the solution of these values, the results were automatically plotted by Data Processing equipment to show net power cost as a function of reactor $\Delta T$ for the selected combinations of specific tube power, graphite-to-uranium ratio, length-to-diameter ratio of the reactor core and process channel area-to-lattice area ratio.

The equations which were utilized for this program may be summarized as follows:

PC = Power cost in mills/kwh $=142.7\left(\frac{A C}{N_{n}}\right)$

$\mathrm{MW}_{\mathrm{n}}=$ Net electrical generating capacity in megawatts

$A C=$ Total annual cost in $\$ / y r . \times 10^{-6}=0_{c} \neq 0.15 I_{c}+F_{n}$

$O_{c}=$ Annual operating and maintenance cost in $\$ / y x \cdot \times 10^{-6}$

$I_{C} *$ Total capital investment in $\$ \times 10^{-6}$

$F_{n}^{\prime}=$ Net annual fuel cost in $\$ / y r \cdot x 10^{-6}-B \neq F+I_{u} \neq I_{f}-P$

$B=$ Annual burnout cost in $\$ / y r . x 10^{-6}=0.05296\left(E_{i}-E_{f}\right)$

$E_{i}^{* *}=$ Value of enriched green fuel in $\$ / \mathrm{kg}-\mathrm{U}^{238}$

$$
=-24.3+55.51 x_{i}+59.92 x_{i}^{2}-18.3 x_{i}^{3}+2.845 x_{i}^{4}
$$

$-0.174 \times \frac{5}{i}$

$x_{i}=$ Initial enrichment in weight percent $\mathrm{u}^{235}$

$\mathbf{E}_{f}$ - Value of irradiated fuel in $\$ / \mathrm{kg}-\mathrm{v} 238$

$=-24.3+55.51 x_{f}+59.92 x_{1}^{2}-18.3 x_{f}^{3}+2.845 x_{f}^{4}-0.174 x_{f}^{5}$

$X_{f}=$ Final enrichment in weight percent $U^{235}$

$F=$ Annual fabrication, separation and conversion cost in $\$ / y x \times 10^{-6}$

$$
=0.1325 \mathrm{f}+\mathrm{I}
$$

* Total capital investment was charged at the rate of 15 percent per year. ** Equations for $E_{i}$ and $E_{f}$ are valid only within the range of 0.5 to 5.0 percent enrichment. 
$f=22.281-49.865 r+63.919 r^{2}-27.571 r^{3}$

$r=$ Outside diameter of canned fuel element in inches

$I_{u}=$ Annual inventory charge on $U^{235}$ in $\$ /$ yr $\times 10^{-6}$

$=(T+29.2)\left(3.6288 \times 10^{-5} E_{i}\right)$

$T=$ Pile loading in tons of $U^{238}=\frac{6.047 \times 10^{5}\left(1-R_{a}\right)}{N_{g} / N_{u}(q)}$

$R_{a}=$ Process channel-to-lattice area ratio

$\mathrm{N}_{\mathrm{g}} / \mathrm{N}_{\mathrm{u}}=$ Graphite-to-uranium ratio (atom-to-atom)

$q=$ Average power in maximum performance tube in $k w / f t$.

$I_{f}=$ Annual inventory charge on fabricated fuel elements in $\$ /$ yr $\times 10^{-6}$

$=(\mathrm{T} \phi 29.2)\left(3.4 \times 10^{-4} \mathrm{f}\right)$

$P=$ Annual plutonium credit* in $\$ /$ Yr X $10^{-6}=0.701 \mathrm{Z}$

$\mathrm{Z}=$ Plutonium yield in $\mathrm{kg} / \mathrm{T}-\mathrm{U}^{238}$

As mentioned above, the results of these calculations were plotted in order to delineate the trends in power cost which result from variations in the parameters considered. These plots are shown in Figures 17 to 64 inclusive of the Appendix. By cross plotting the more optimum cases, it was also possible to determine the optimum range of values for each of the variables under consideration. This data is tabulated in Table I, page 6 , and is shown graphically in Figures $1,13,14$ and 15 . From this it appears that the optimum value of flow area-to-lattice area would occur at about 20 percent.

As an indication of the various components which result in the se power costs, Table IV and $V$ have been included. While none of these cases are "optinum", they are the nearest ones to this condition for which detailed cost evaluations were made and are believed to be representative of the costs which would be expected for a reactor concept wich would be selected on the basis of the results of this study.

FIutonium yield was credited at $\$ 12 / \mathrm{g} m$ regardless of Pu240 concentration. 


\section{TABIE IV}

Description of Cases Shown in Table $\nabla$

\begin{tabular}{cccccc} 
Case No. & $A_{f} / A_{I}$ & $N_{g} / \mathrm{N}_{u}$ & $L / D$ & $q$ & $\Delta T$ \\
\hline 1 & 25 & 70 & 1.25 & 80 & 500 \\
2 & 25 & 70 & 0.75 & 80 & 500 \\
3 & 25 & 80 & 1.25 & 80 & 500 \\
4 & 25 & 80 & 0.75 & 80 & 500 \\
5 & 15 & 70 & 0.75 & 80 & 500 \\
6 & 15 & 70 & 0.50 & 80 & 500 \\
7 & 15 & 80 & 0.75 & 80 & 500 \\
8 & 15 & 80 & 0.50 & 80 & 500
\end{tabular}

Note:

Reactor Power Level $=1000 \mathrm{MW}$ for all cases

Goal Exposure $=5000 \mathrm{MWD} / \mathrm{T}$ for all cases

$A_{f} / A_{1}=$ Flow area-to-lattice area ratio

$\mathrm{N}_{\mathrm{g}} / \mathrm{N}_{\mathrm{u}}=$ Graphite-to-uranium ratio (atom-to-atom)

$I / D=$ Length-to-diameter ratio of reactor core

$q=$ Average power in maximum performance tube (kw/ft)

$\Delta \mathrm{T}=$ Reactor temperature rise $(\mathrm{F})$ 


\section{TABIE V}

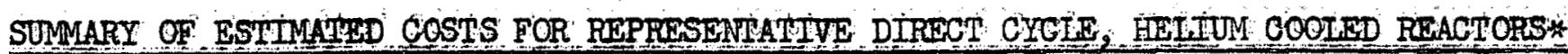

\begin{tabular}{|c|c|c|c|c|c|c|c|c|c|c|}
\hline \multirow{2}{*}{ Item } & \multirow[b]{2}{*}{ Units } & \multicolumn{8}{|c|}{ Case Number } & \\
\hline & & $I$ & 2 & 3 & 4 & 5 & 6 & 7 & 8 & 舁 \\
\hline Burnout Cost & $\$ / y r \cdot \times 10^{-6}$ & 4.501 & 4.690 & 4.571 & 4.731 & 3.816 & 3.985 & 3.905 & 4.104 & 团 \\
\hline $\begin{array}{l}\text { Fabrication, Separation \& Con- } \\
\text { version Cost }\end{array}$ & $"$ & 2.908 & 3.032 & 2.999 & 3.112 & 2.590 & 2.712 & 2.714 & 2.825 & \\
\hline $\mathrm{U}^{235}$ Inventory Charge & $"$ & 0.924 & 1.054 & 0.862 & 0.990 & 0.642 & 0.712 & 0.599 & 0.661 & \\
\hline Fuel Element Inventory Charge & n & 0.539 & 0.575 & 0.513 & 0.542 & 0.494 & 0.532 & 0.482 & 0.513 & \\
\hline Plutonium Credit & $"$ & 2.166 & 2.152 & 2.054 & 2.033 & 2.019 & 2.005 & 1.929 & 1.912 & \\
\hline Net Annual Fuel Cost & $"$ & 6.706 & 7.199 & 6.891 & 7.342 & $5: 523$ & 5.936 & 5.771 & 6.191 & \\
\hline Annual Operating \& Maintenance & $"$ & 2.120 & 2.120 & 2.120 & 2.120 & 2.120 & 2.120 & 2.120 & 2.120 & $E$ \\
\hline Total Capital Investment & $"$ & 86.016 & 84.350 & 86.016 & $84: 350$ & 85.498 & 85.358 & 85.498 & 85.358 & \\
\hline Annual Capital Charge & " & 12.902 & 12.652 & 12.902 & 12.652 & 12.825 & 12.804 & 12.825 & 12.804 & \\
\hline Total Annual Cost & $"$ & 27.728 & 21.971 & 21.913 & 22.114 & 20.468 & 20.860 & 20.716 & 21.115 & \\
\hline Saleable Power & $\operatorname{ME}(e)$ & 317 & 326 & 317 & 326 & 310 & 318 & 312 & 319 & \\
\hline Net Power Cost & Mills/kwh & 9.781 & 9.612 & 9.865 & 9.680 & 9.422 & 9.361 & 9.475 & 9.446 & \\
\hline $\begin{array}{c}\text { Gross Capital Investment/ } \\
\text { Saleable Power Unit }\end{array}$ & $\$ / \mathrm{kw}$ & 271 & 259 & 271 & 259 & 276 & 268 & 274 & 268 & \\
\hline - $\quad+\cdots$ & & & & & & & & & & \\
\hline
\end{tabular}


V. APPENDIX

Figures 17 - 64 inclusive - Net Power Cost as a Function of Reactor $\Delta T$ for Various Combinations of Specific Tube Power, Flow Area Ratio, Graphite-to-Uranium Ratio and Core Iength-to-Diameter Ratio.

Note: Superimposed symbols are to indicate the following:

$\square$ Local Reynolds number of less than 10,000

$\triangle$ Fuel rod diameter less than $1 / 8$ inch 


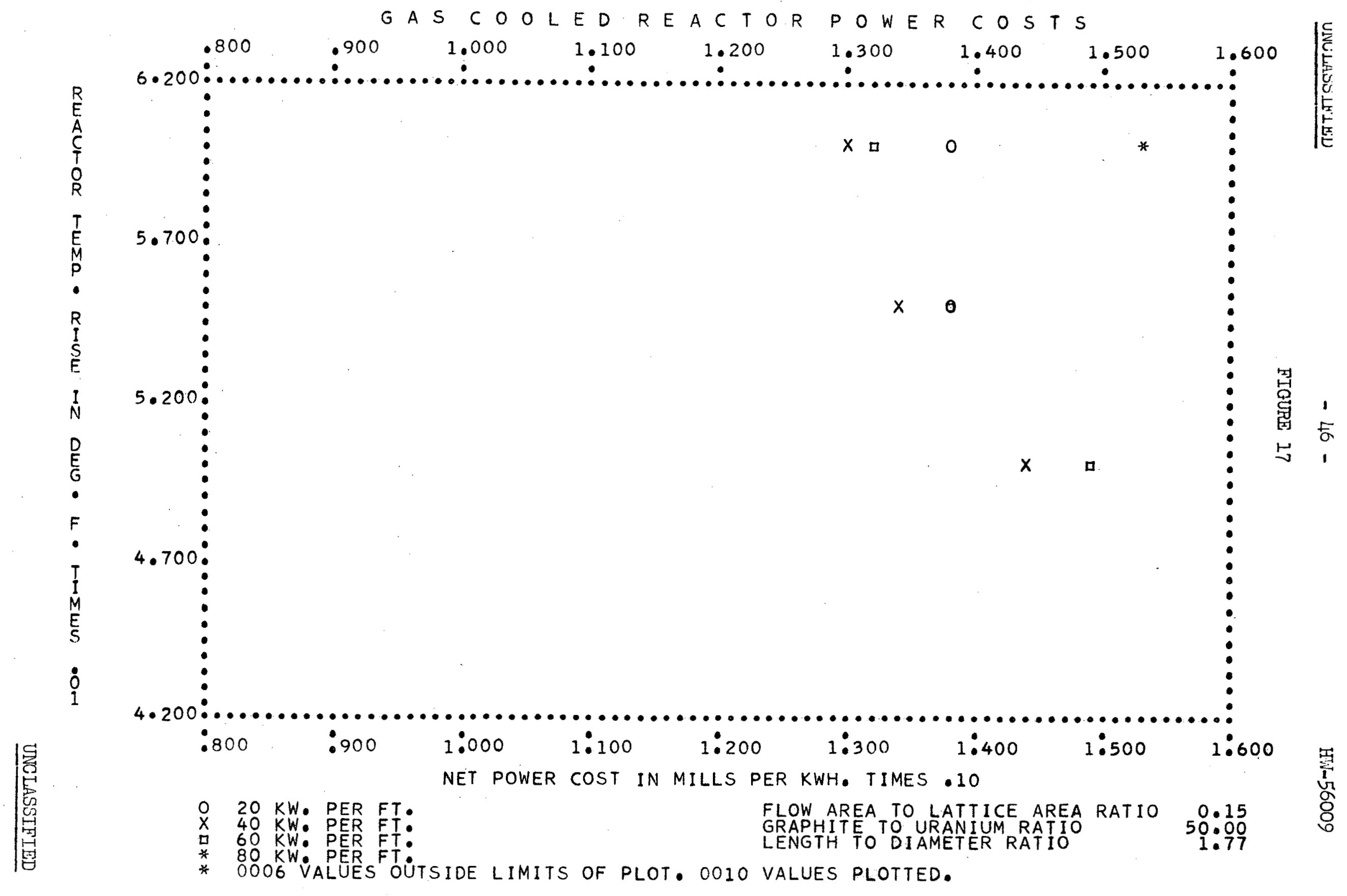




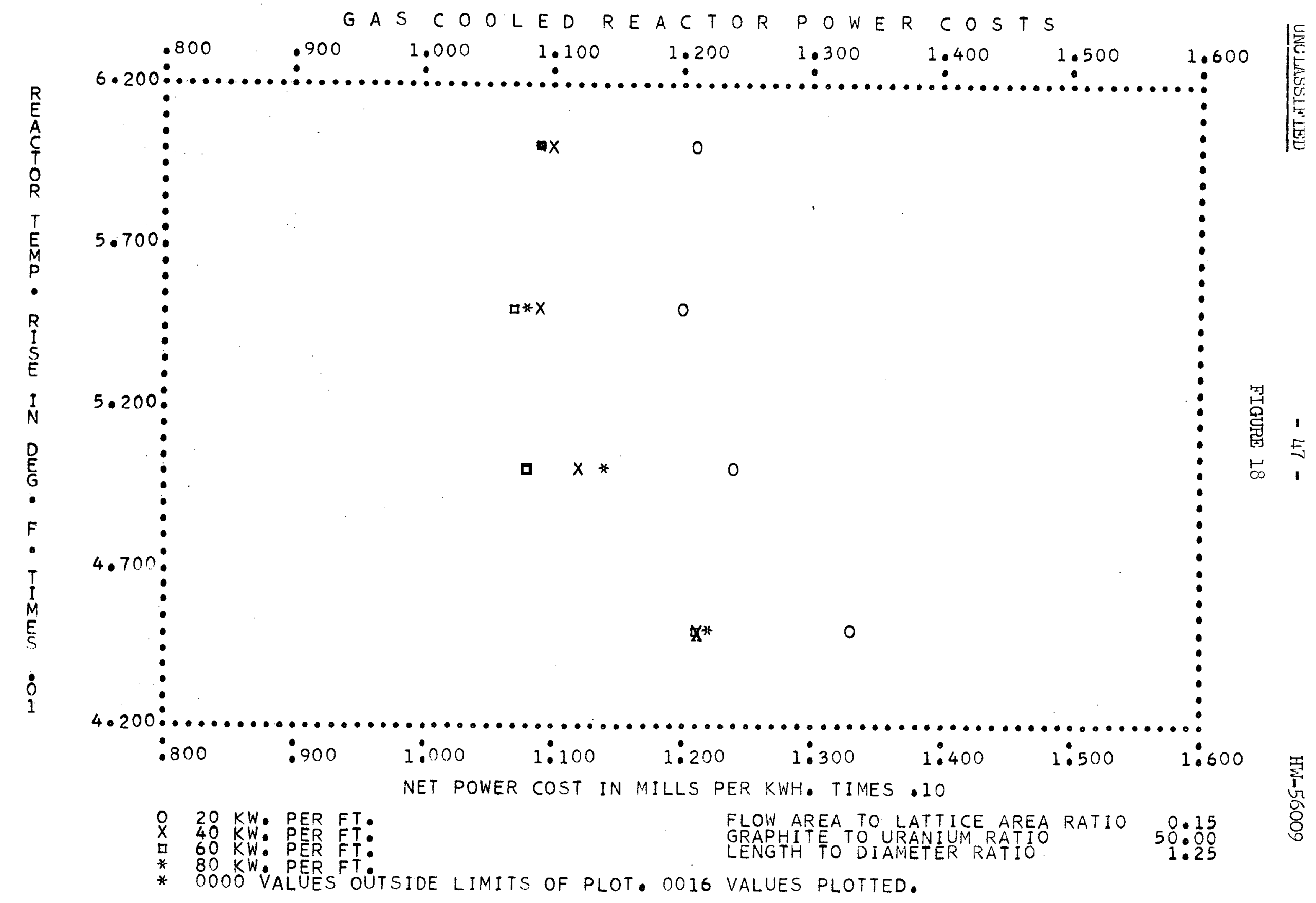




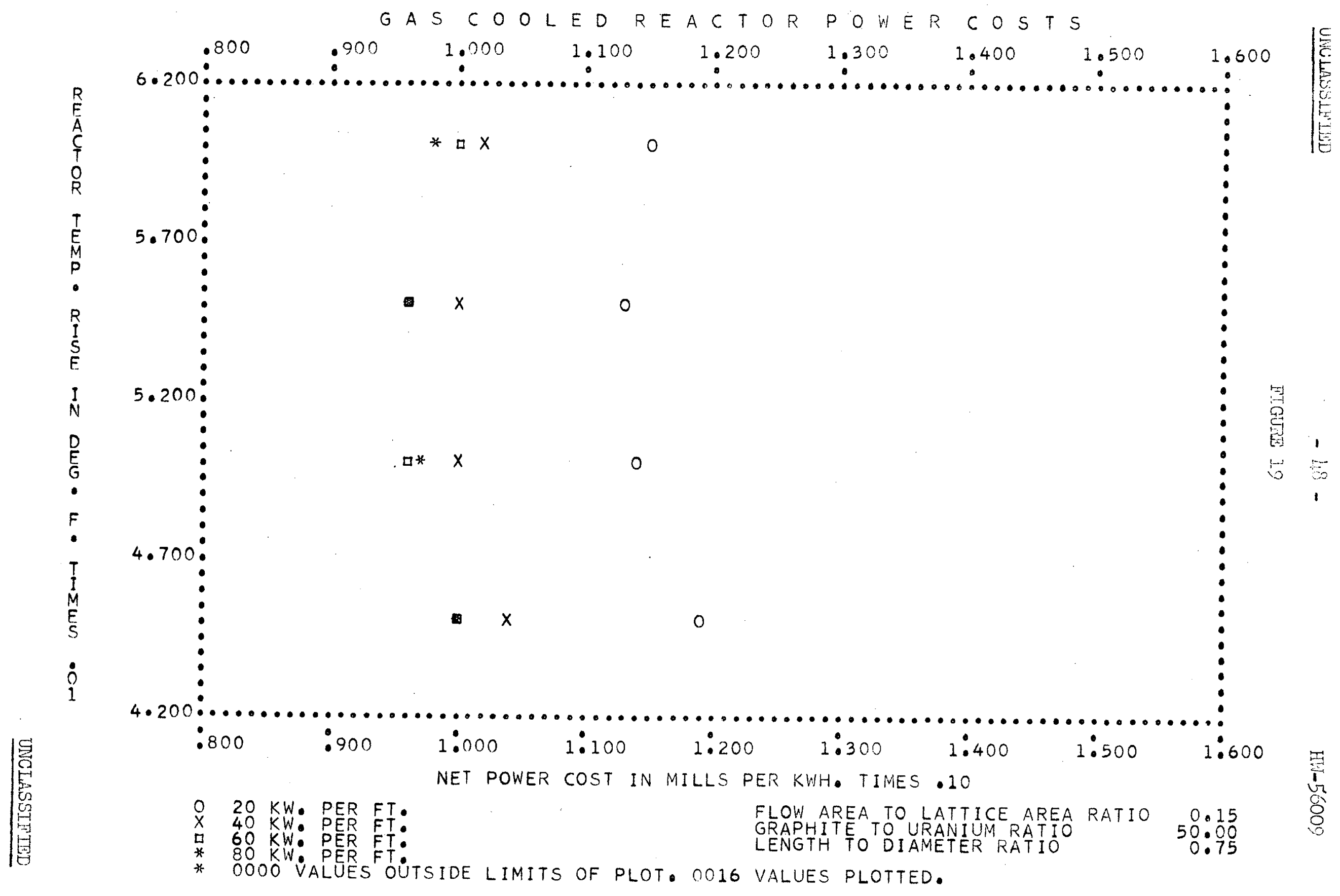




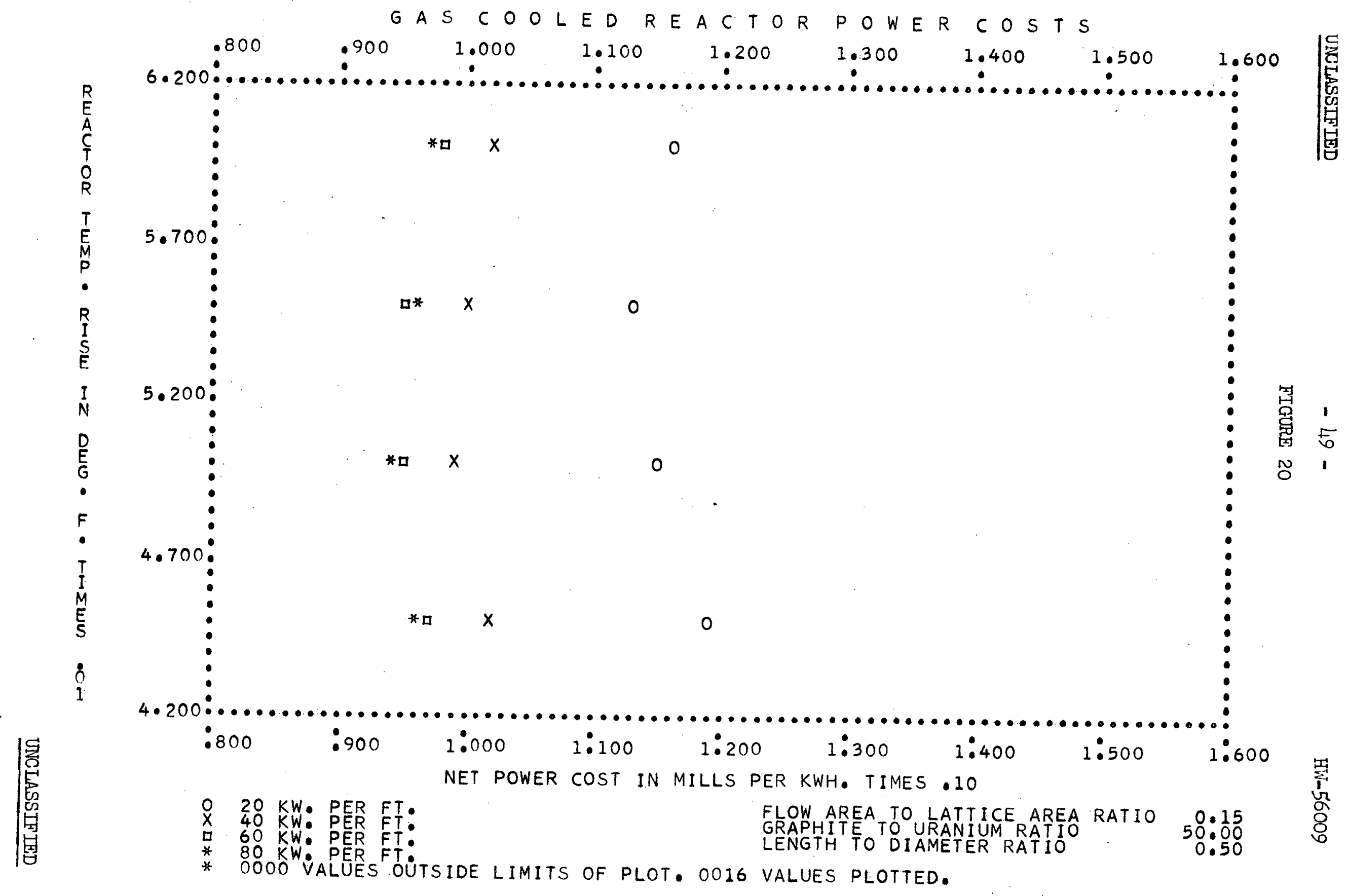




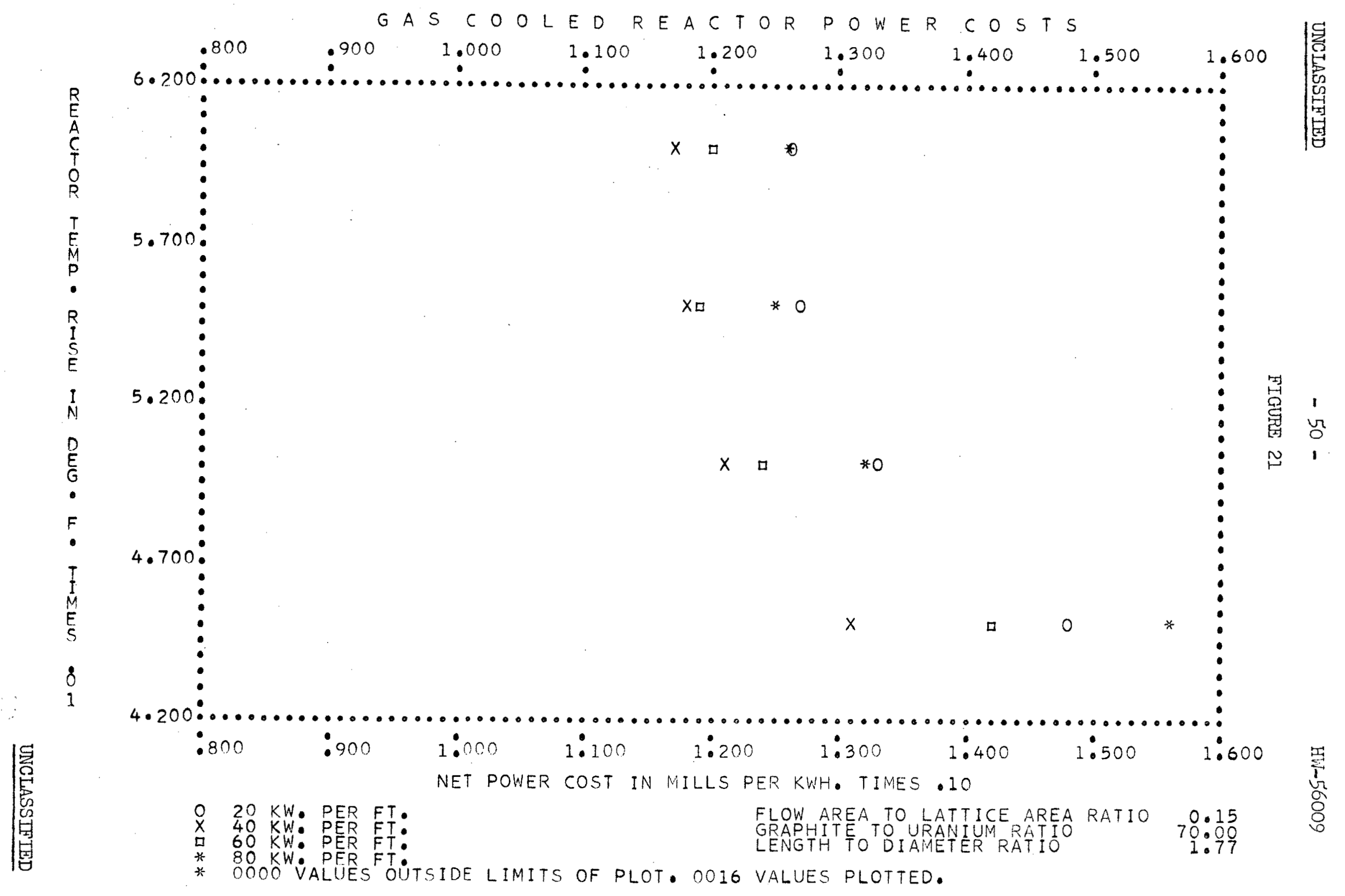




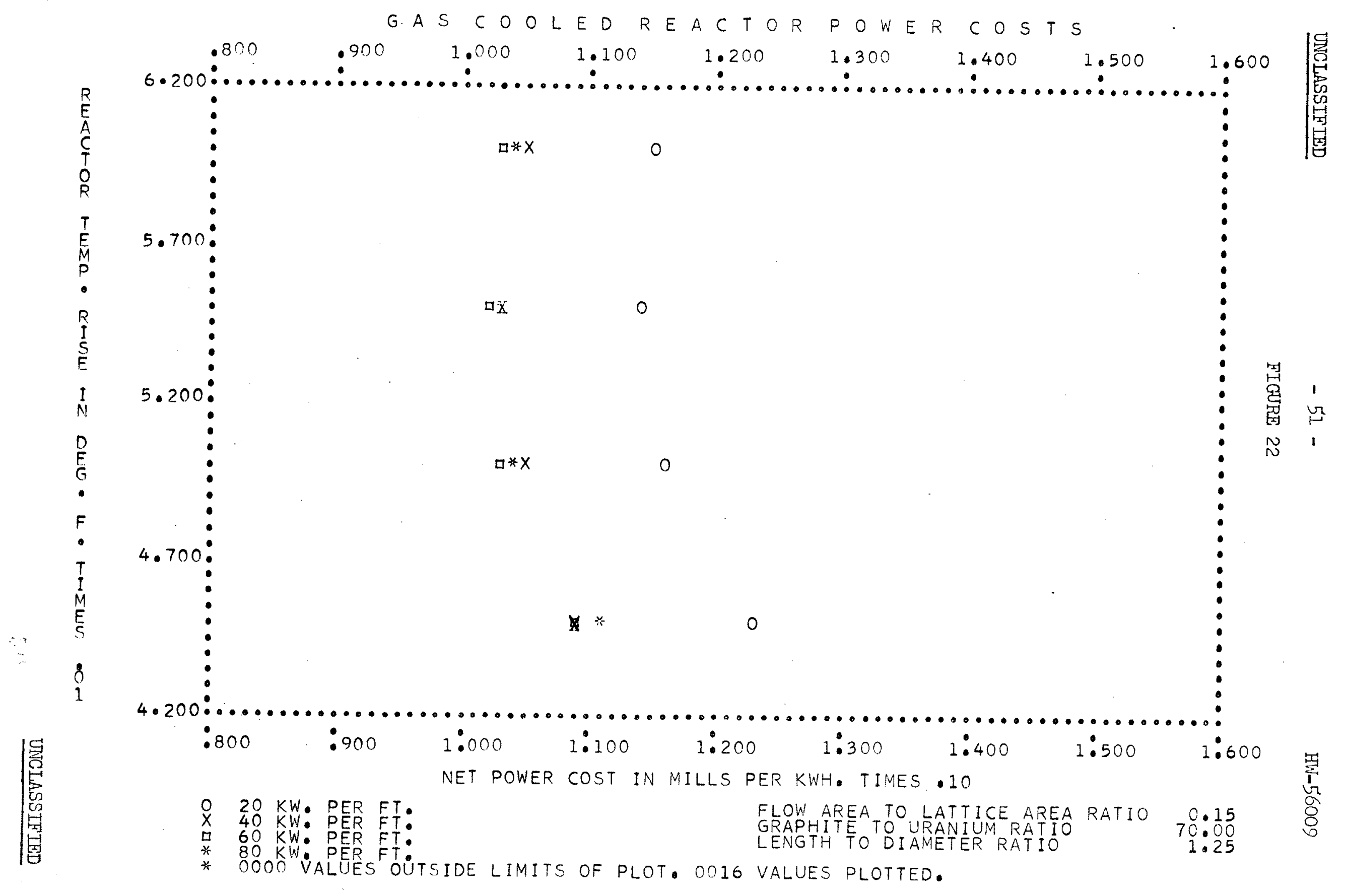




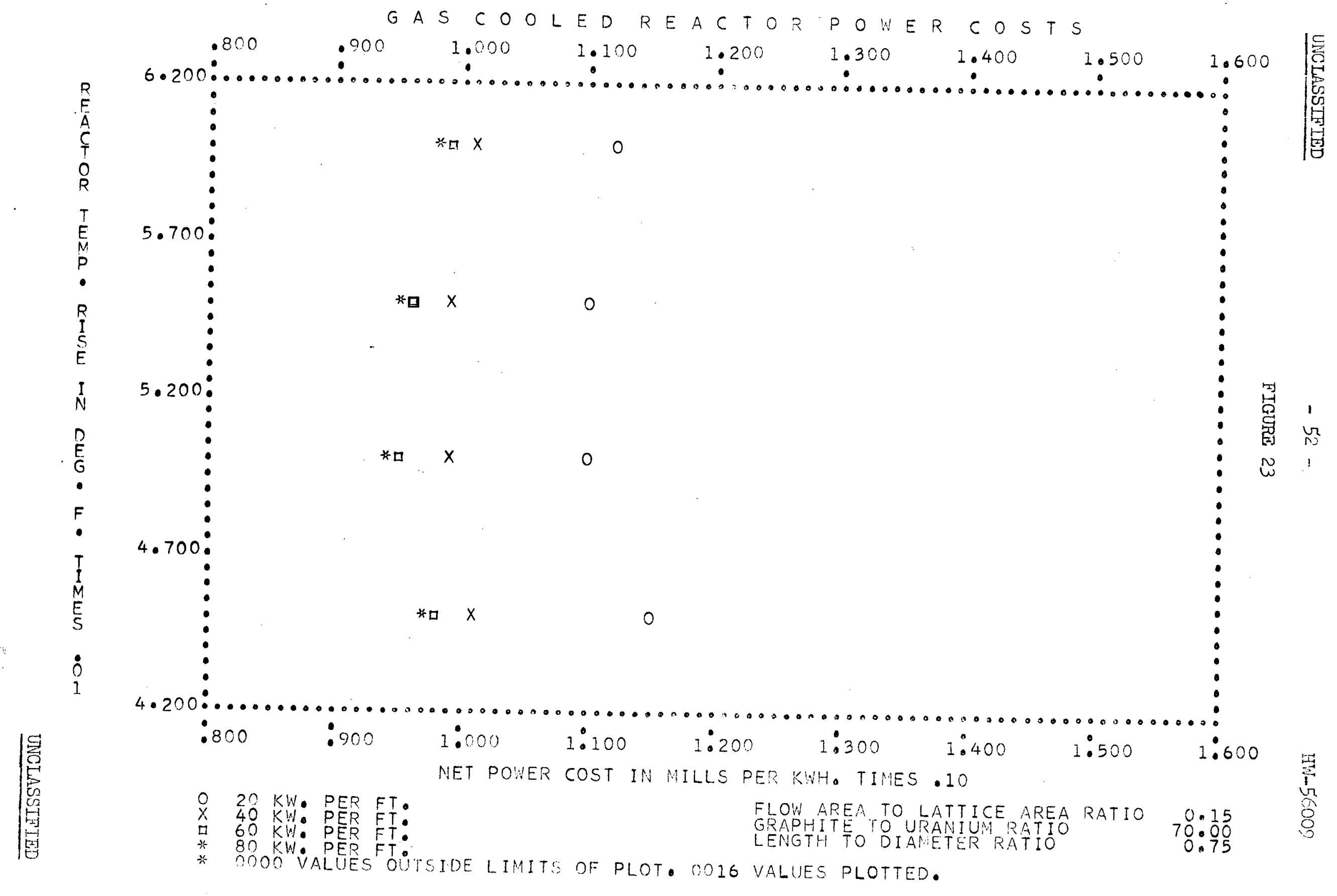




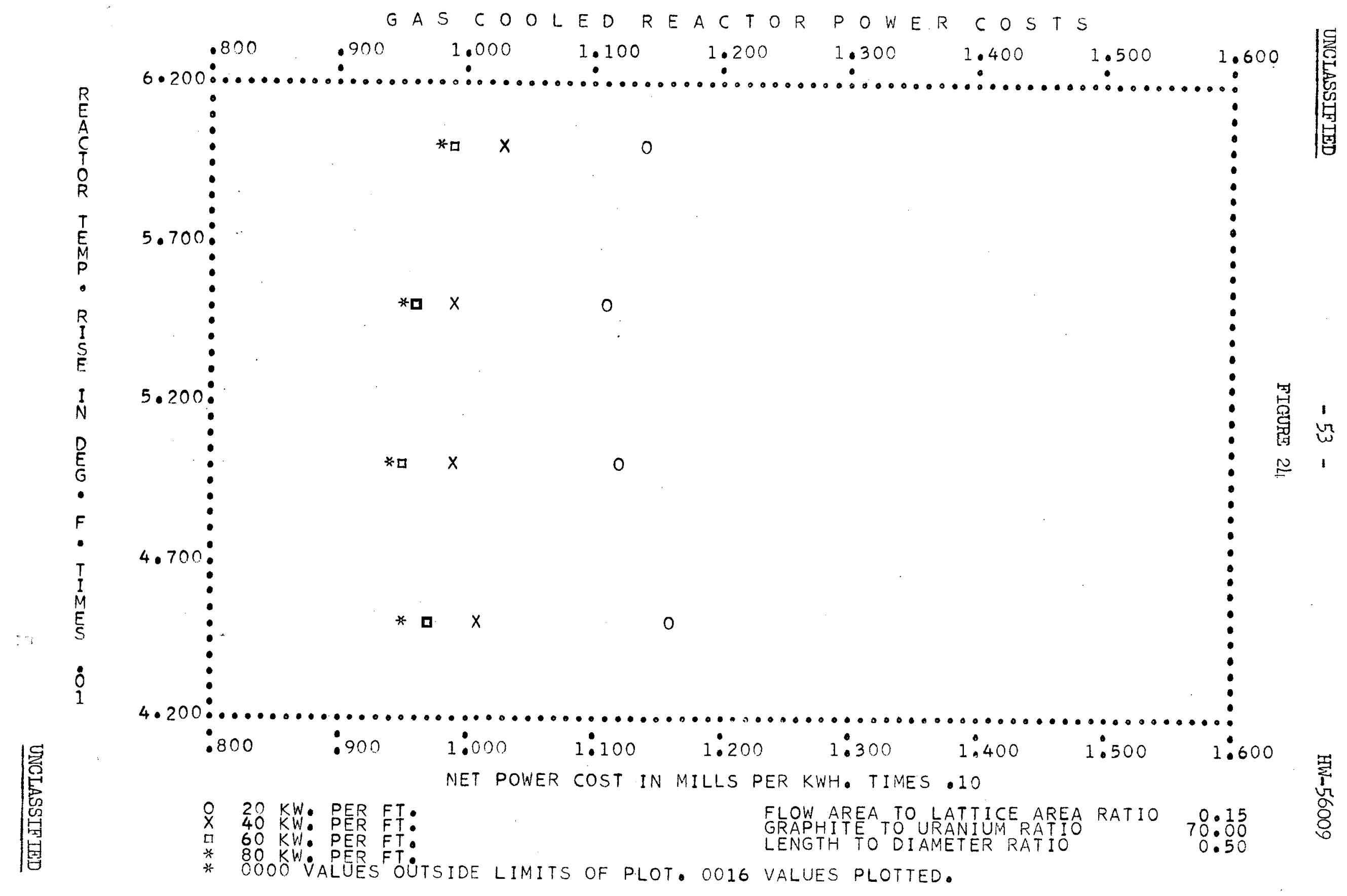




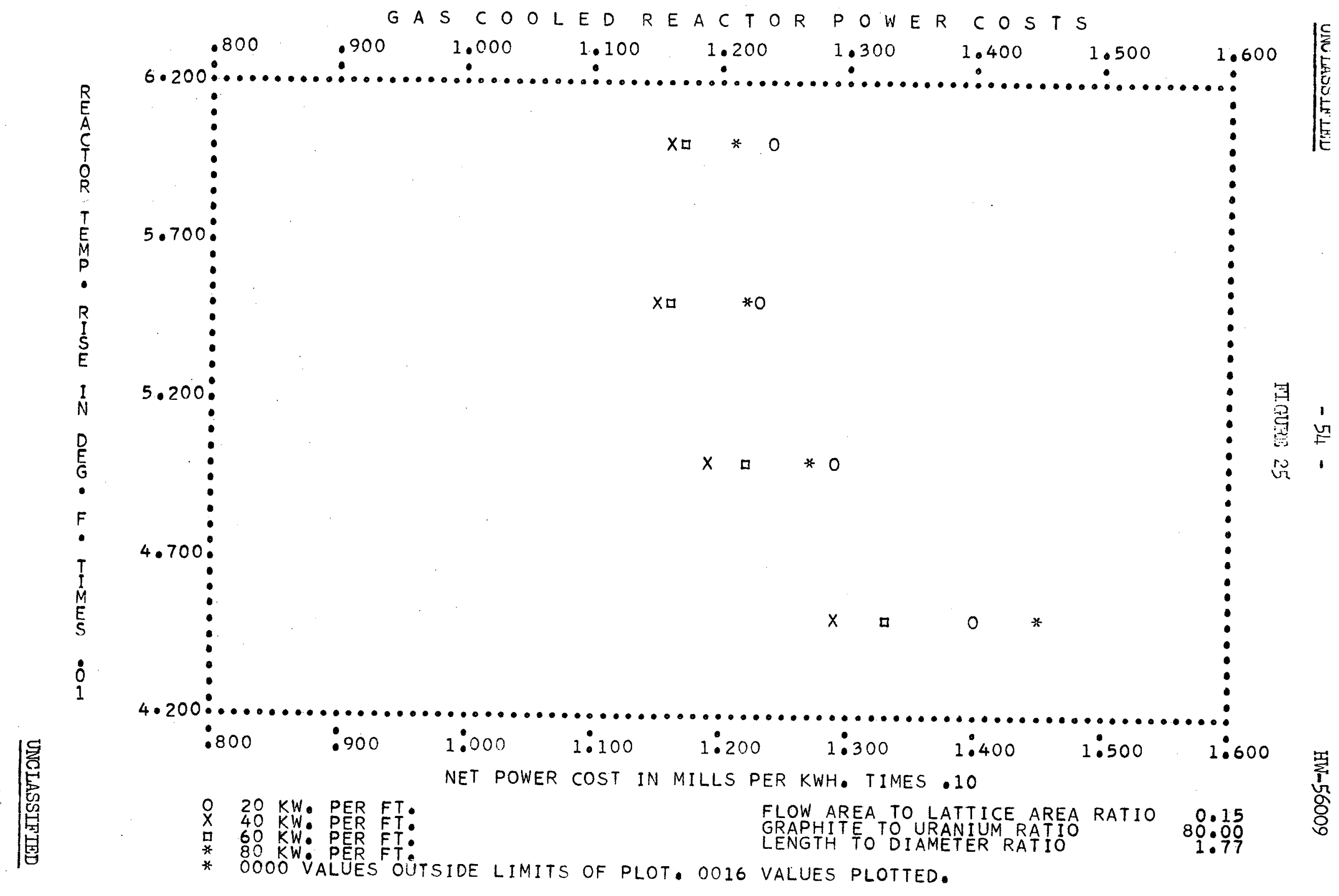




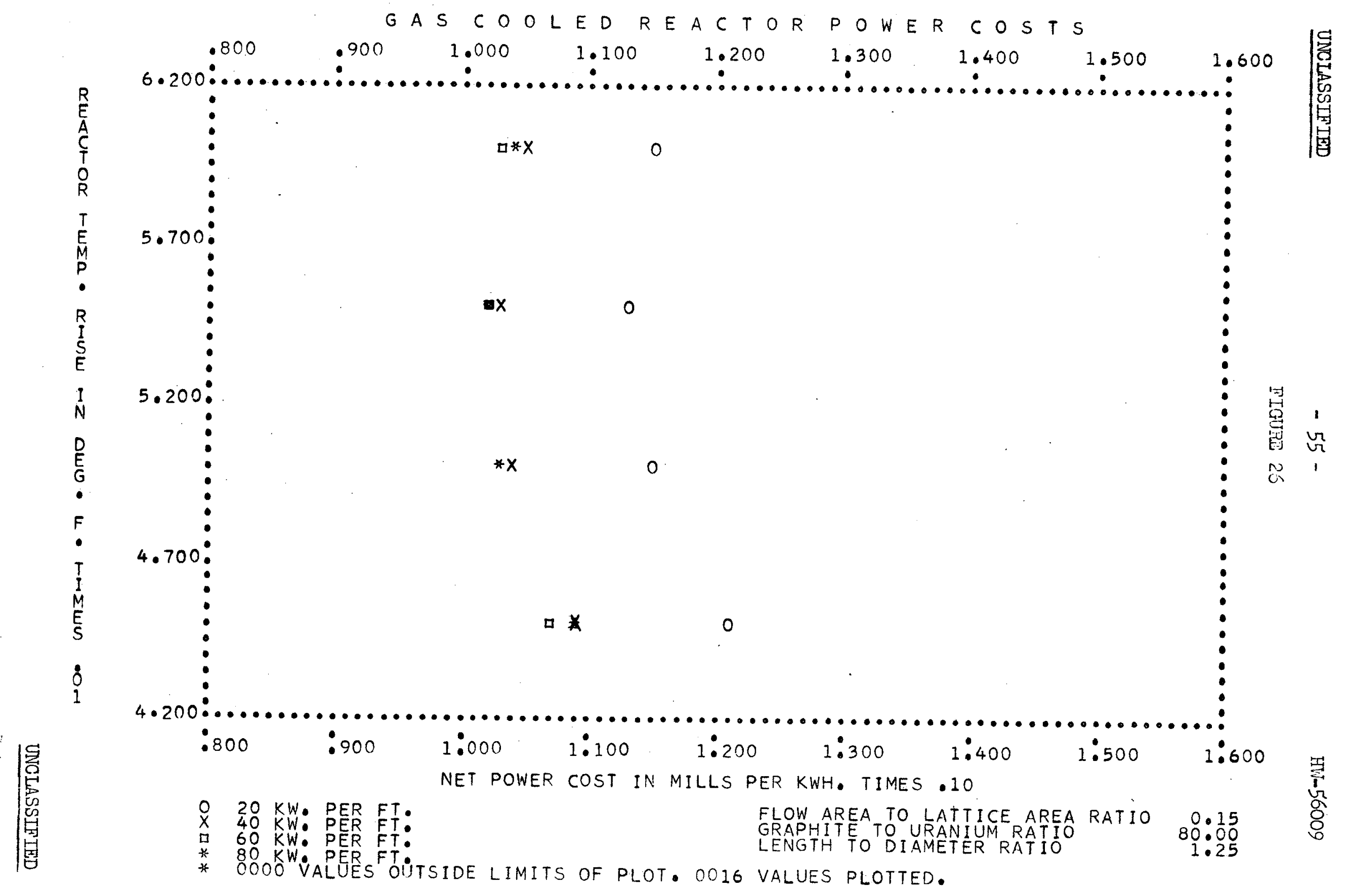




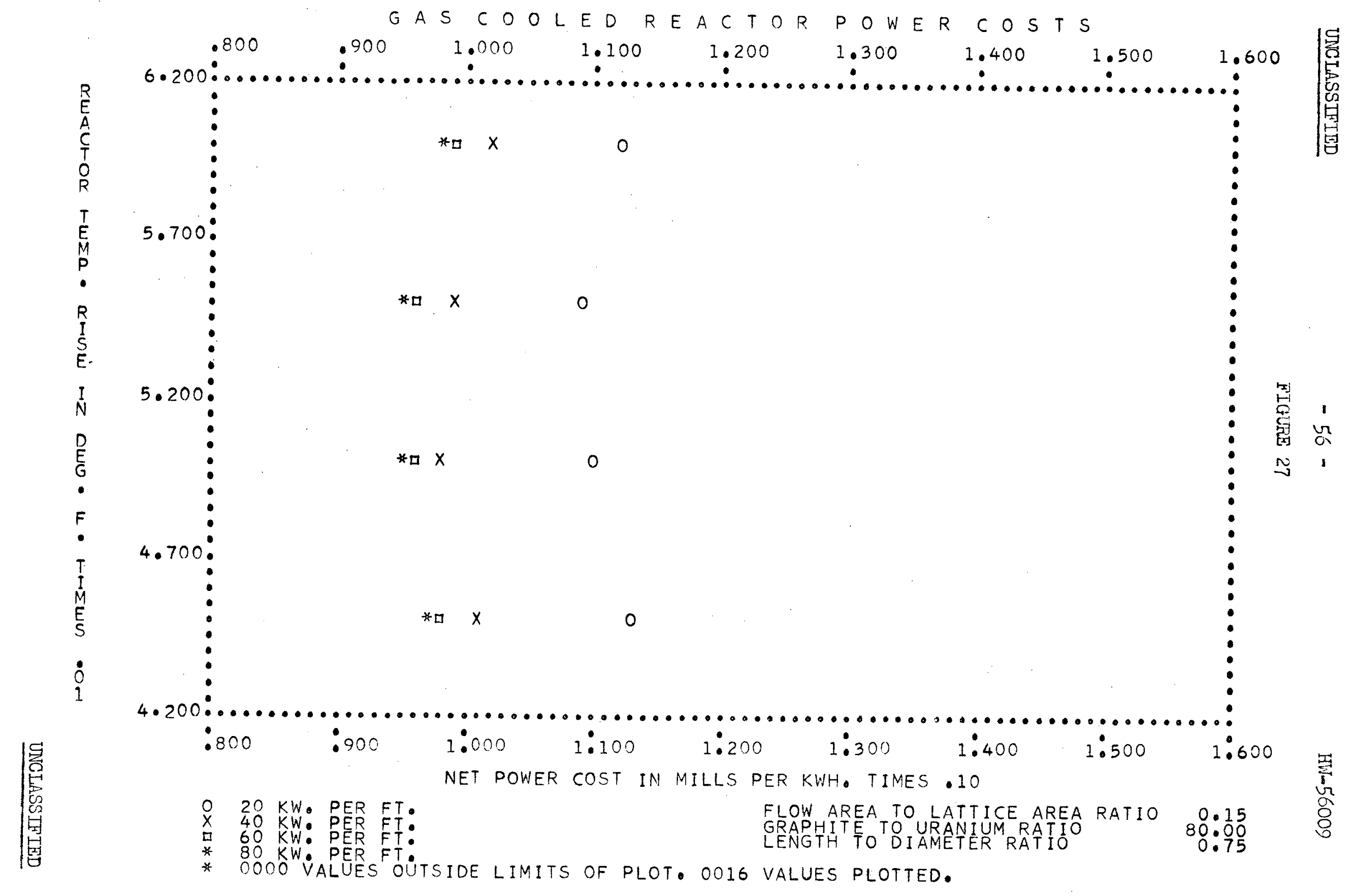




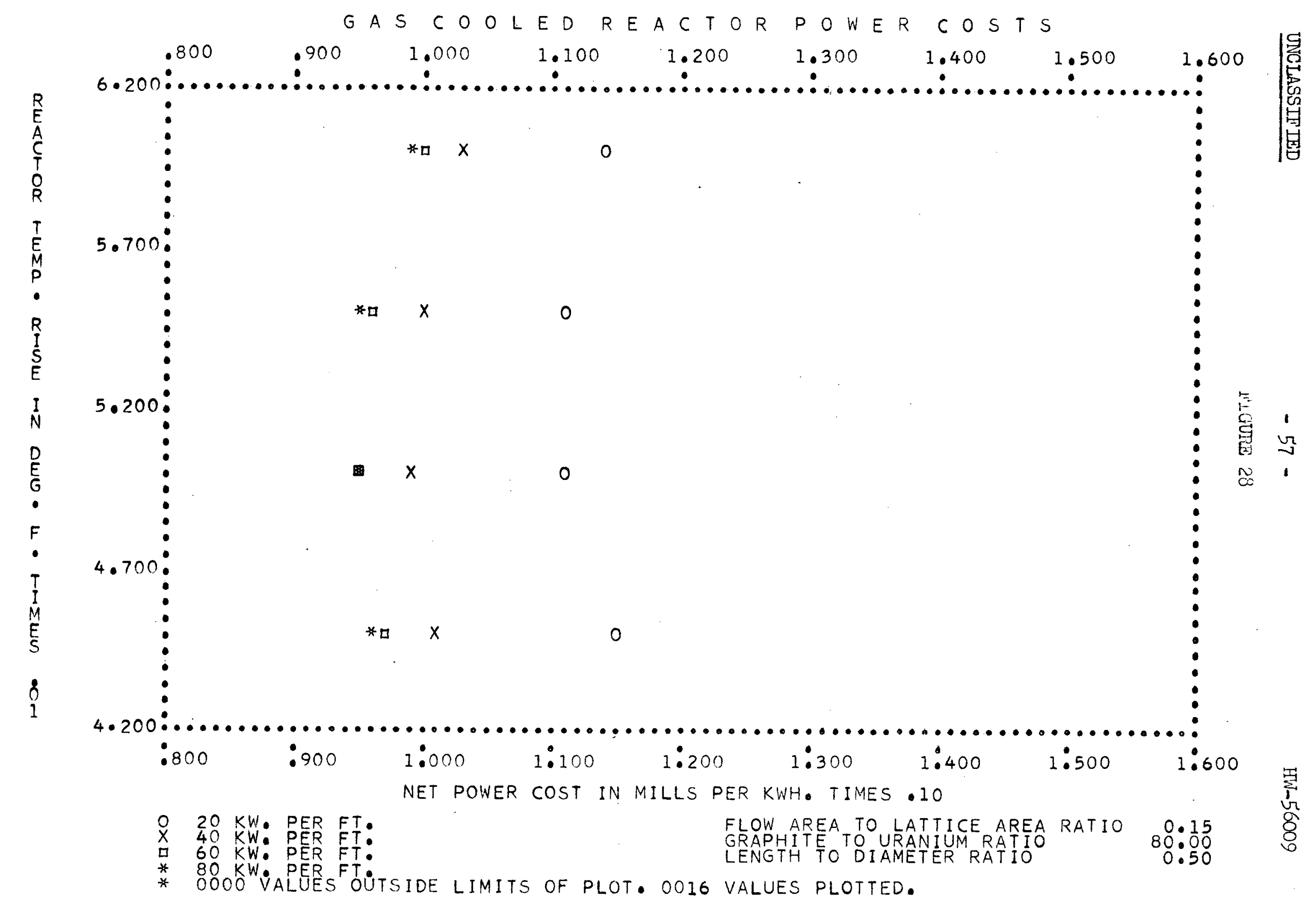




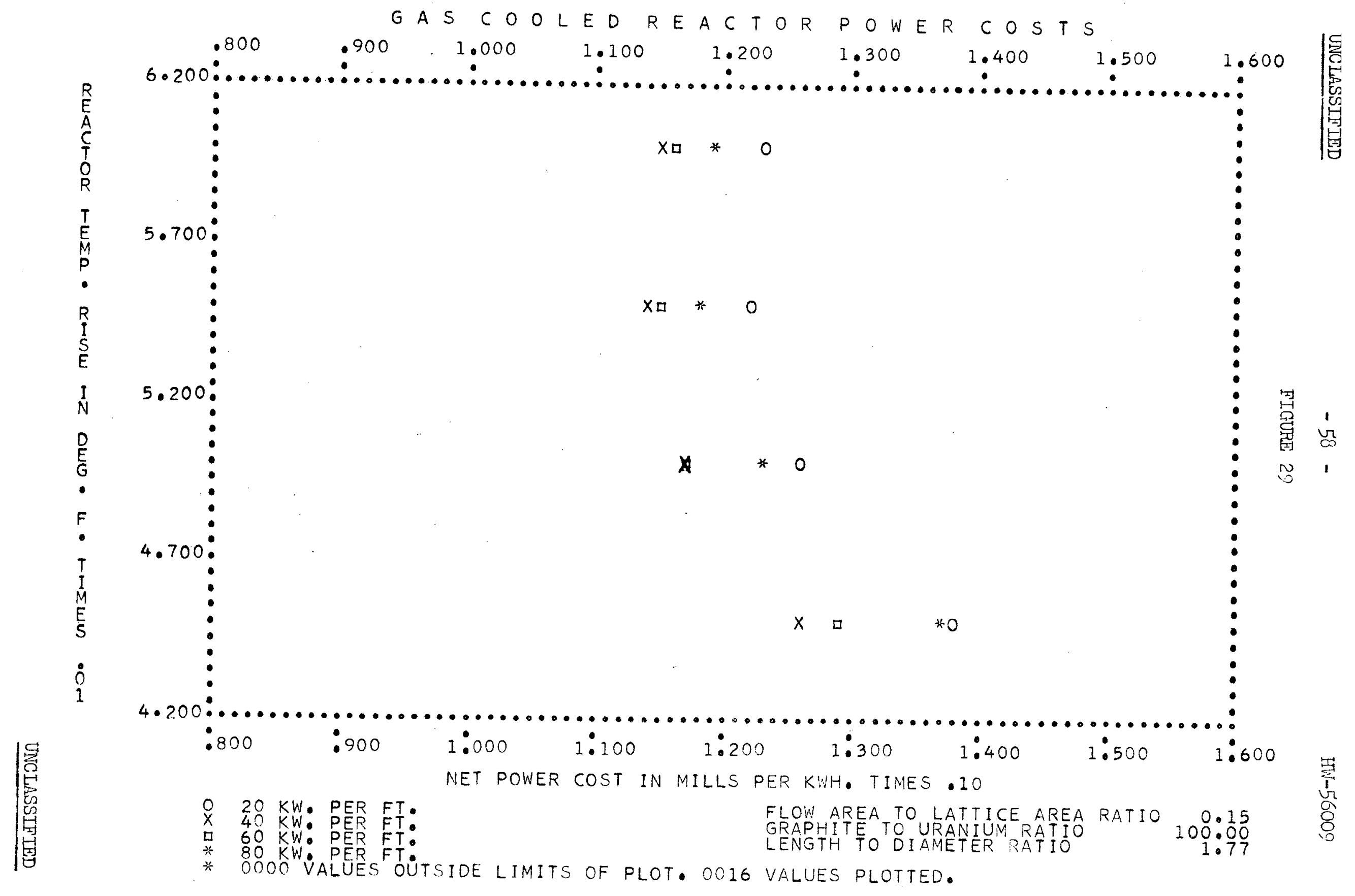




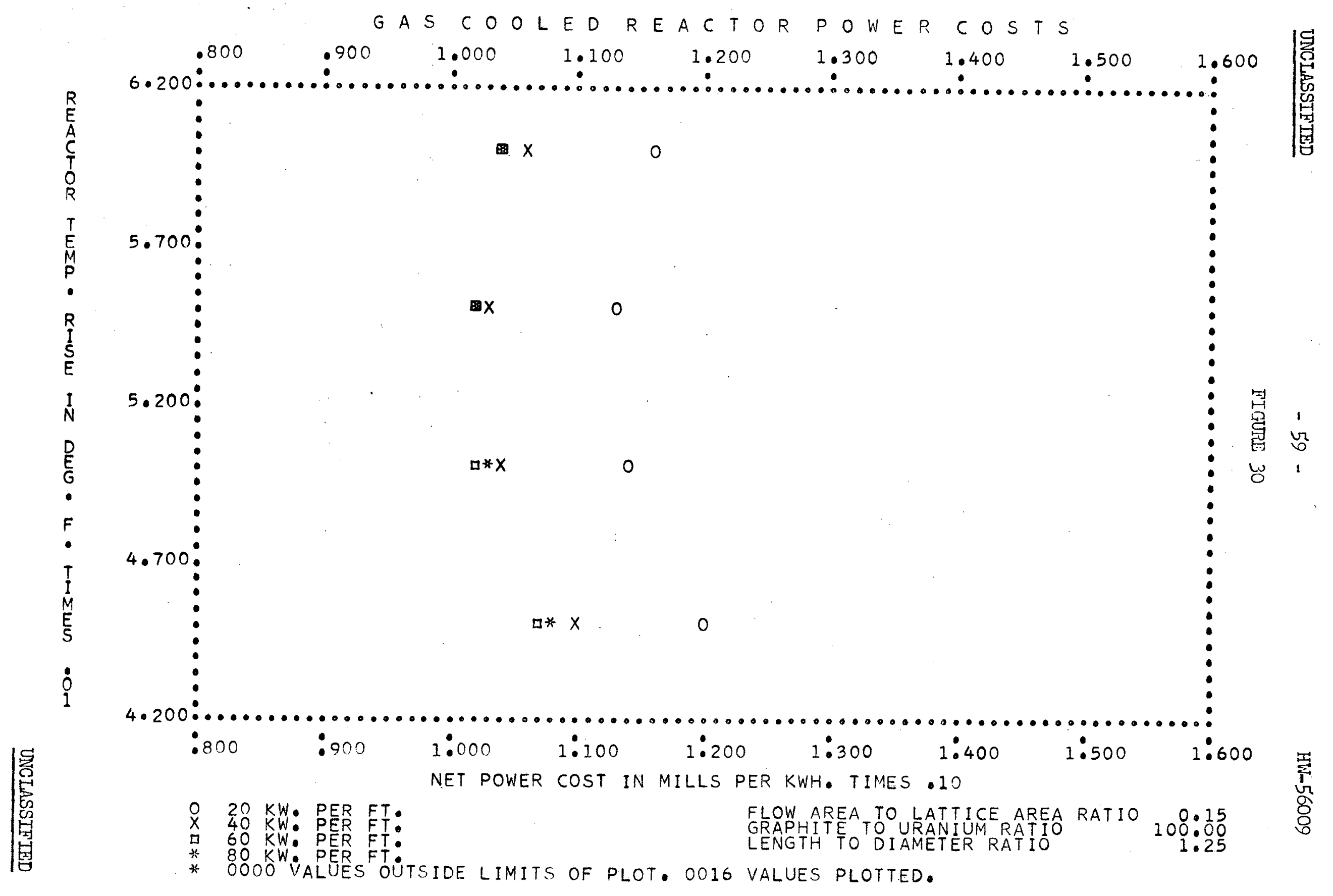




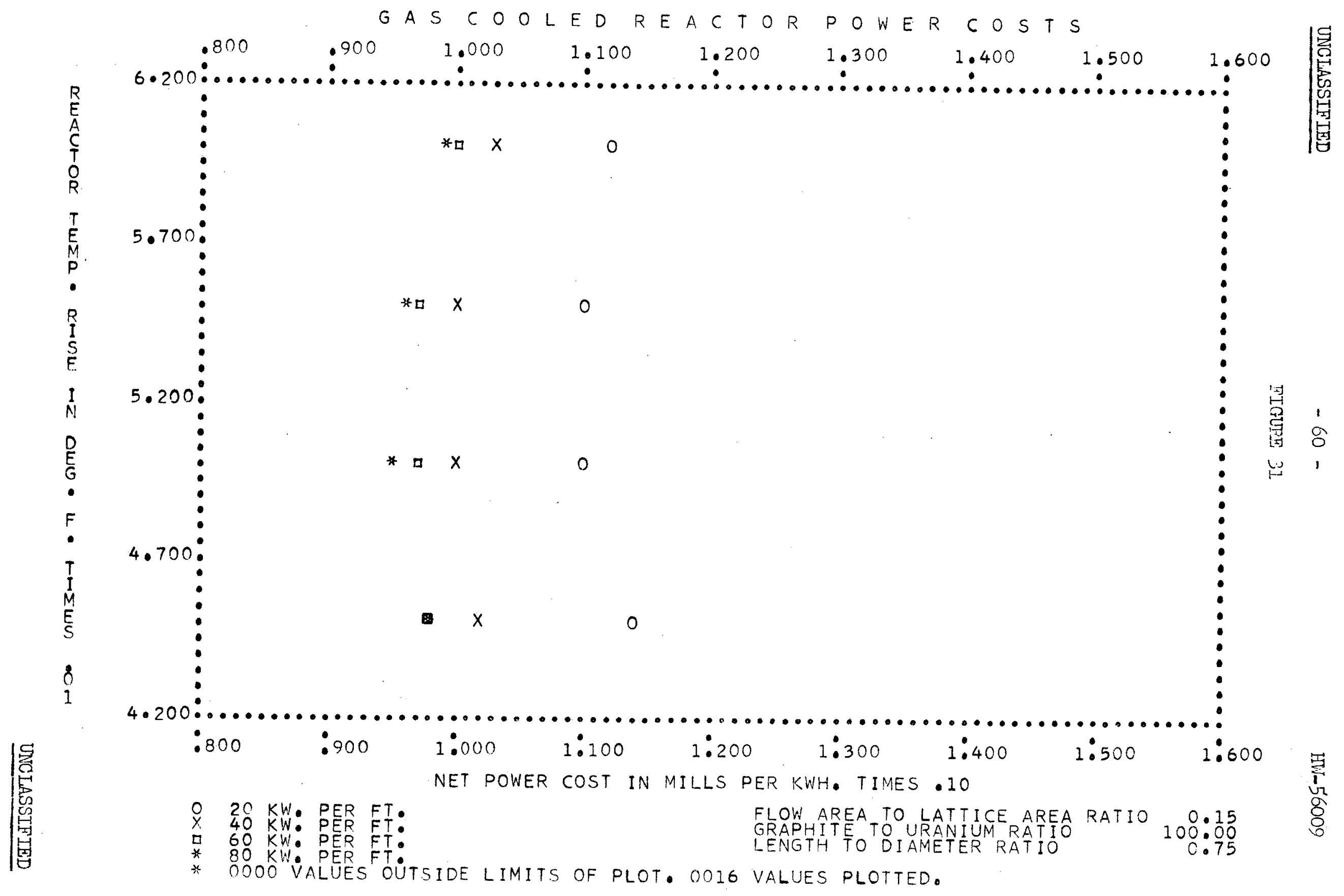




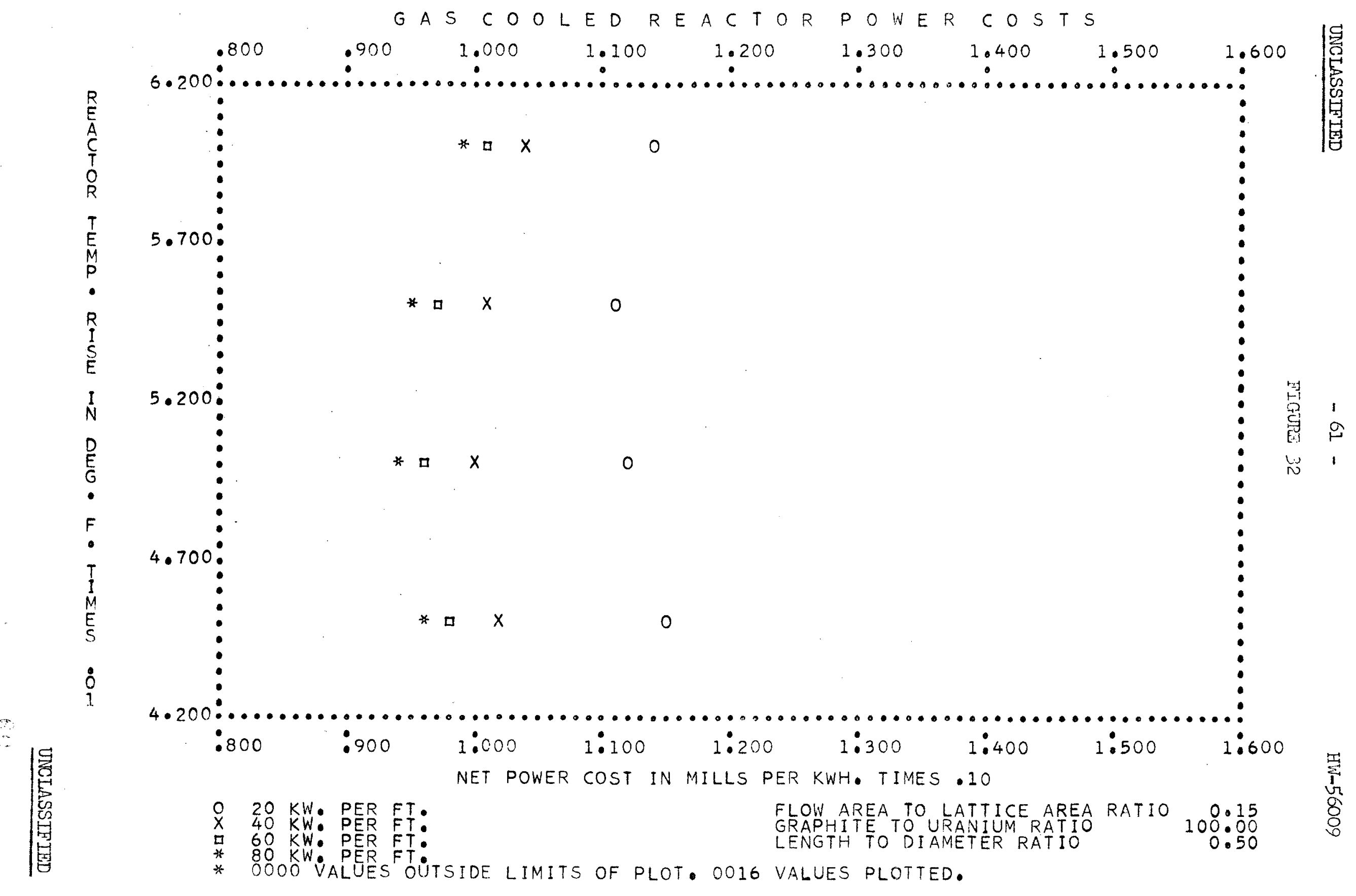




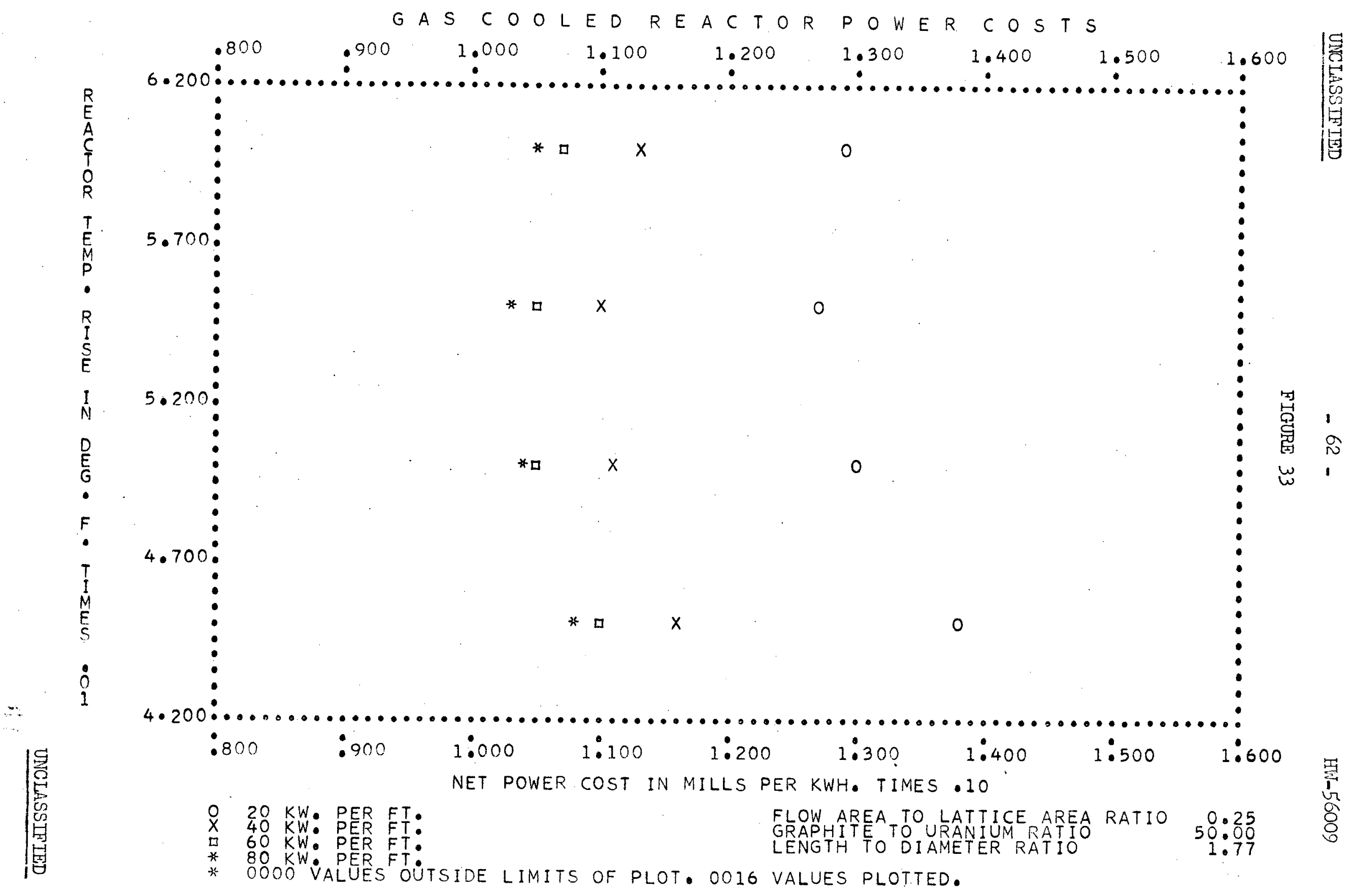




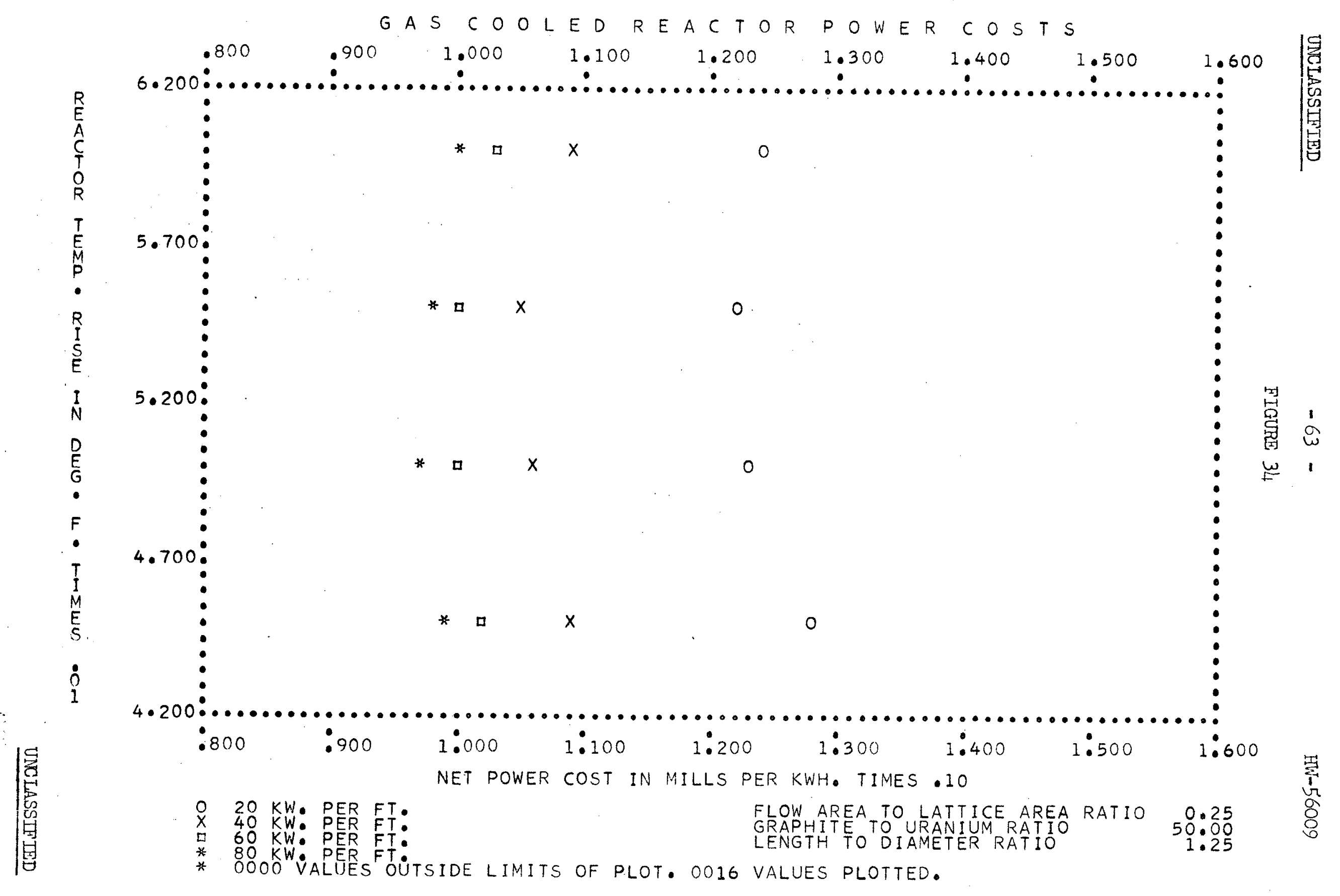




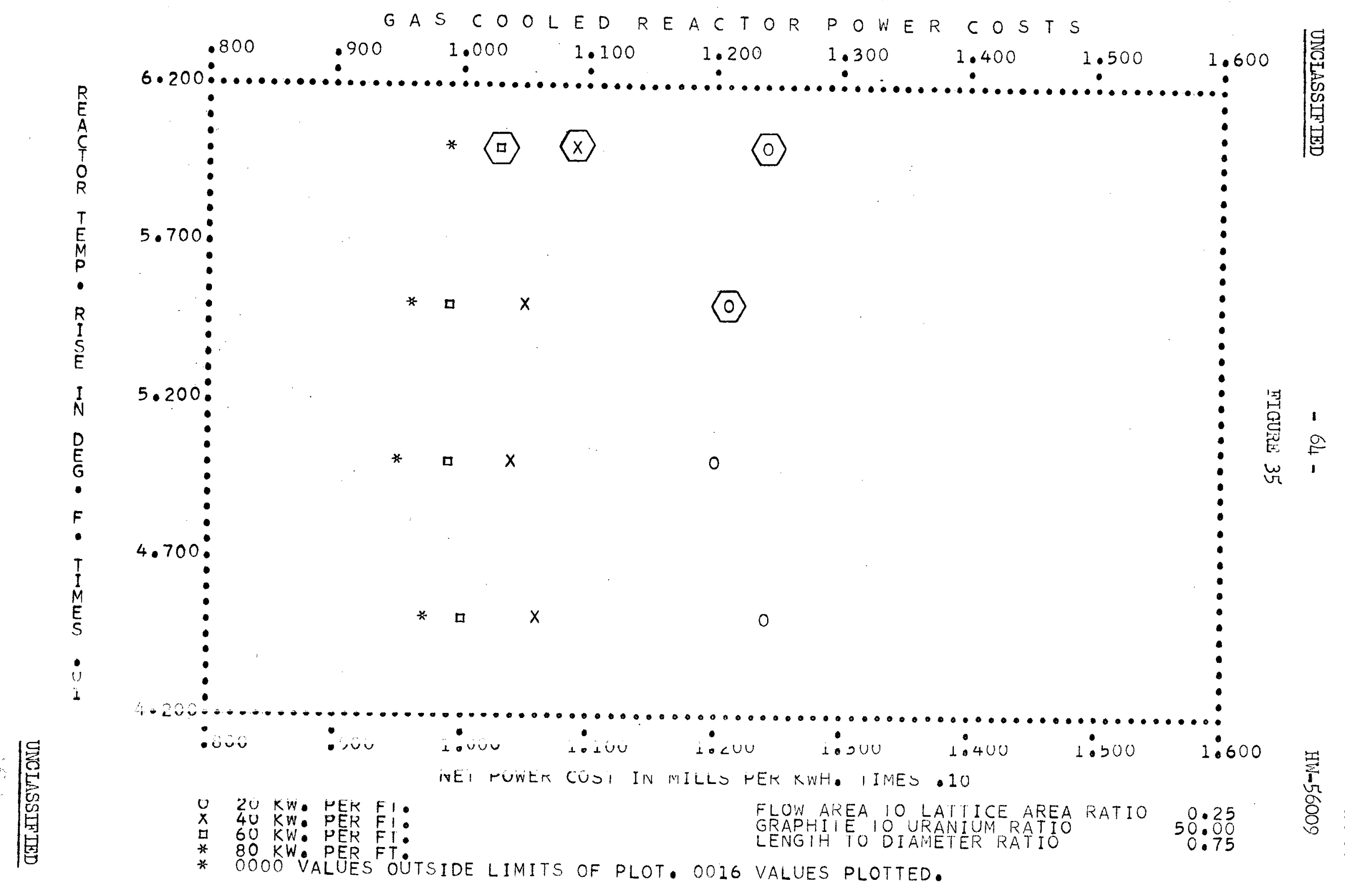




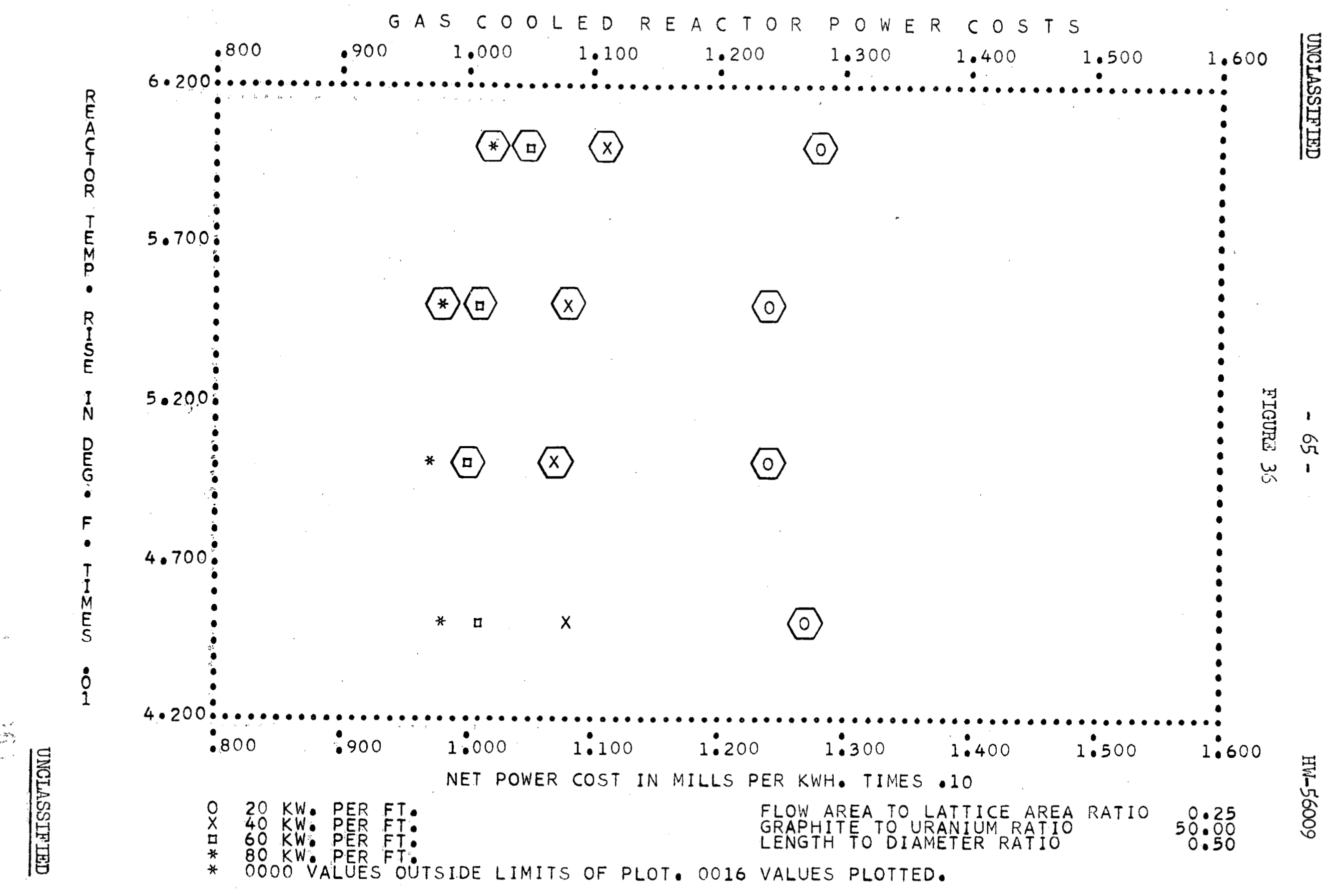




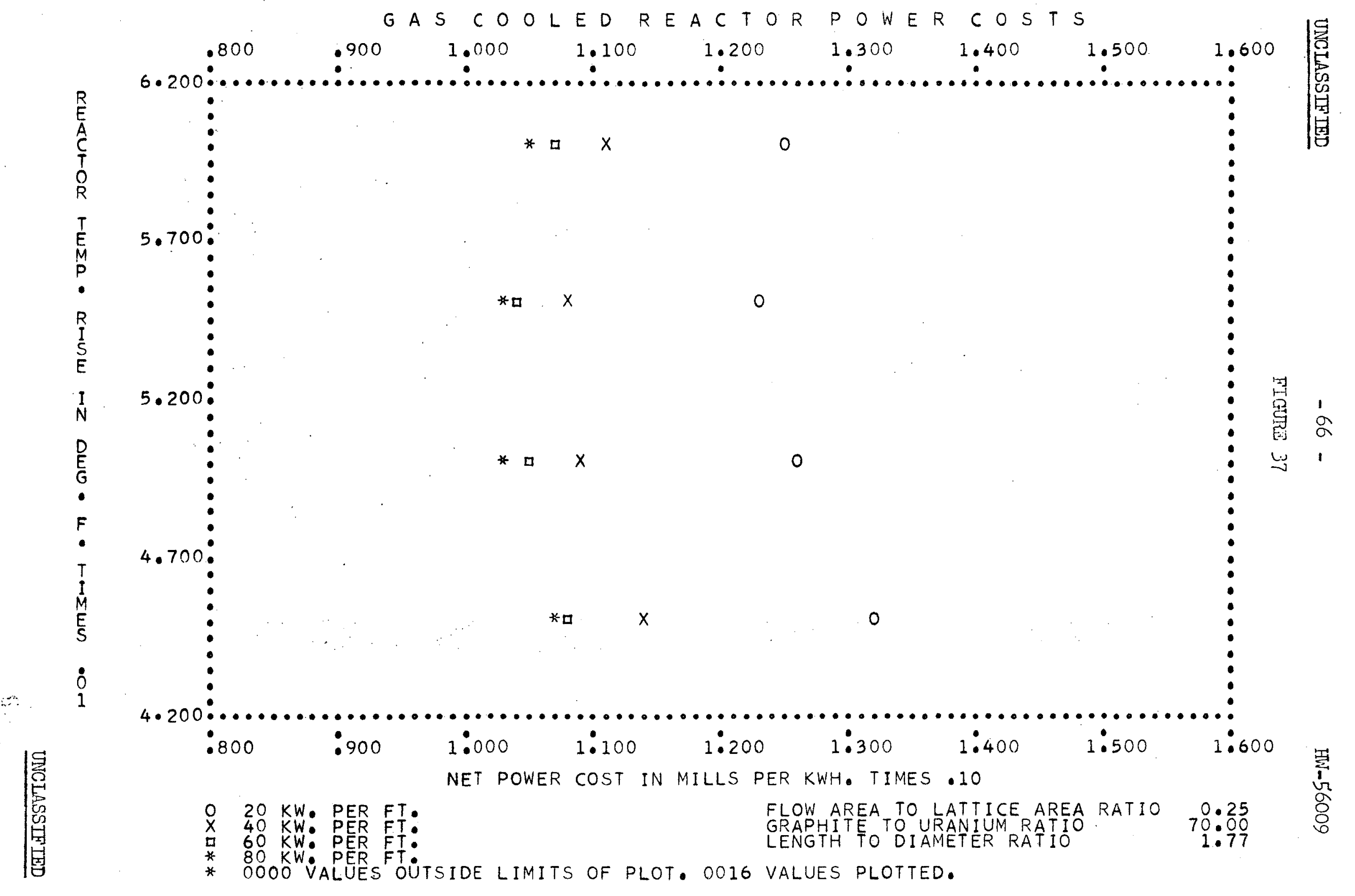




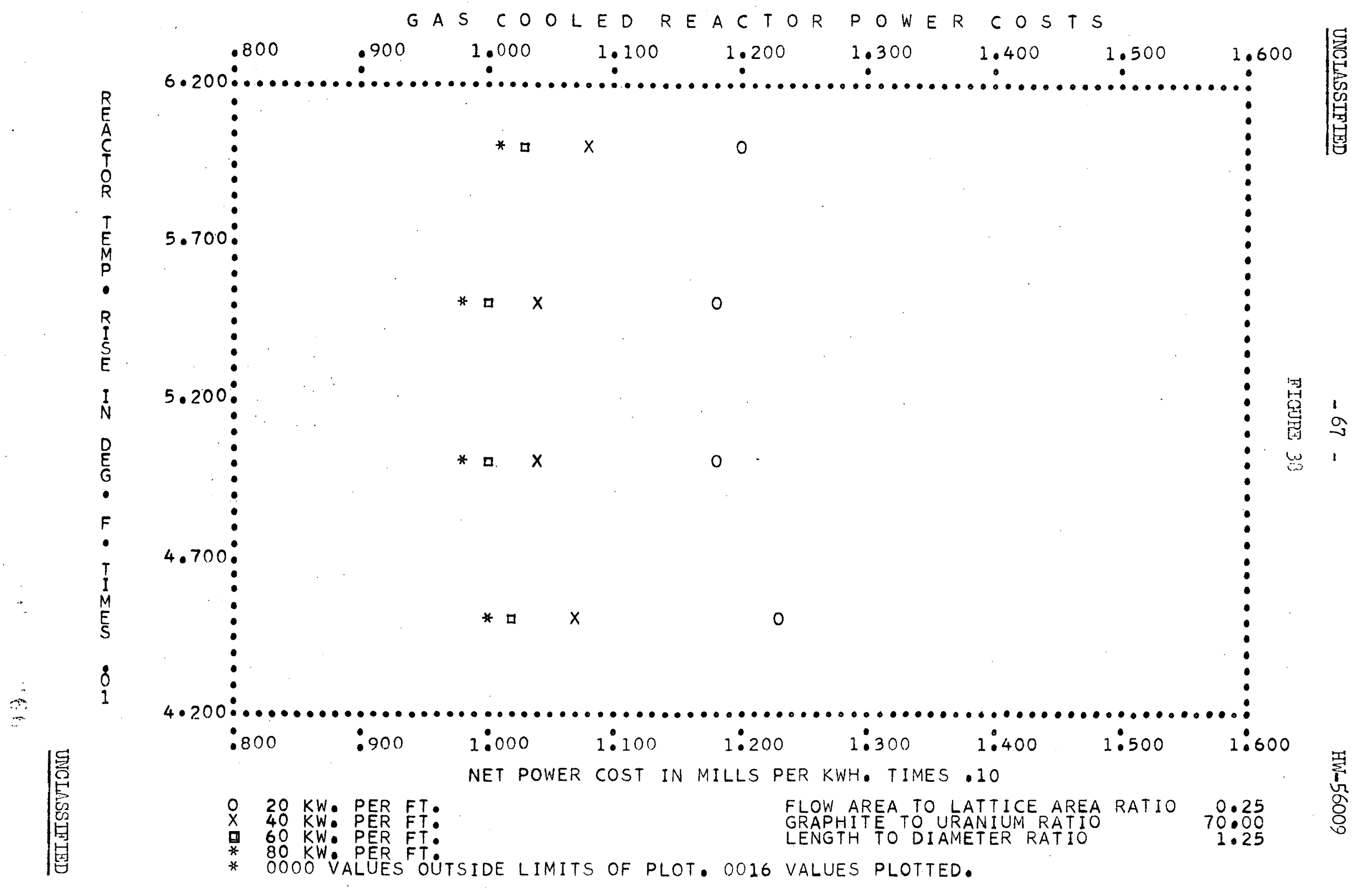




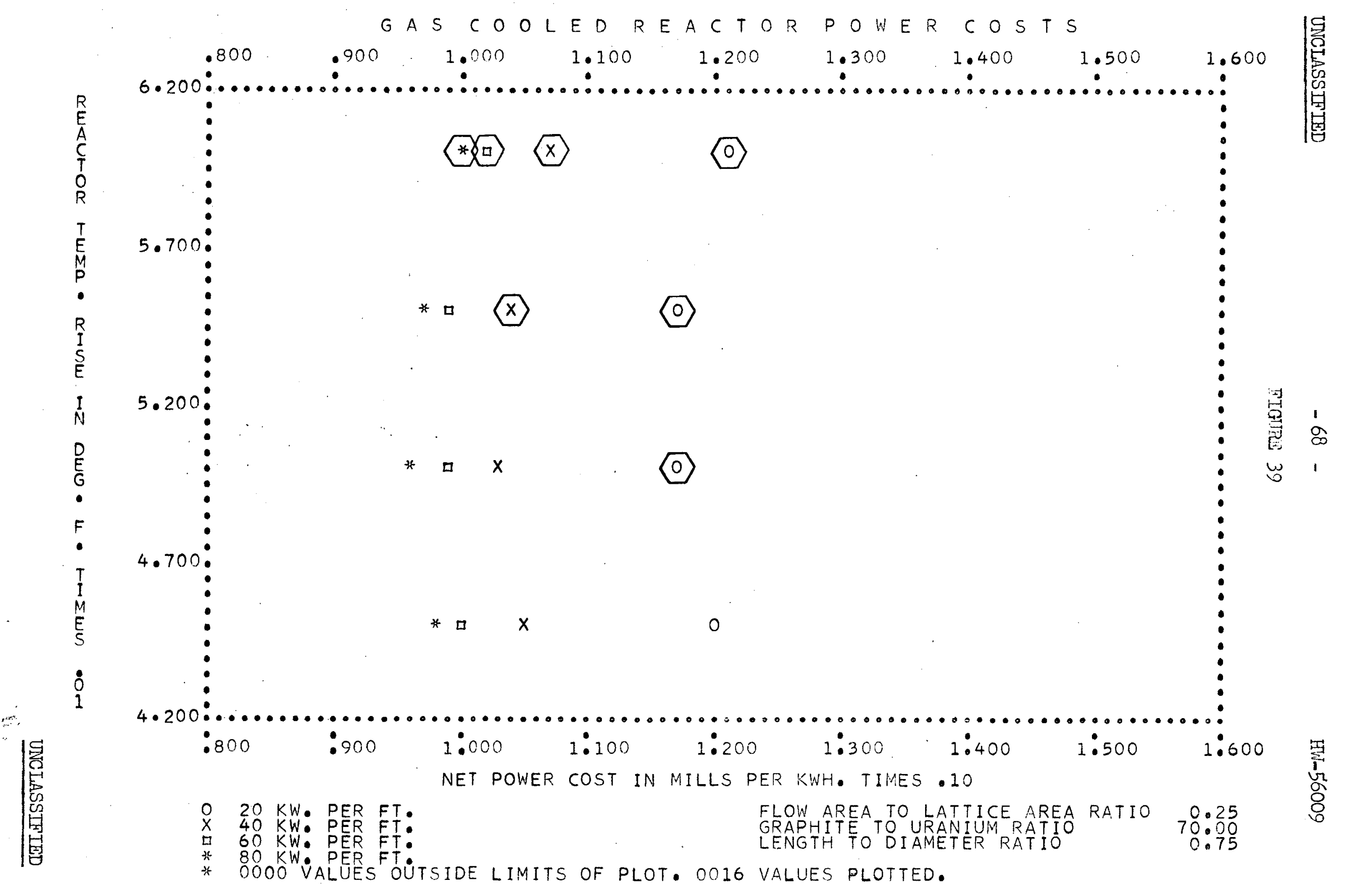




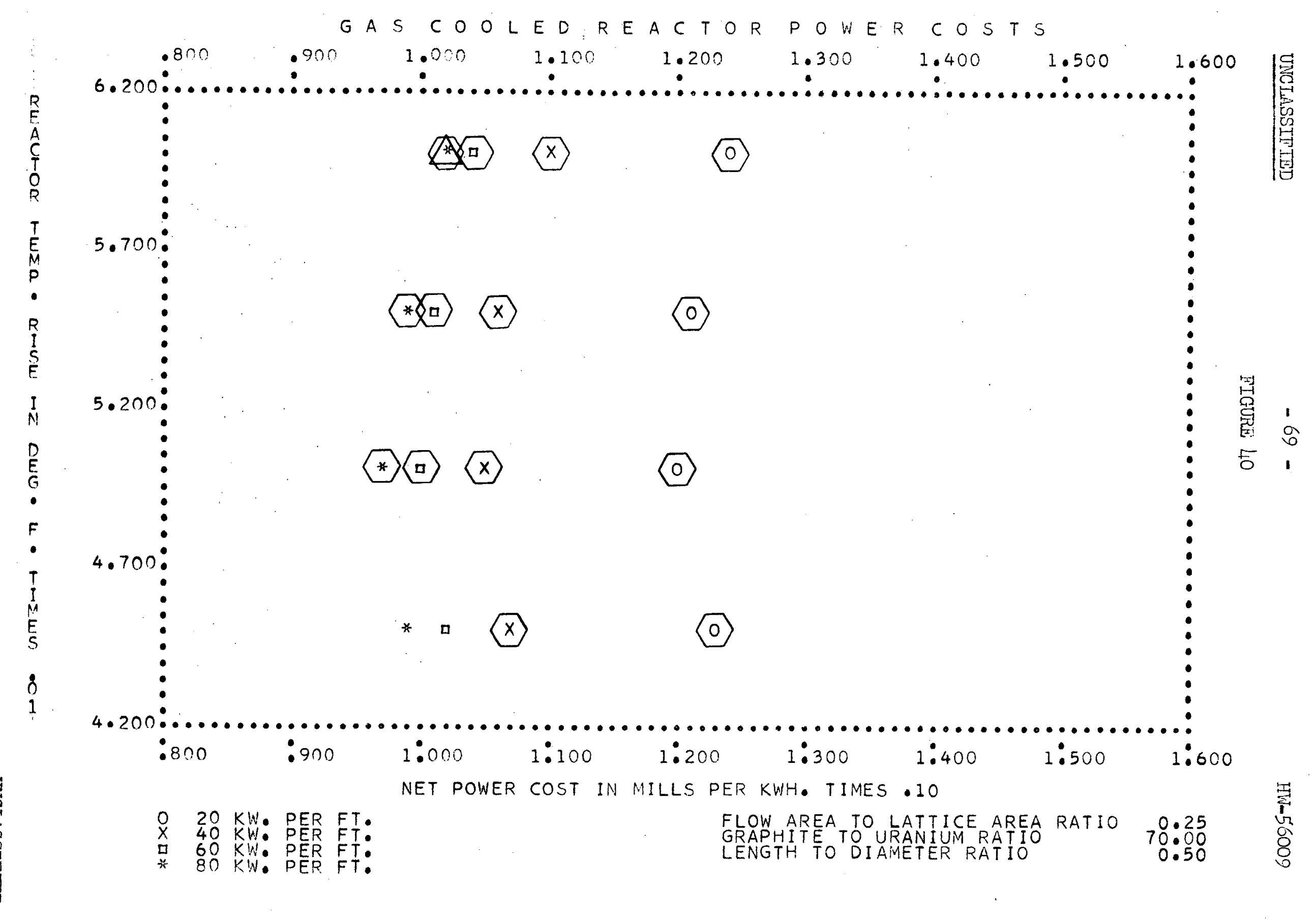




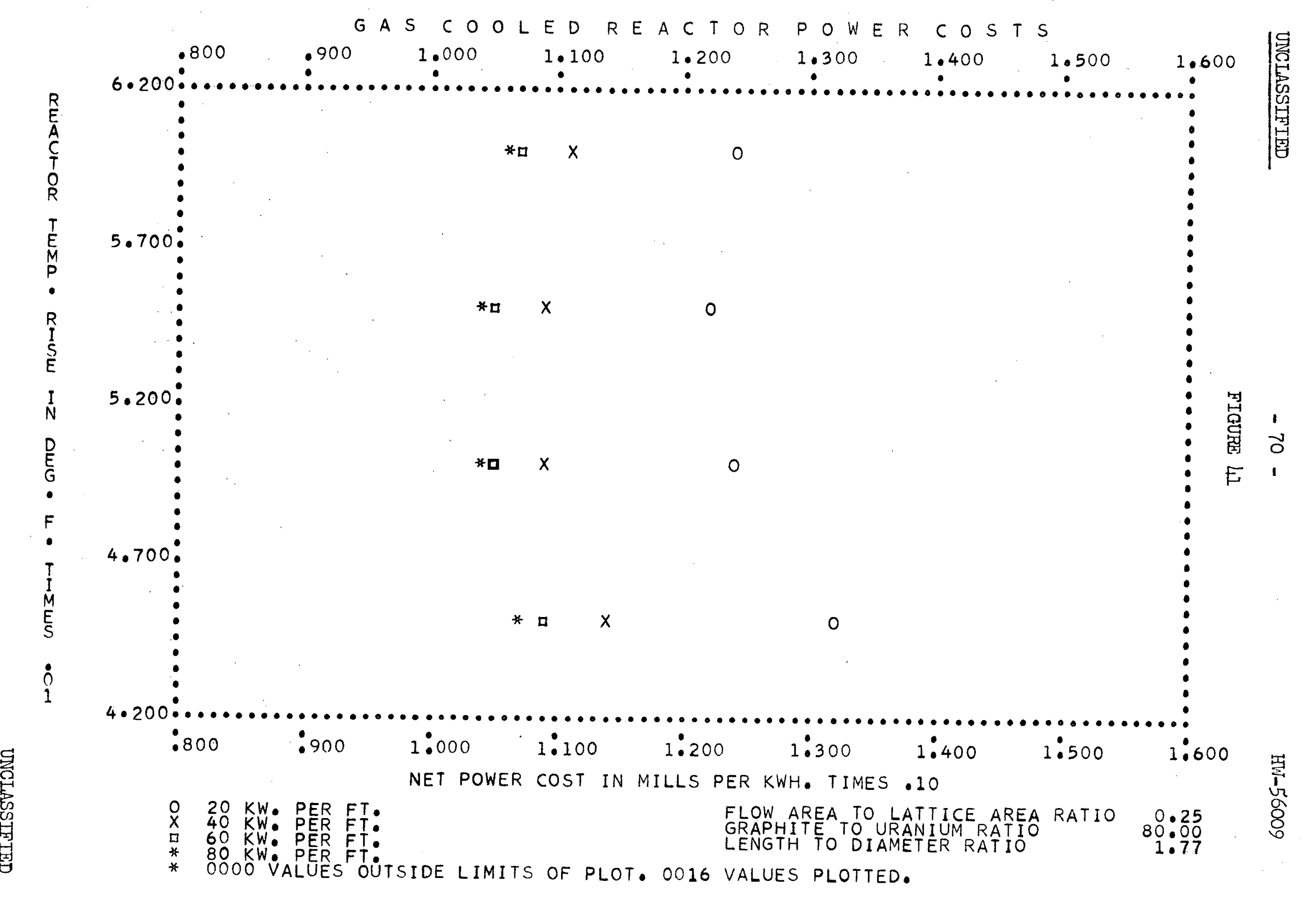




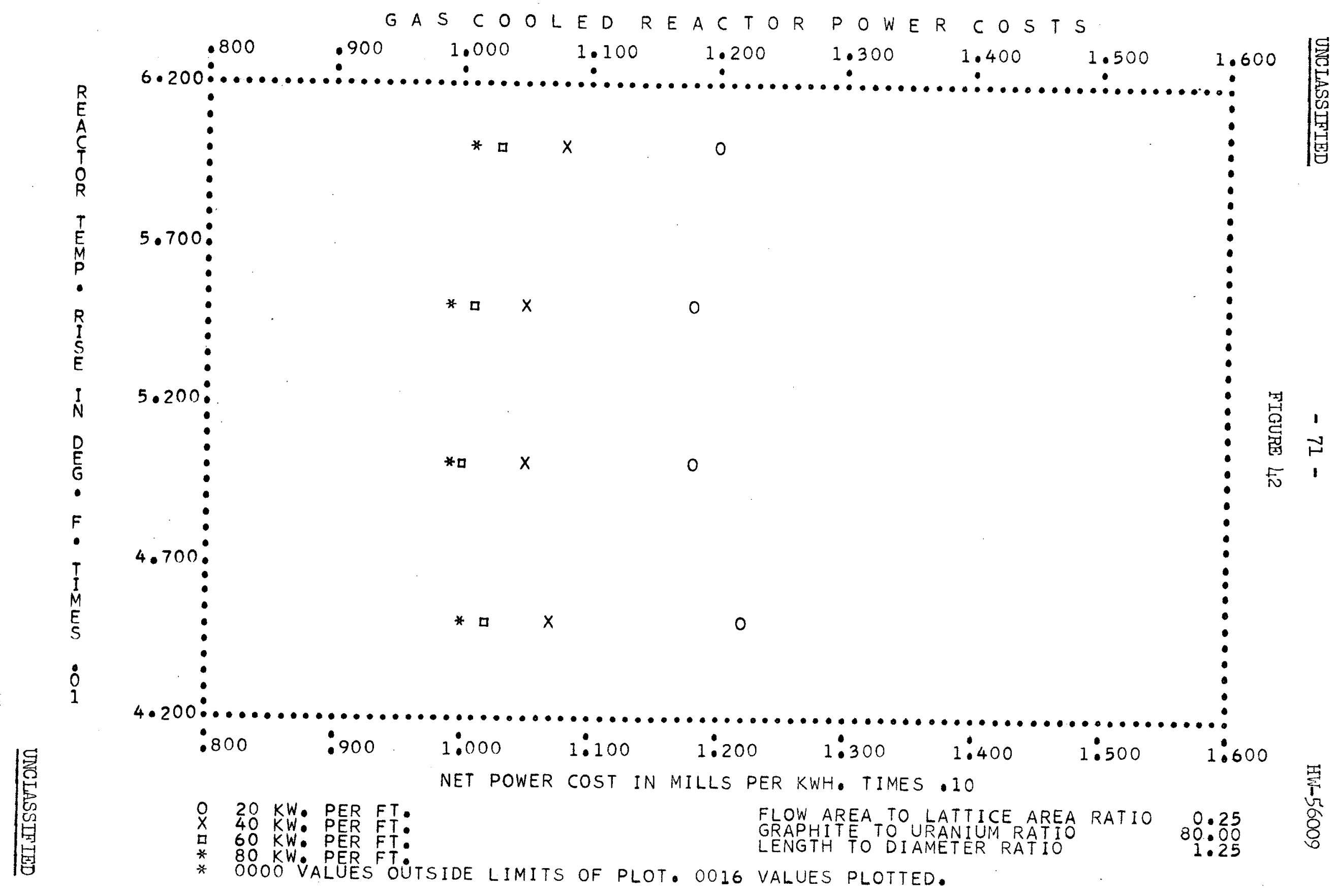




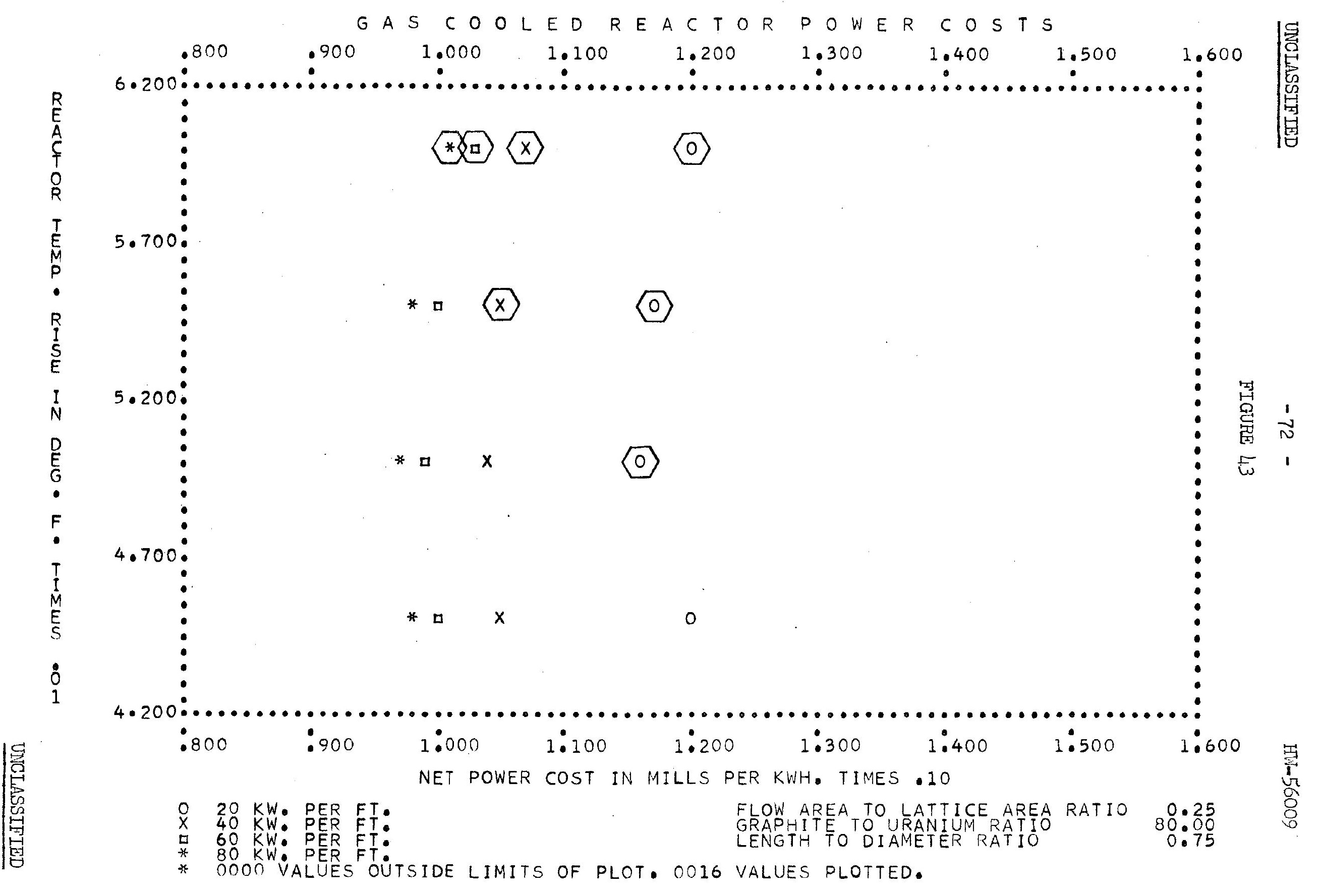




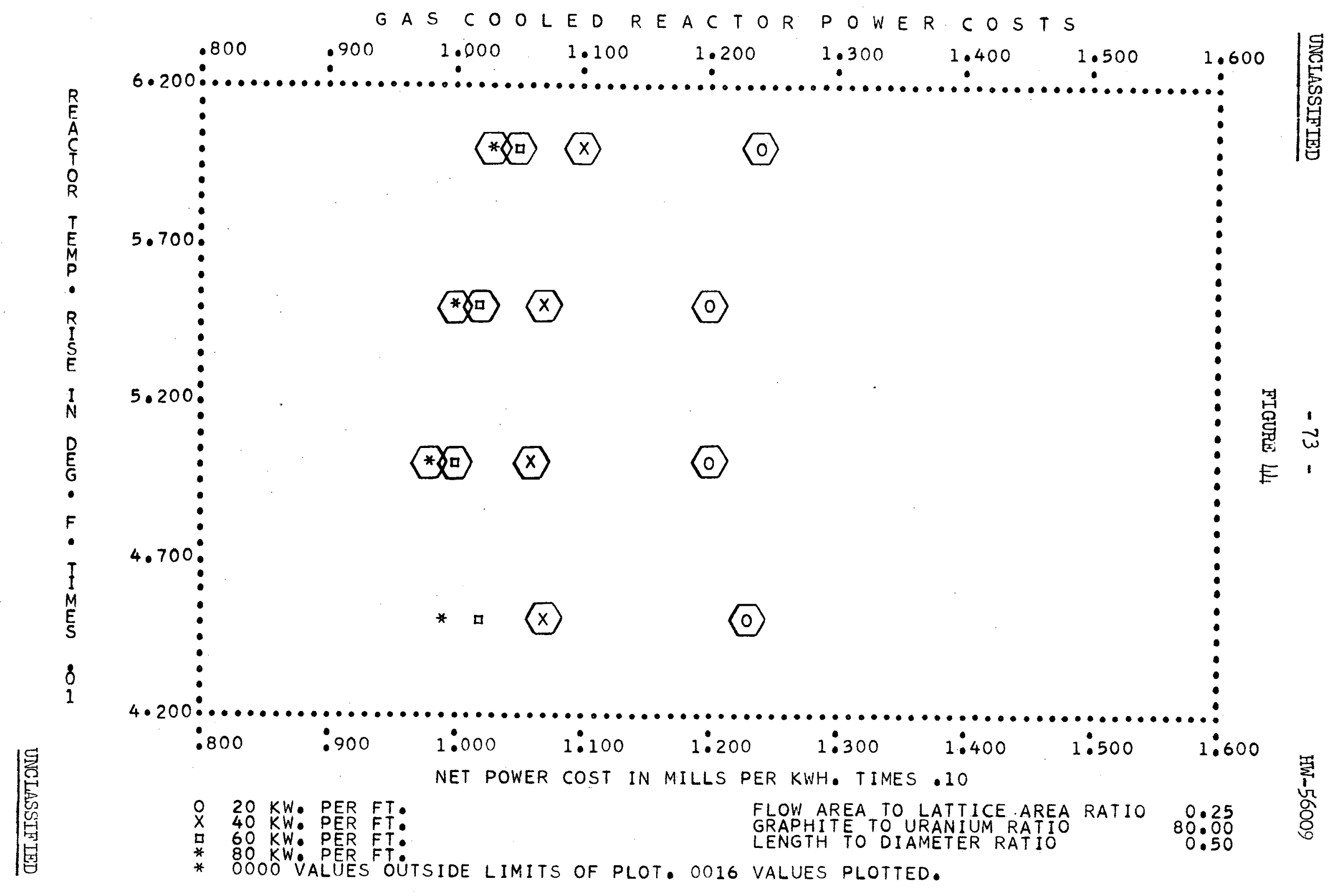




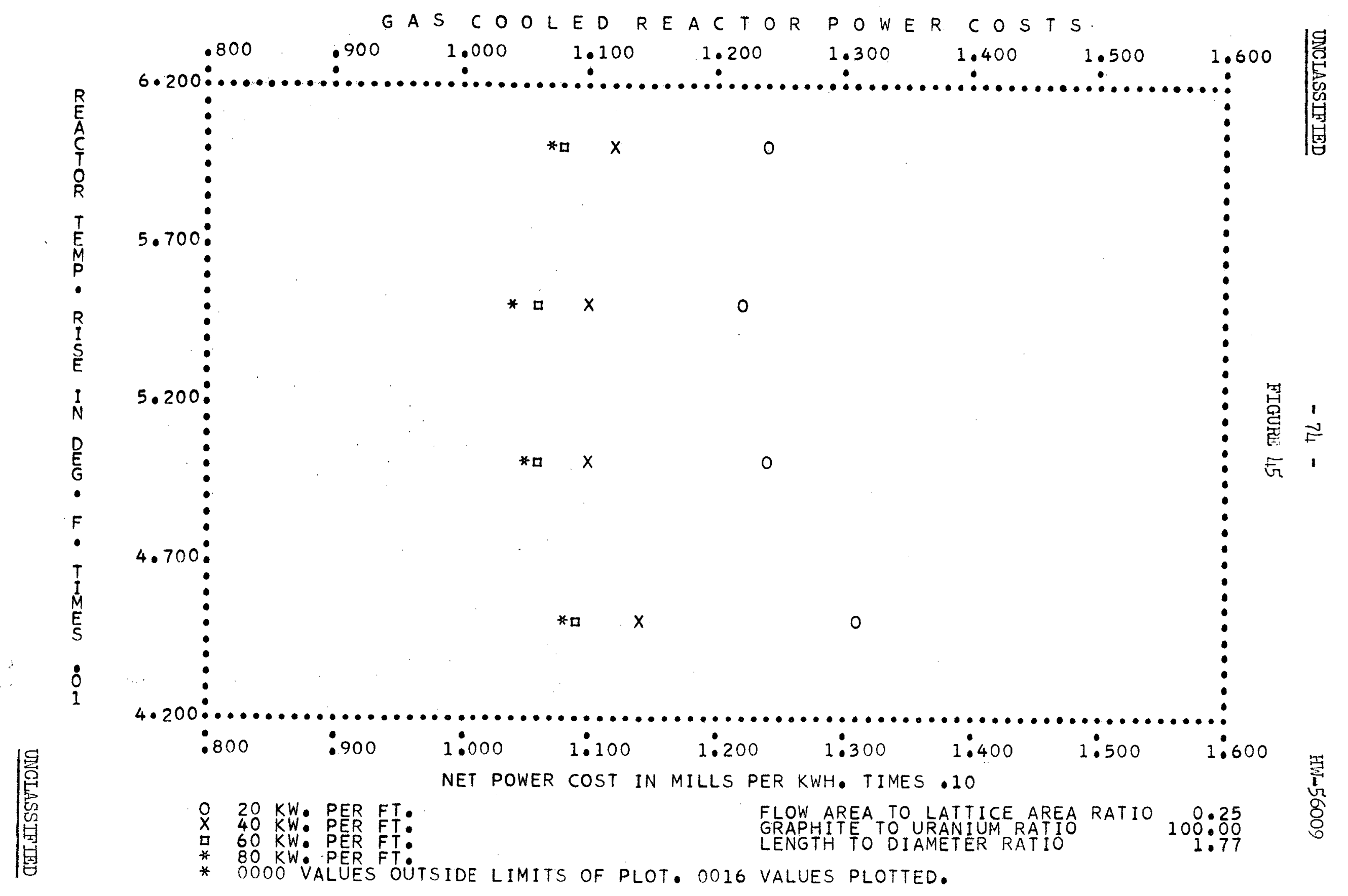




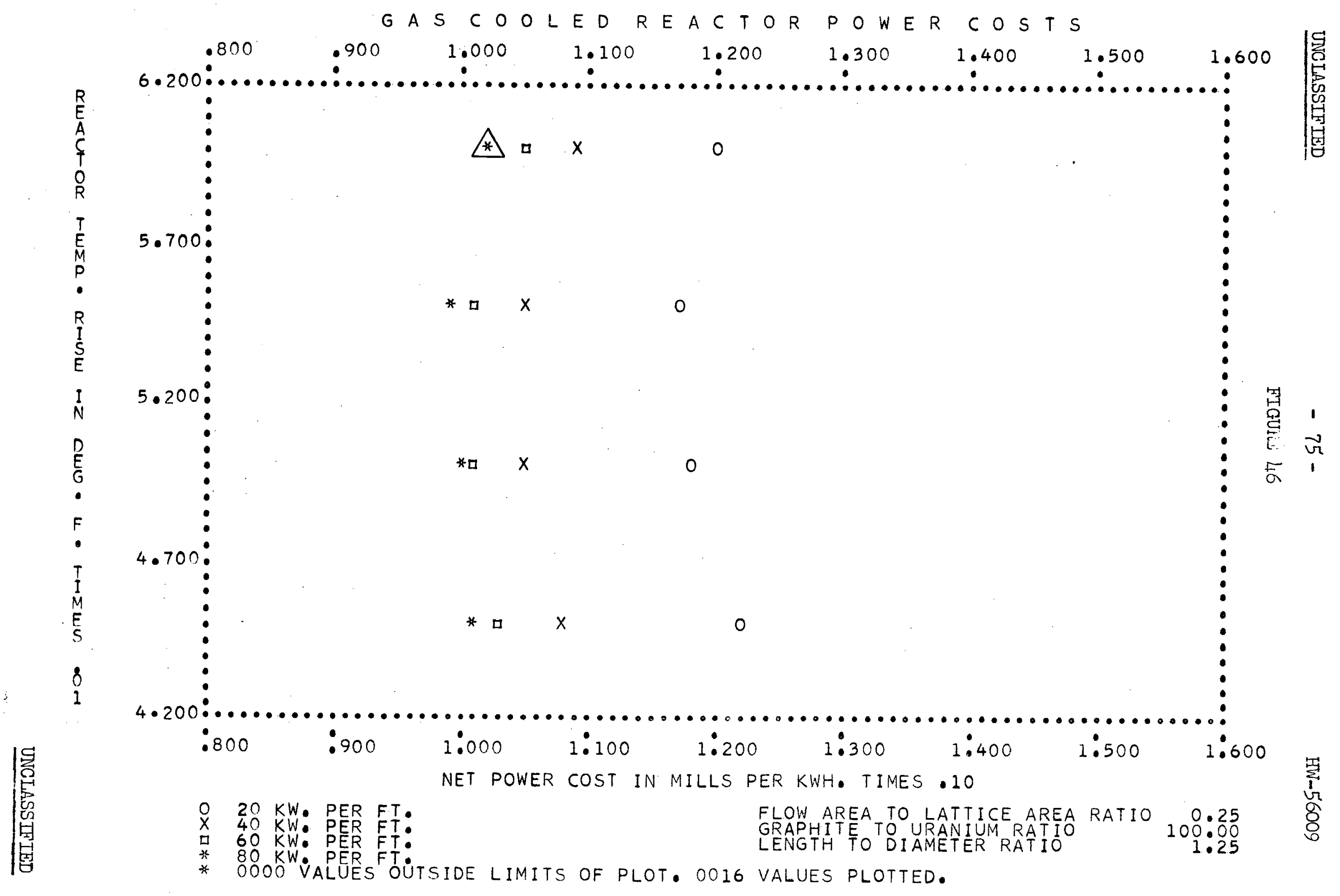




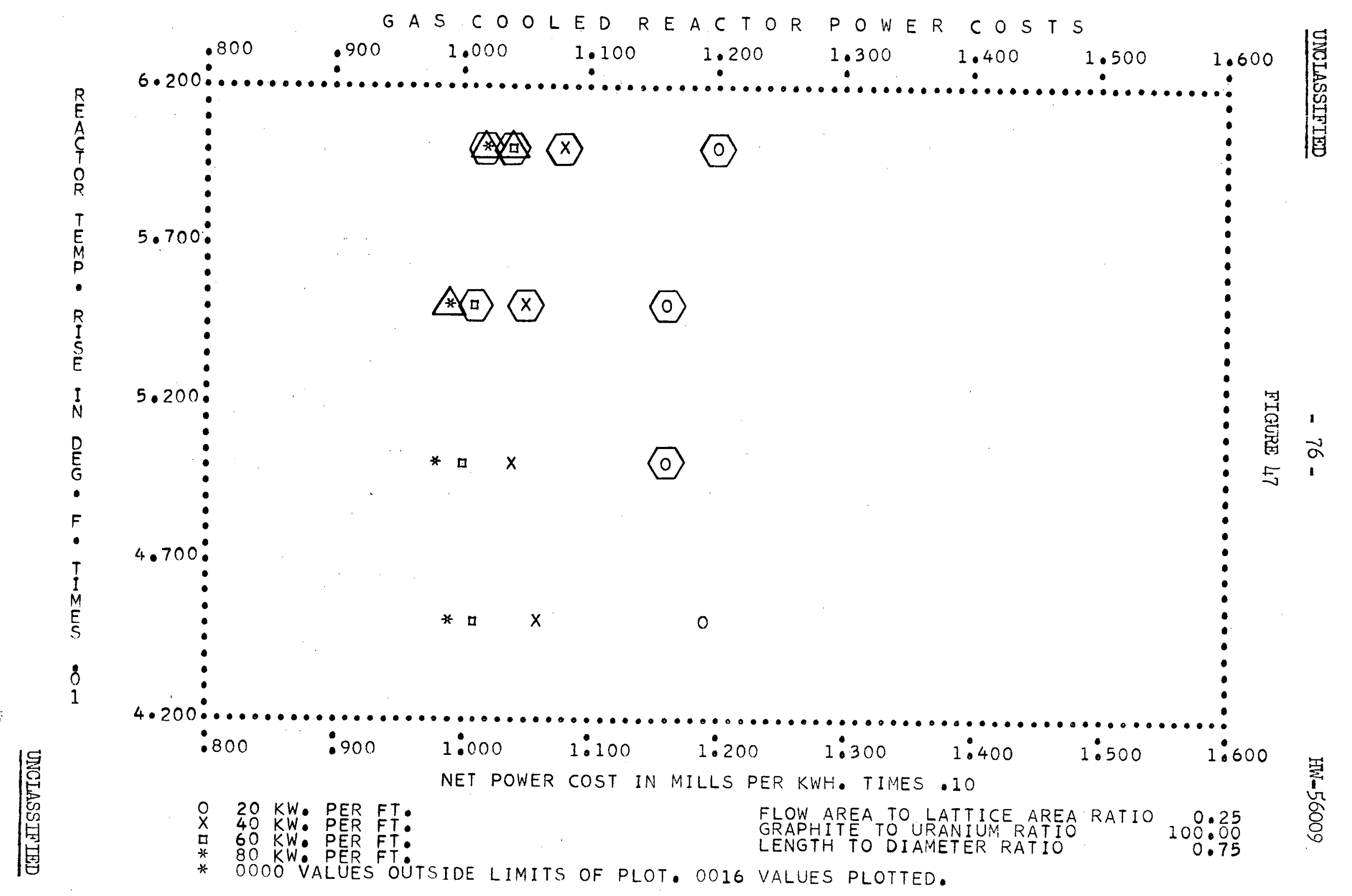




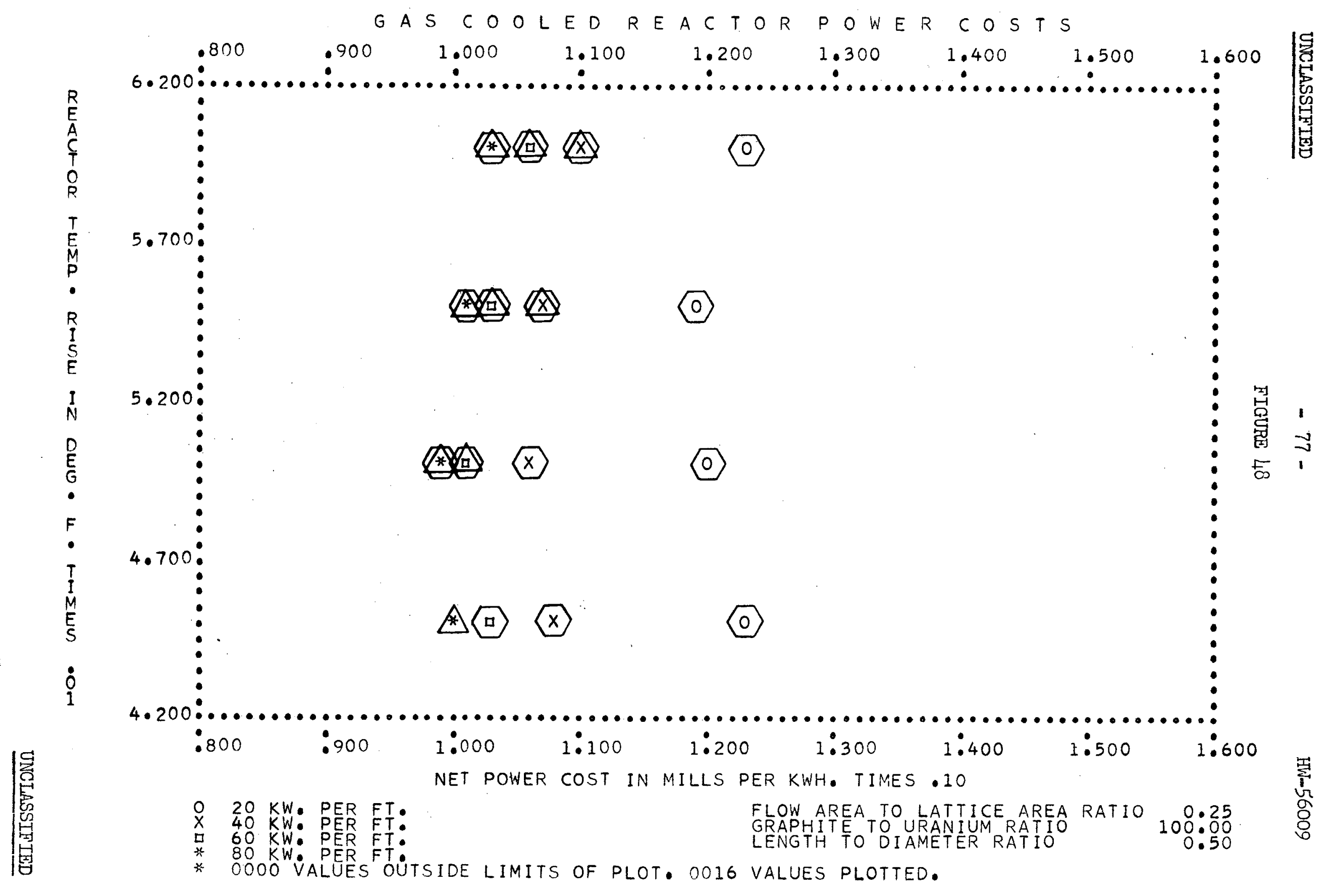




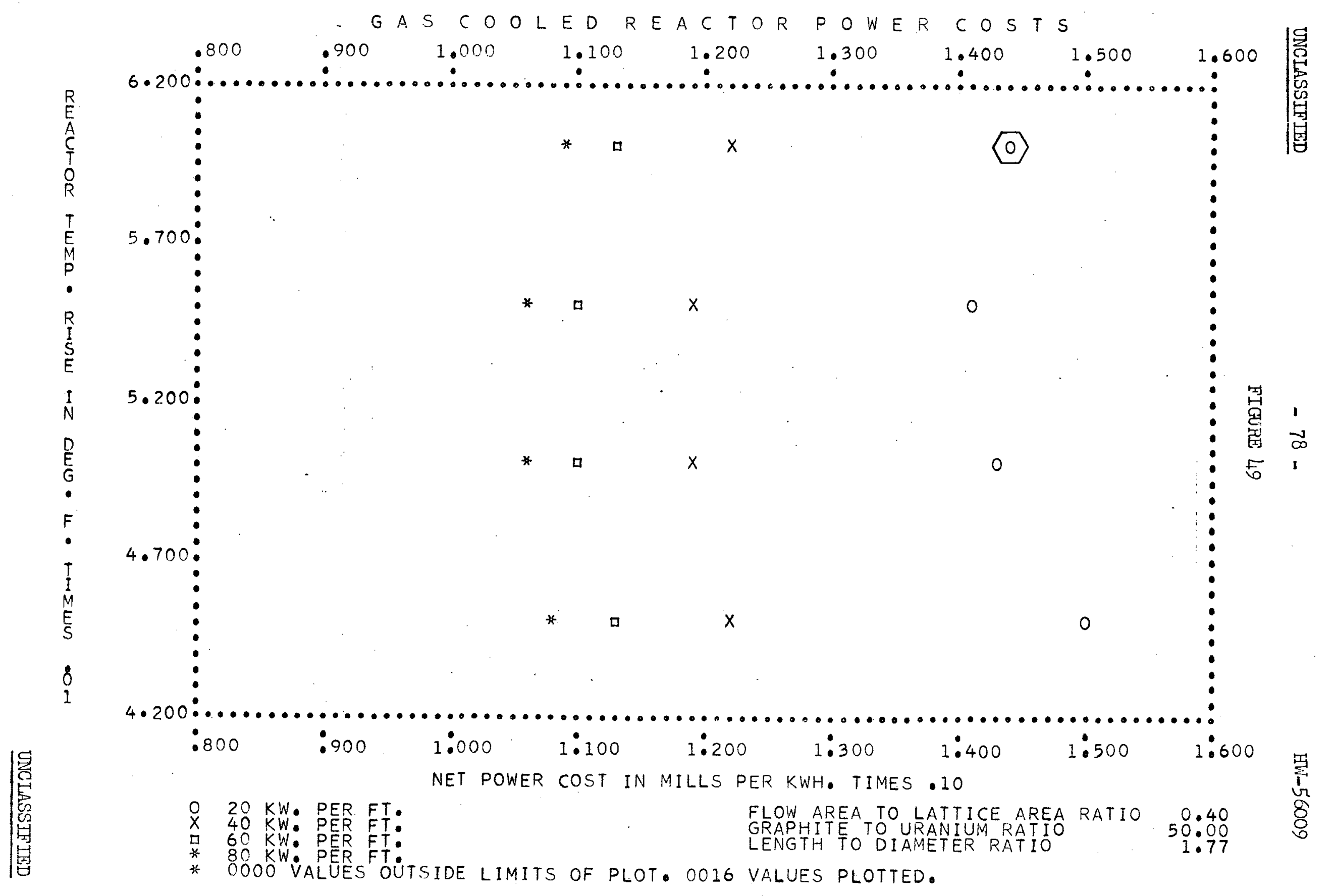




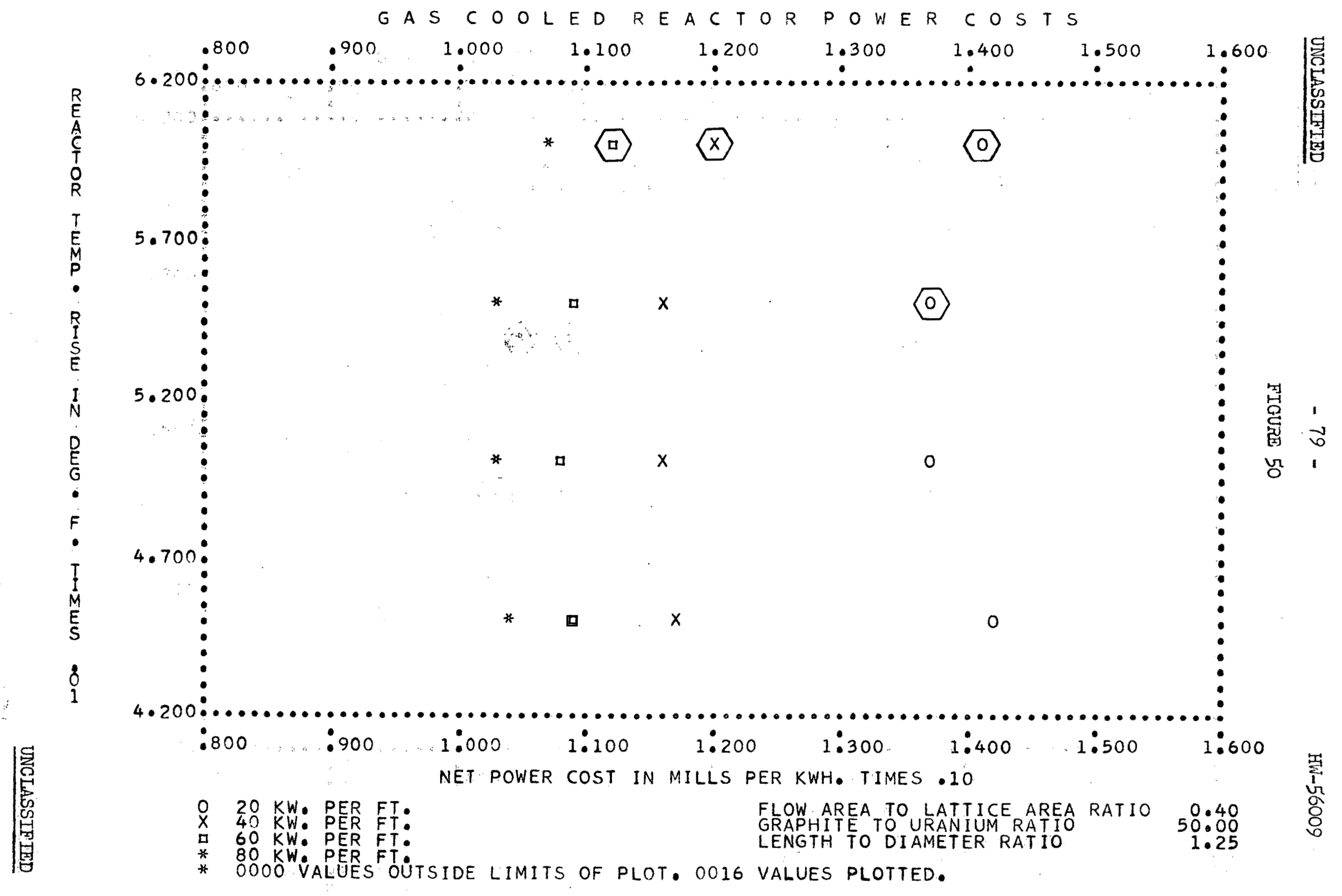




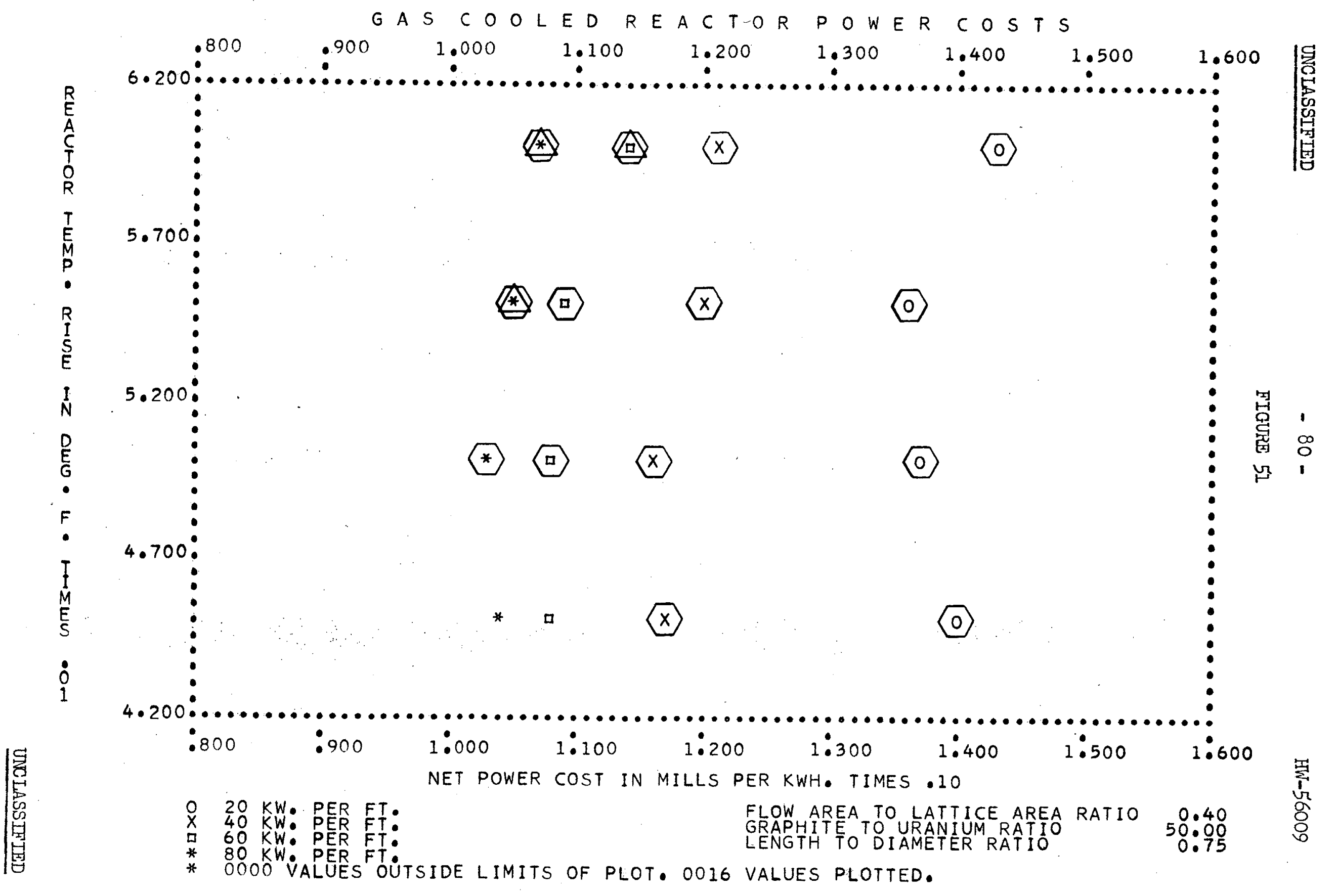




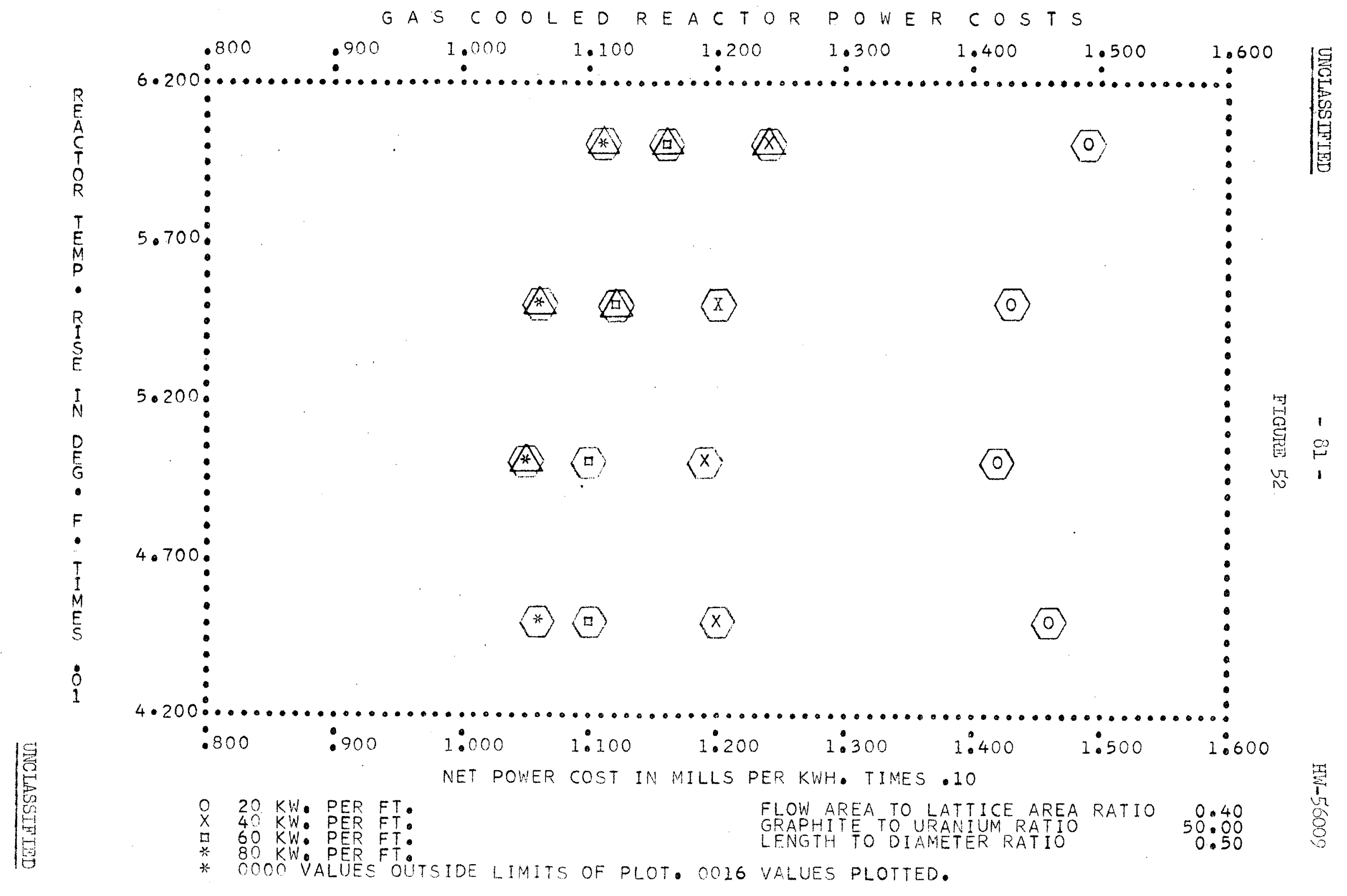




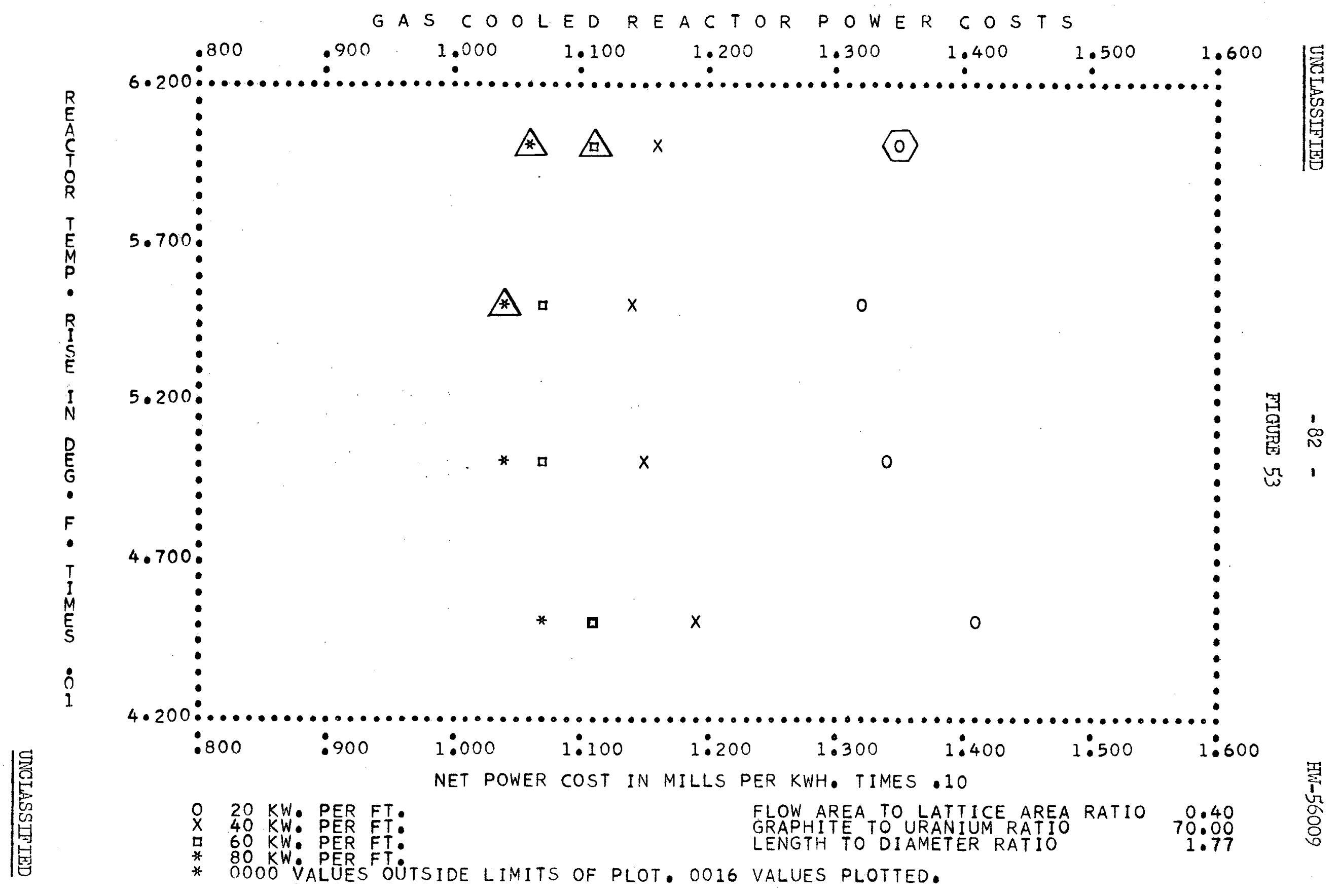




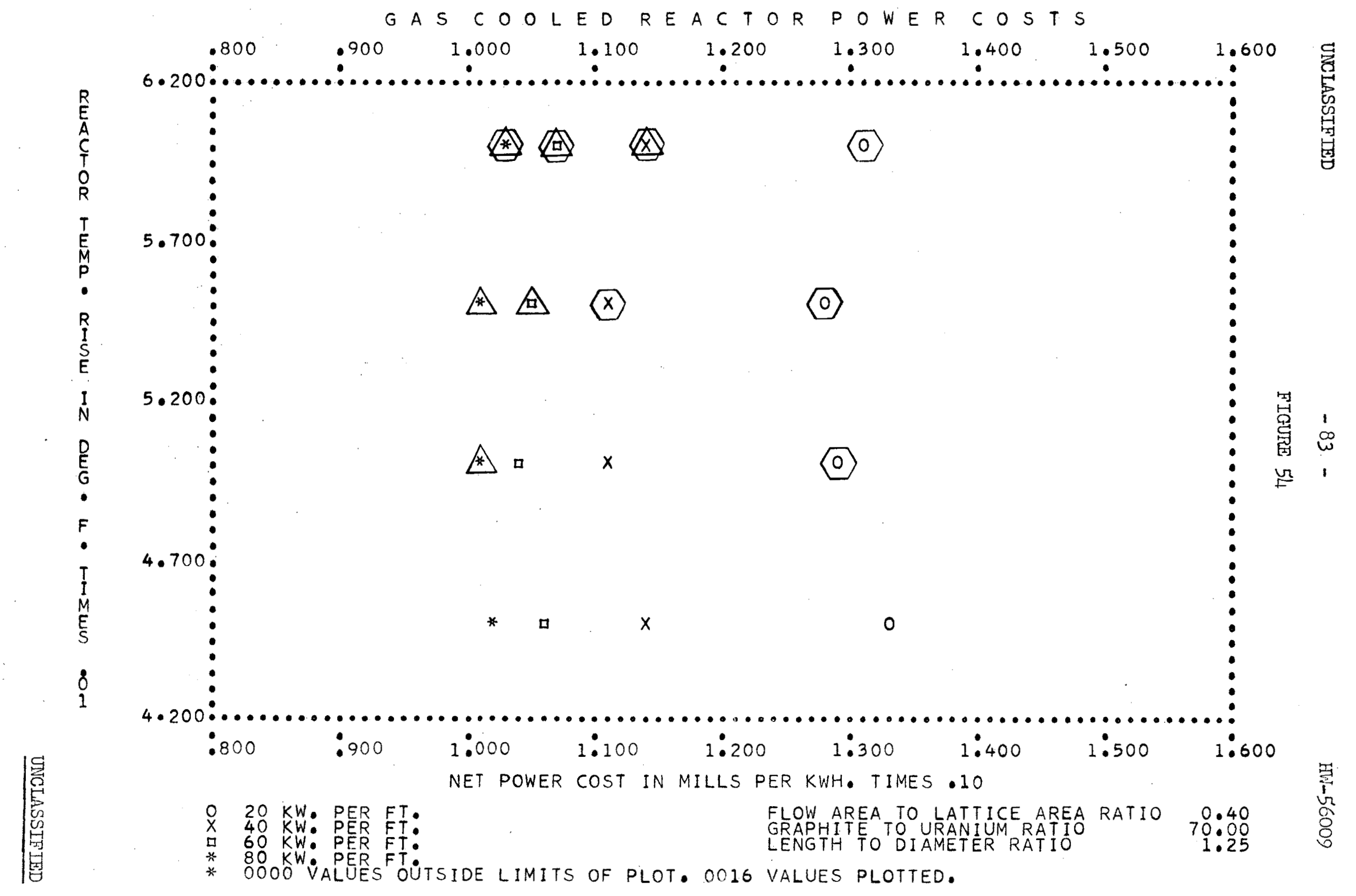




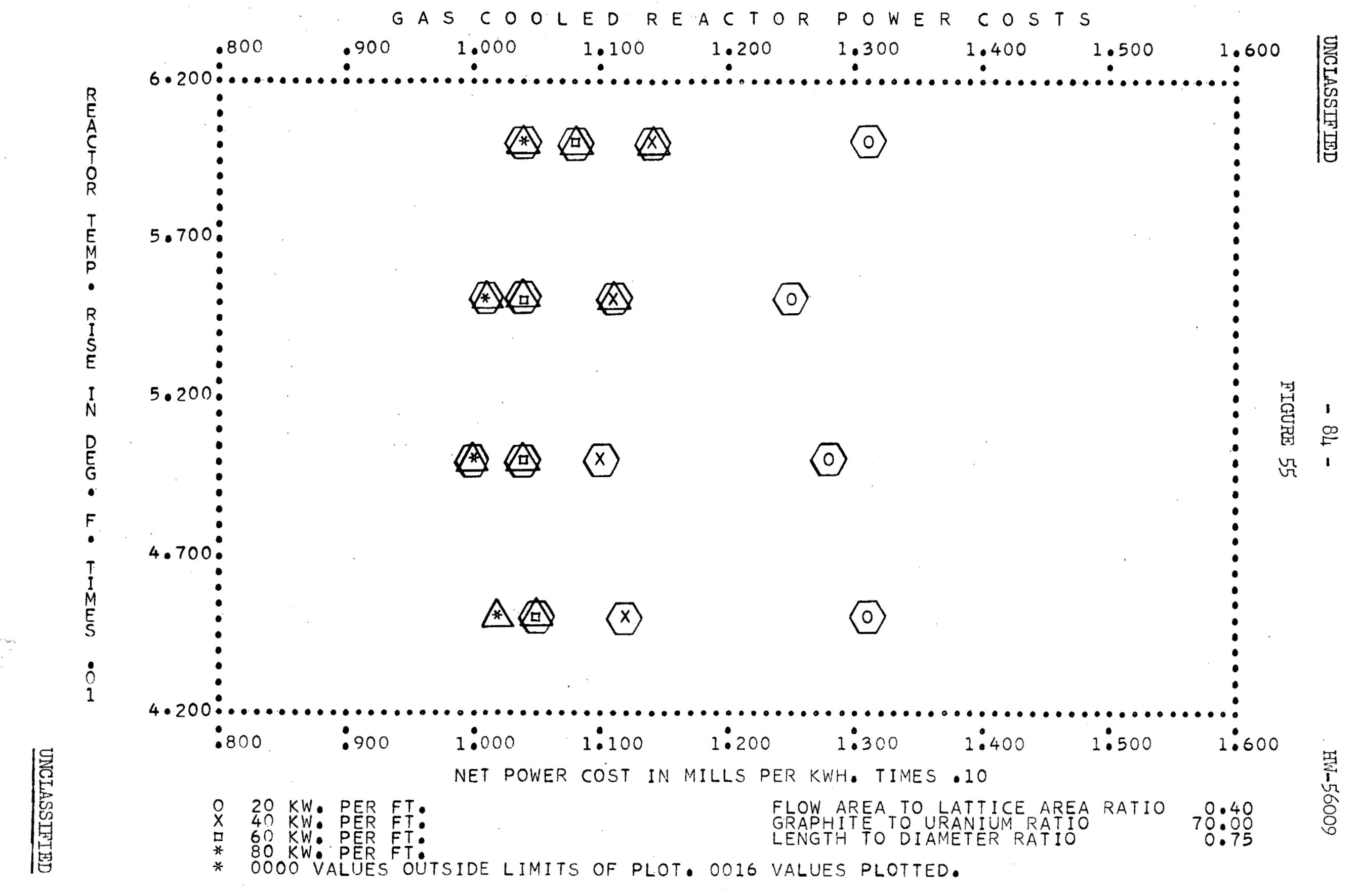




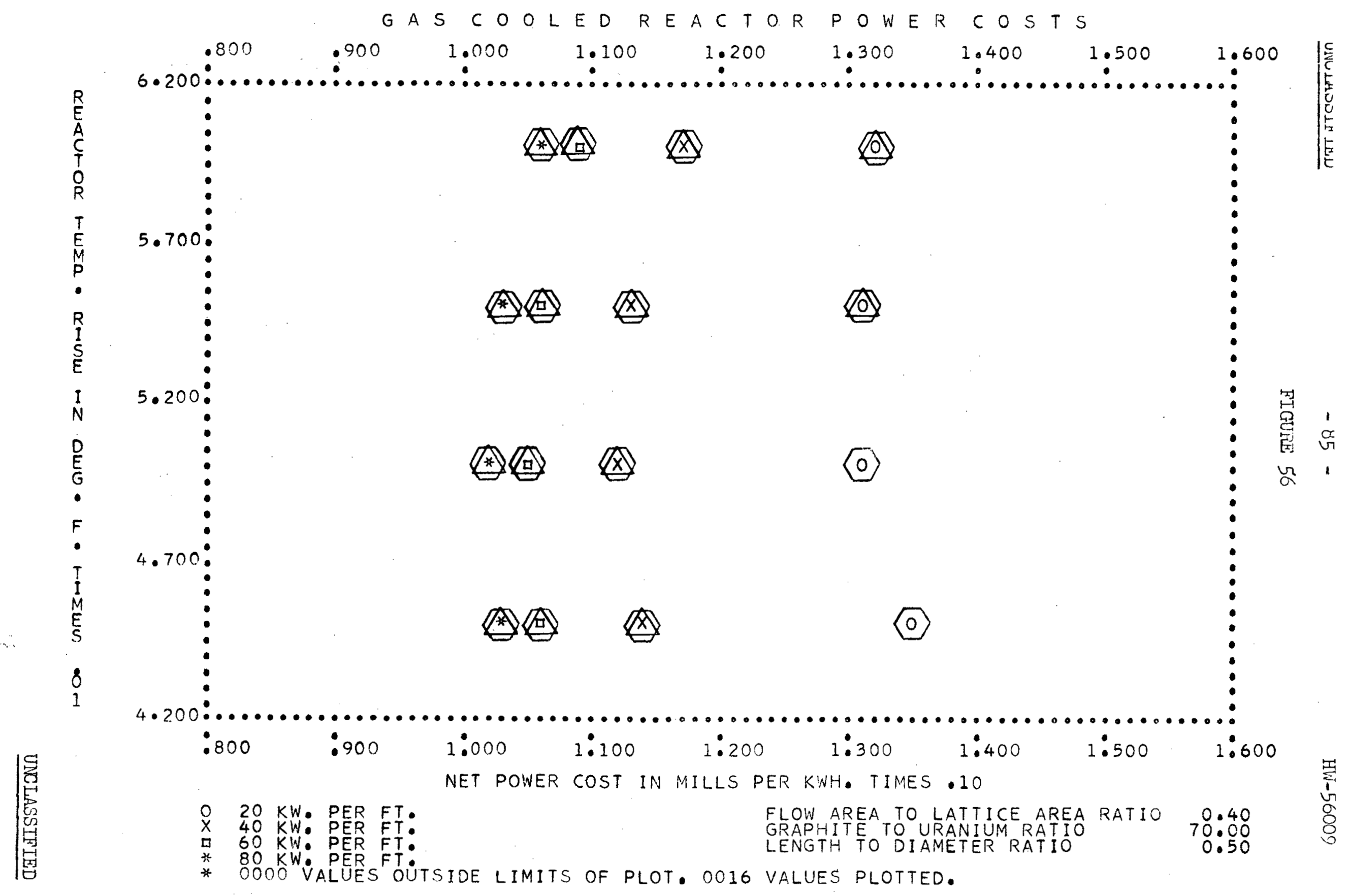




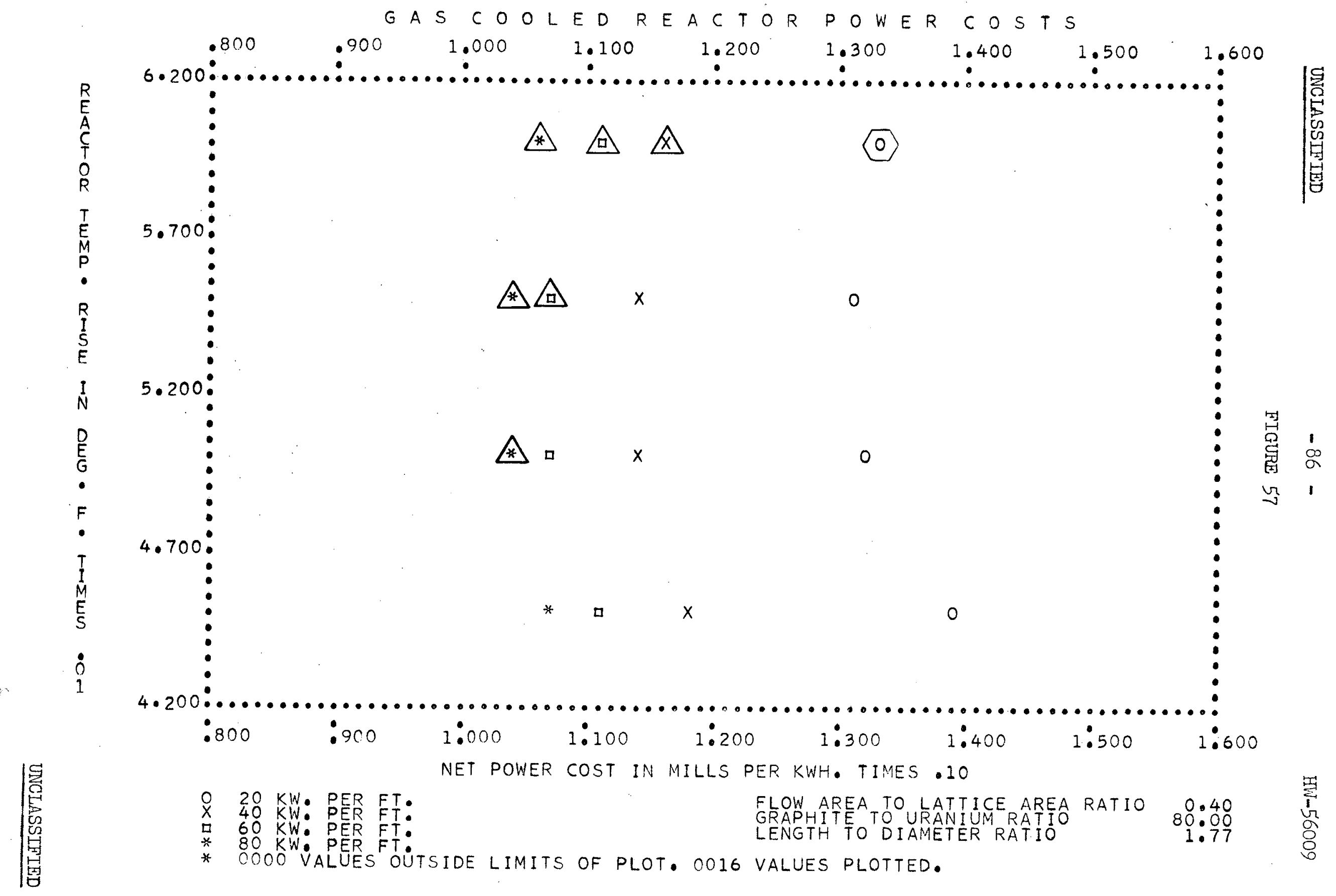




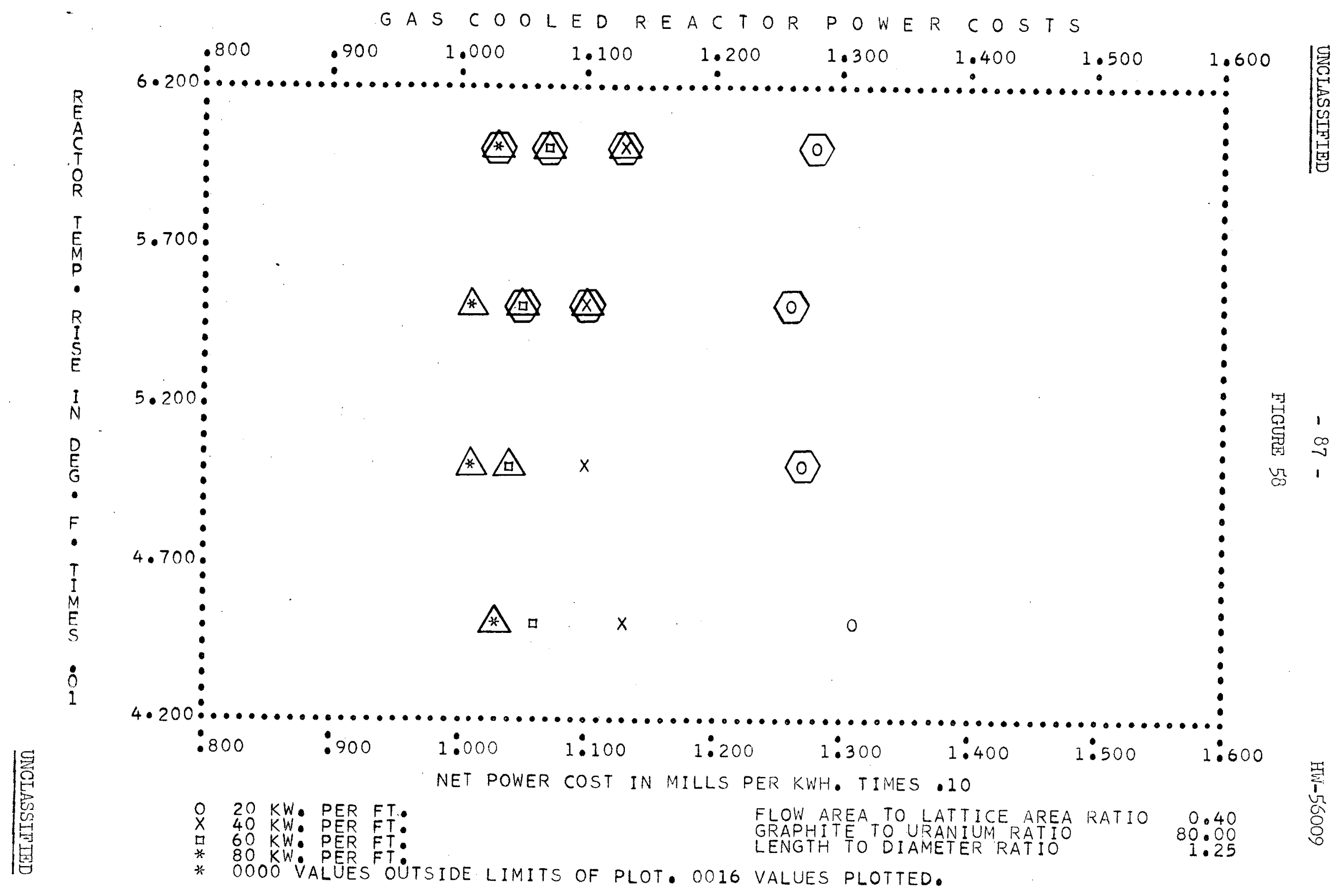




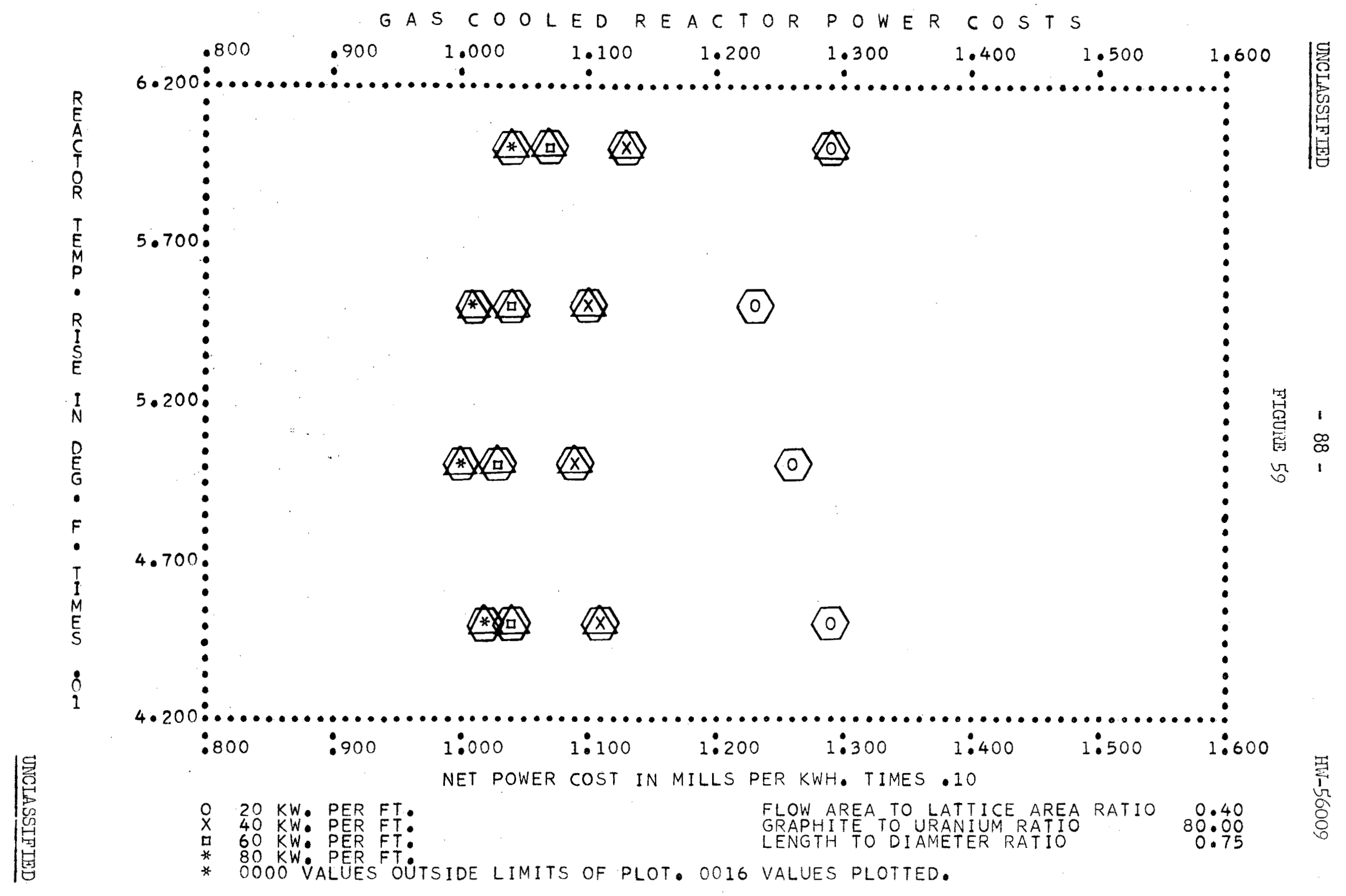




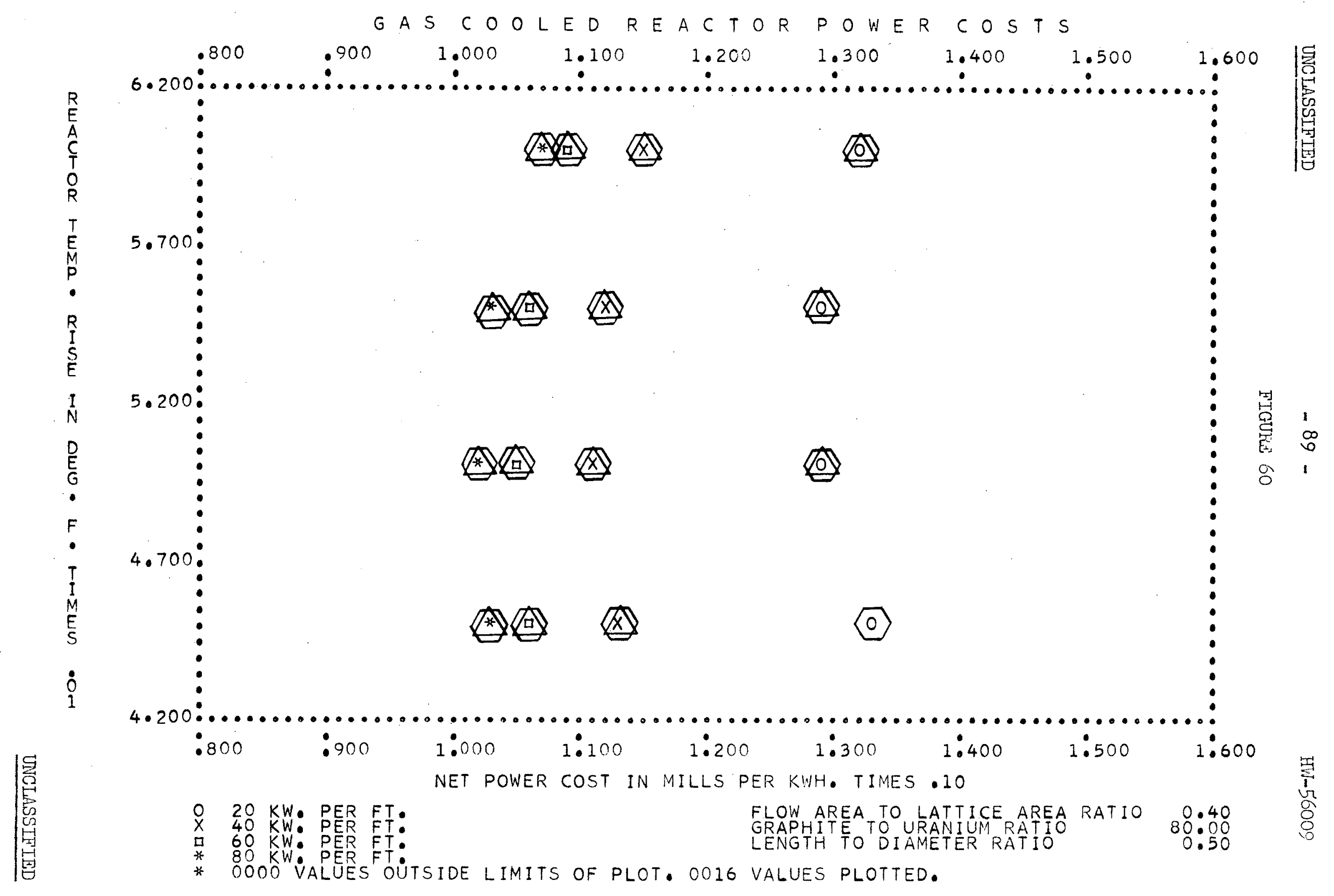




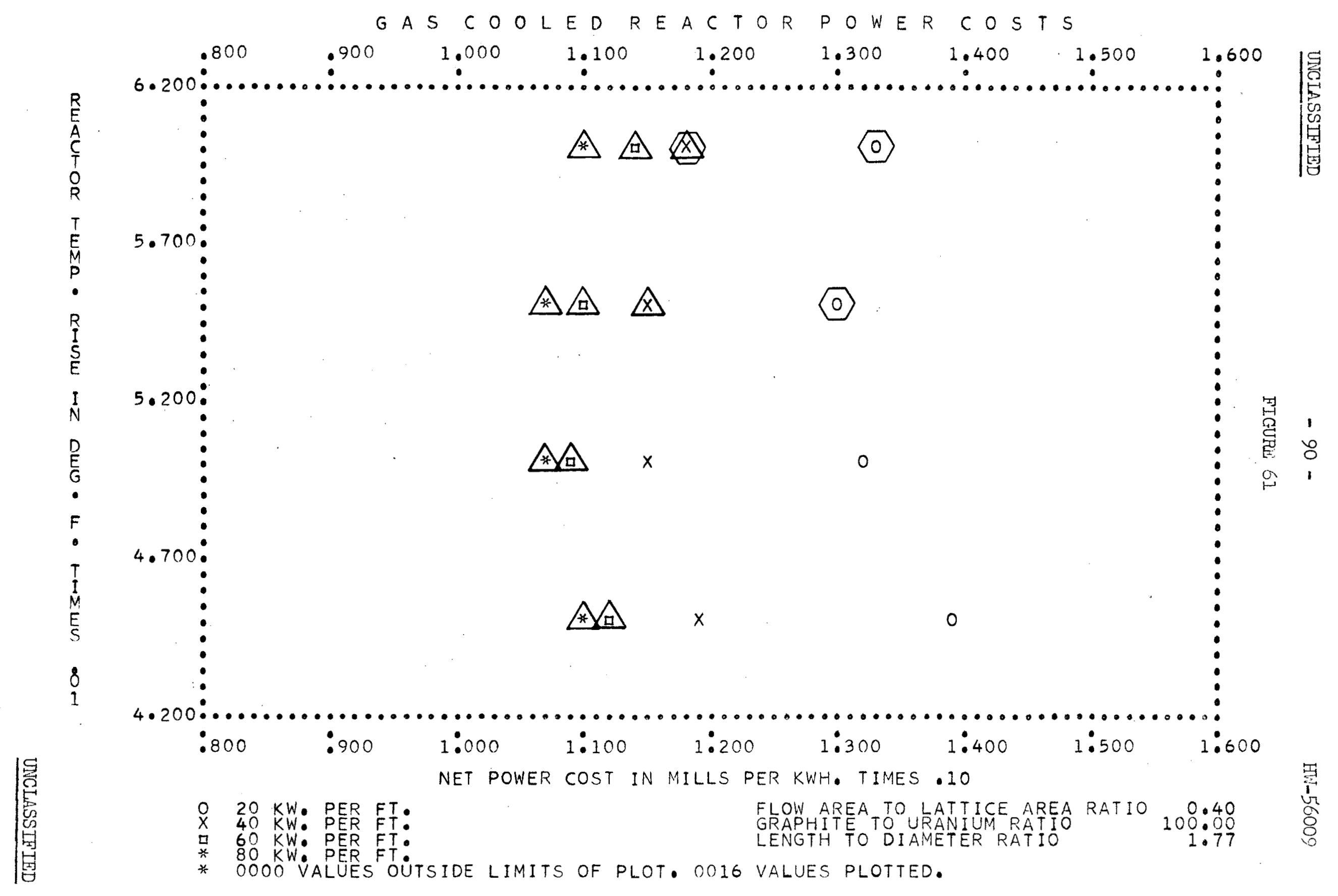




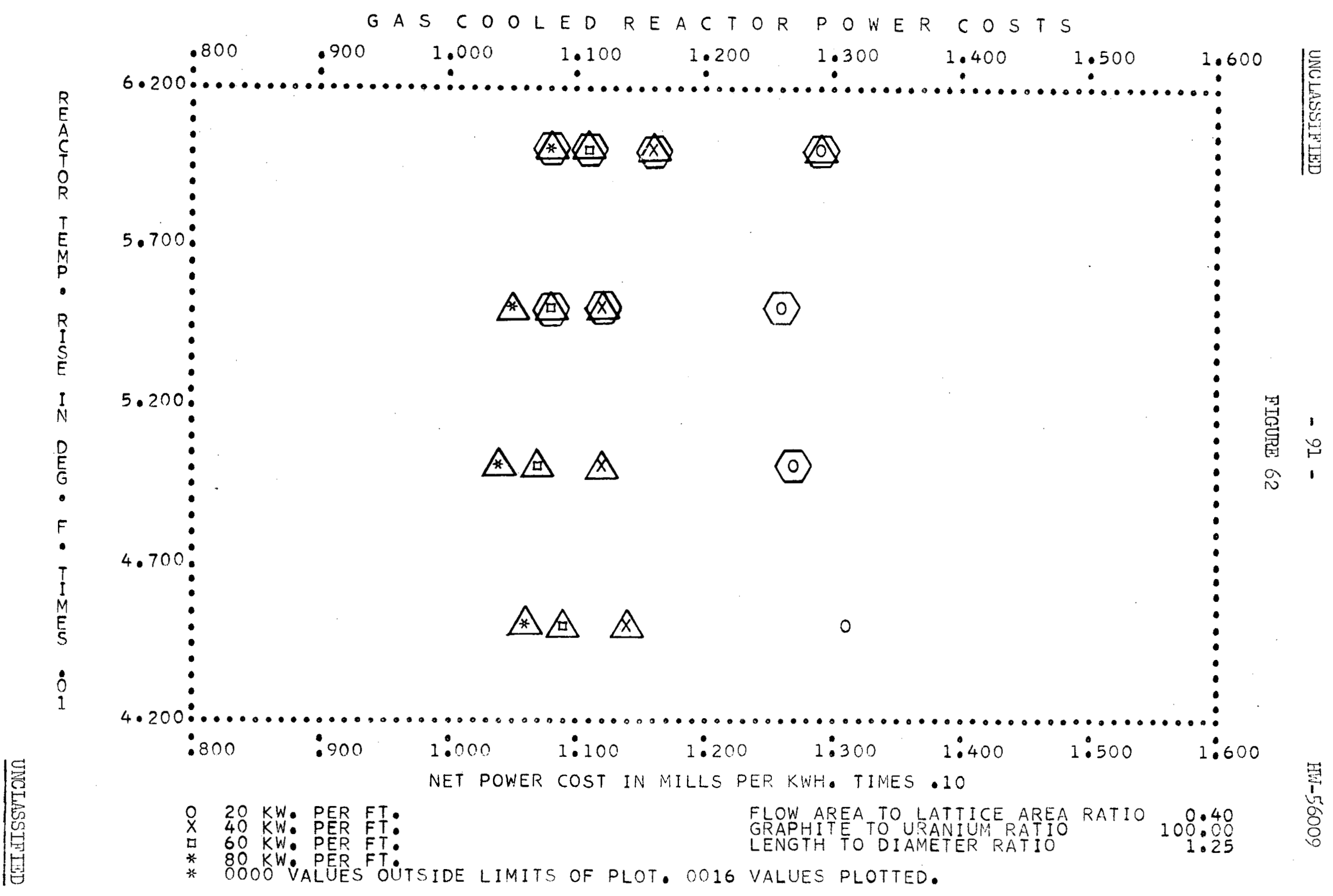




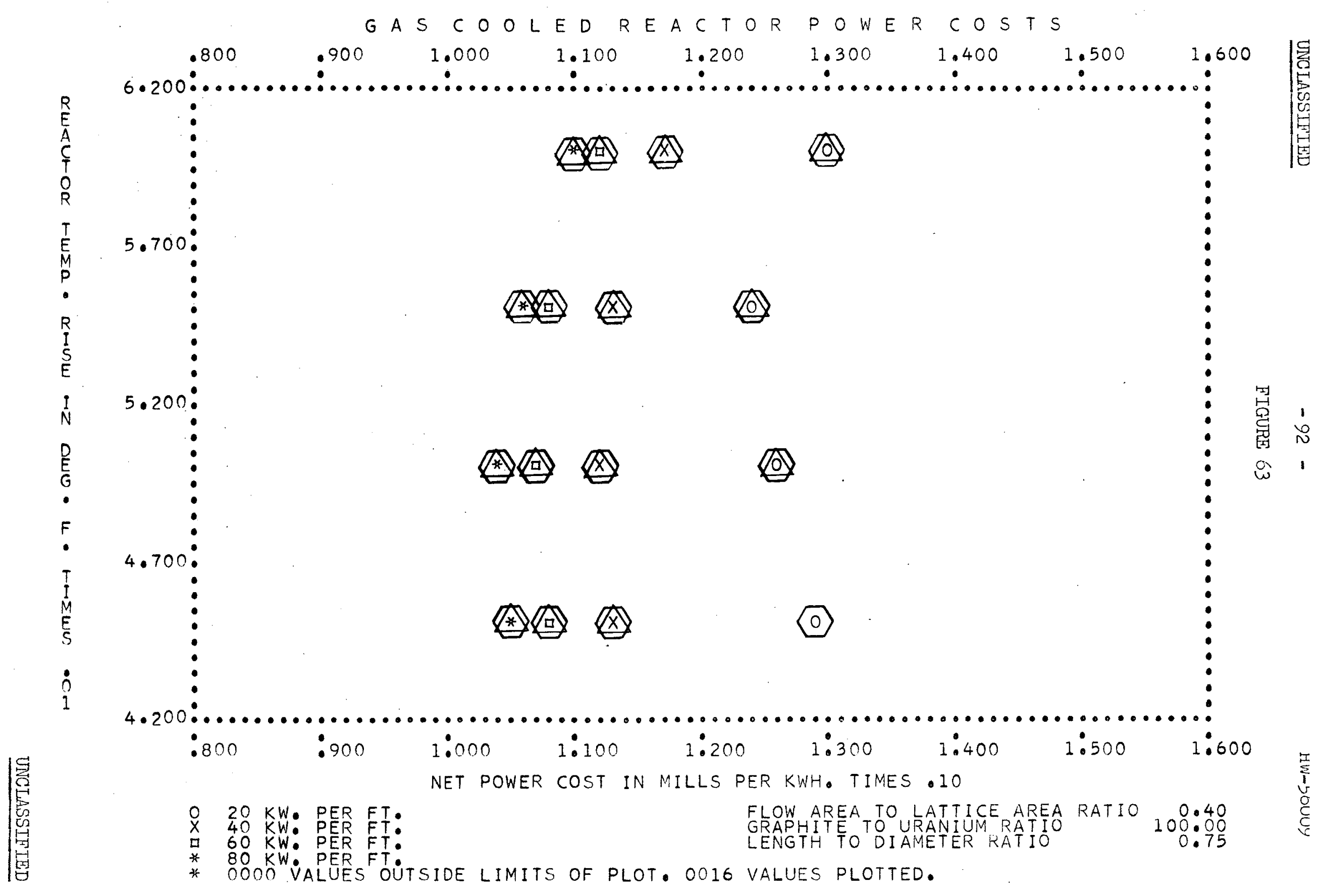




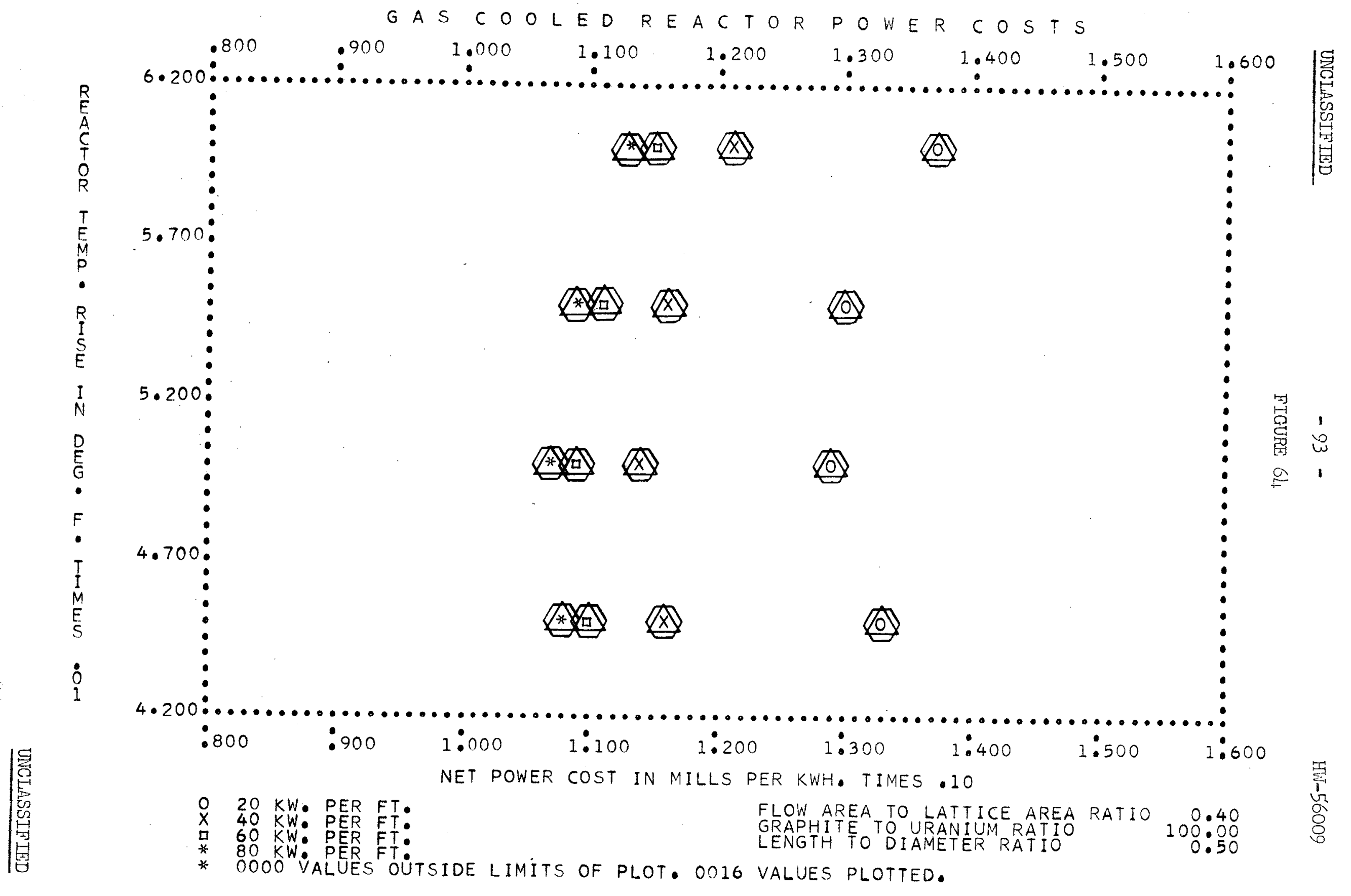

